\title{
An Account of Oak Ridge National Laboratory's Thirteen Nuclear Reactors
}

\author{
August 2009 \\ (Revised March 2010)
}

Prepared by Murray W. Rosenthal Deputy Director, ORNL (retired) 


\section{DOCUMENT AVAILABILITY}

Reports produced after January 1, 1996, are generally available free via the U.S. Department of Energy (DOE) Information Bridge.

Web site http://www.osti.gov/bridge

Reports produced before January 1, 1996, may be purchased by members of the public from the following source.

National Technical Information Service

5285 Port Royal Road

Springfield, VA 22161

Telephone 703-605-6000 (1-800-553-6847)

TDD 703-487-4639

Fax 703-605-6900

E-mail info@ntis.gov

Web site http://www.ntis.gov/support/ordernowabout.htm

Reports are available to DOE employees, DOE contractors, Energy Technology Data Exchange (ETDE) representatives, and International Nuclear Information System (INIS) representatives from the following source.

Office of Scientific and Technical Information

P.O. Box 62

Oak Ridge, TN 37831

Telephone 865-576-8401

Fax 865-576-5728

E-mail reports@osti.gov

Web site http://www.osti.gov/contact.html

This report was prepared as an account of work sponsored by an agency of the United States Government. Neither the United States Government nor any agency thereof, nor any of their employees, makes any warranty, express or implied, or assumes any legal liability or responsibility for the accuracy, completeness, or usefulness of any information, apparatus, product, or process disclosed, or represents that its use would not infringe privately owned rights. Reference herein to any specific commercial product, process, or service by trade name, trademark, manufacturer, or otherwise, does not necessarily constitute or imply its endorsement, recommendation, or favoring by the United States Government or any agency thereof. The views and opinions of authors expressed herein do not necessarily state or reflect those of the United States Government or any agency thereof. 
Office of the Laboratory Director

\title{
AN ACCOUNT OF OAK RIDGE NATIONAL LABORATORY'S THIRTEEN NUCLEAR REACTORS
}

\author{
Murray W. Rosenthal
}

Date Published: August 2009

Revised: March 2010

\author{
Prepared by \\ OAK RIDGE NATIONAL LABORATORY \\ Oak Ridge, Tennessee 37831-6283 \\ managed by \\ UT-BATTELLE, LLC \\ for the \\ U.S. DEPARTMENT OF ENERGY \\ under contract DE-AC05-00OR22725
}





\section{CONTENTS}

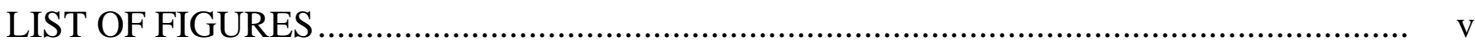

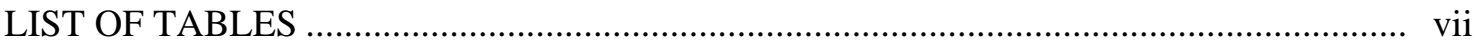

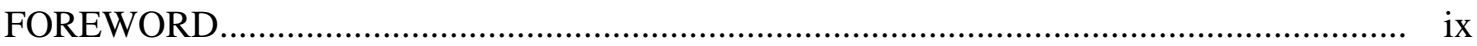

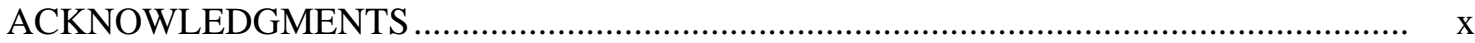

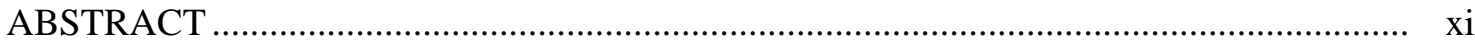

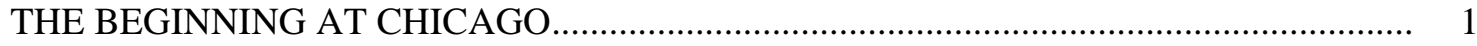

THE OAK RIDGE GRAPHITE REACTOR ........................................................................ 3

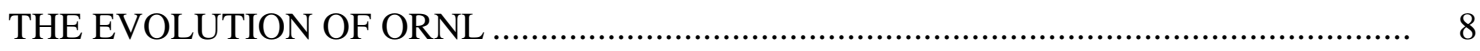

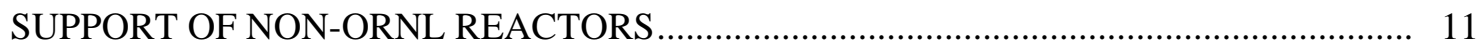

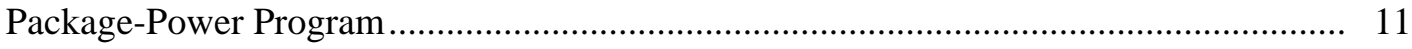

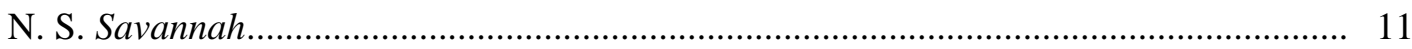

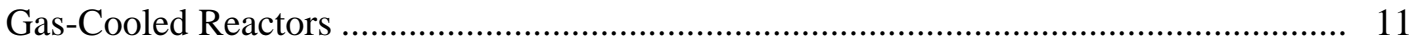

AQUEOUS HOMOGENEOUS REACTORS ................................................................. 14

Homogeneous Reactor Experiment ........................................................................ 14

Homogeneous Reactor Test .................................................................................... 18

AIRCRAFT NUCLEAR PROPULSION PROGRAM …................................................... 24

Aircraft Reactor Experiment Development .................................................................. 24

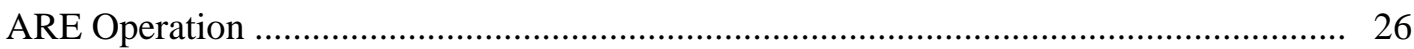

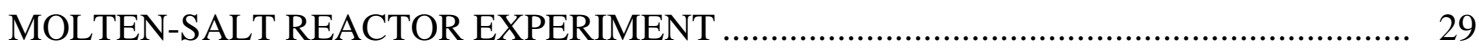

HEALTH PHYSICS RESEARCH REACTOR …................................................................ 35

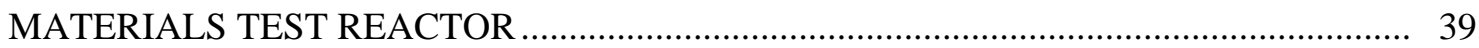

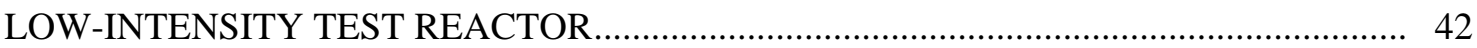

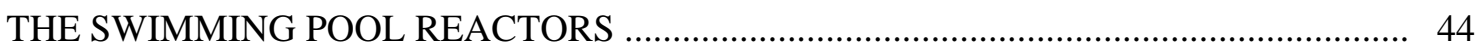

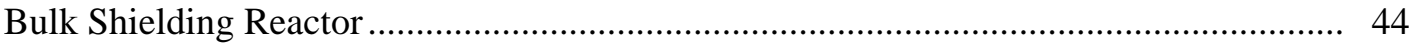

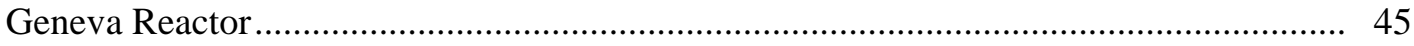

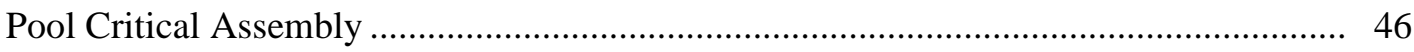

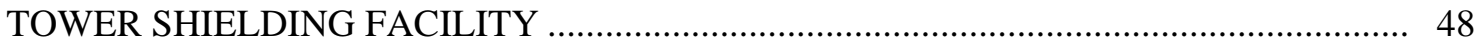

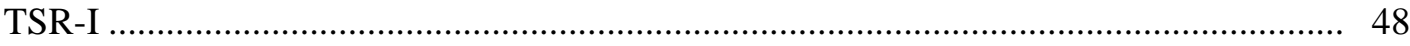

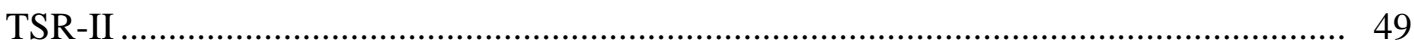

OAK RIDGE RESEARCH REACTOR ........................................................................ 52

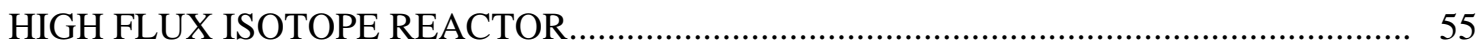

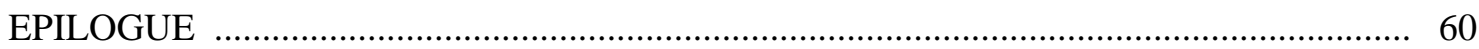

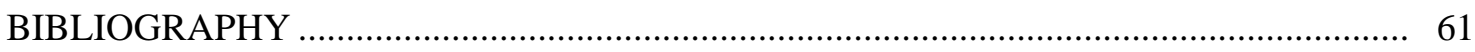

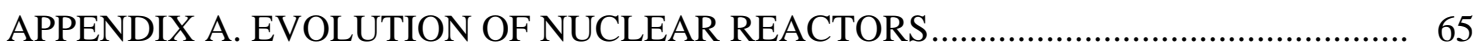




\section{LIST OF FIGURES}

Figure

Page

1 Final layer of the Chicago Pile.

2 The Chicago Pile at the approach to criticality

2

3 The Oak Ridge Graphite Reactor and chemical processing pilot plant under construction in August 1943 ......................................................................... 3

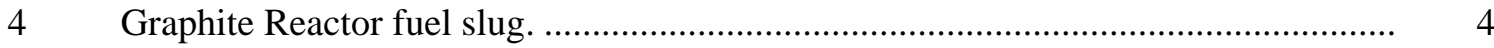

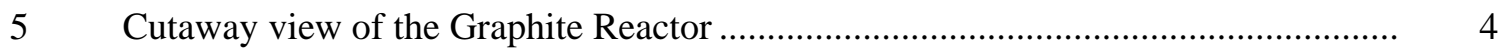

$6 \quad$ Loading fuel into the Graphite Reactor …............................................................. 5

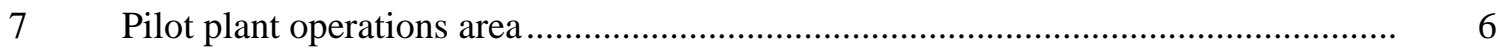

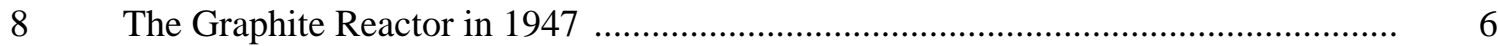

$9 \quad$ ORNL's nuclear reactors, from criticality to shutdown ............................................ 9

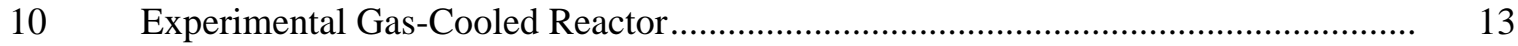

11 HRE reflector vessel during construction ............................................................. 15

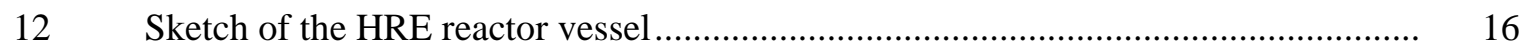

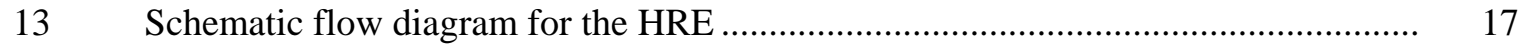

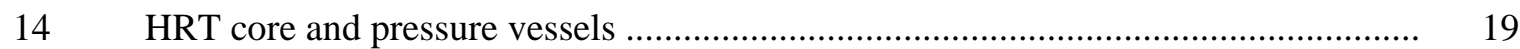

15 Schematic flow diagram for the HRT ….............................................................. 19

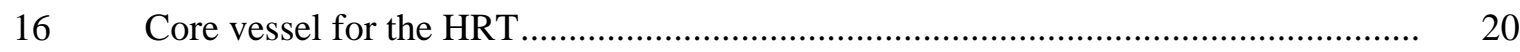

17 HRT building, showing upper shield blocks ............................................................ 21

18 Stacked BeO moderator blocks for the ARE ......................................................... 25

19 ORNL photograph of molten salt, featured on the cover of the British Science Journal in June 1969 ................................................................................. 26

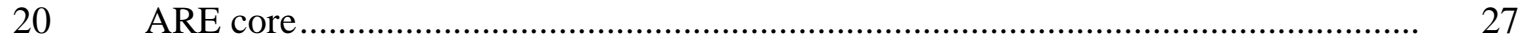

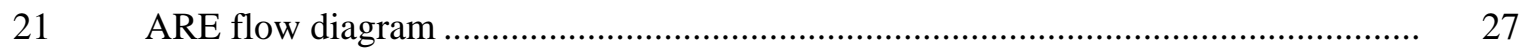

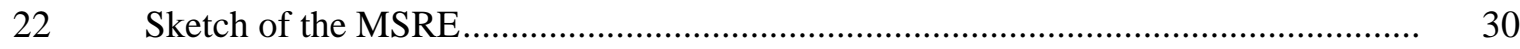

23 Graphite core of the MSRE..............................................................................

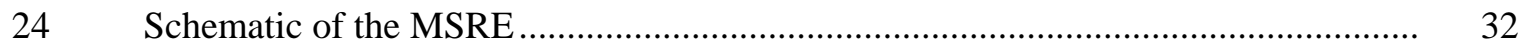

25 MSRE core, fuel circulating pump, and heat exchanger in the primary system containment tank ........................................................................................ 33

26 MSRE air-cooled radiator with its door open ......................................................... 33

27 Glenn Seaborg at the MSRE control panel ........................................................... 34

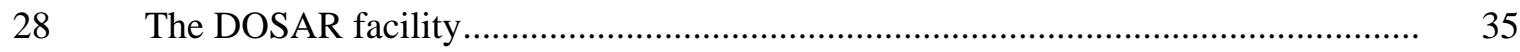

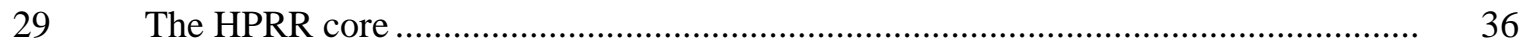

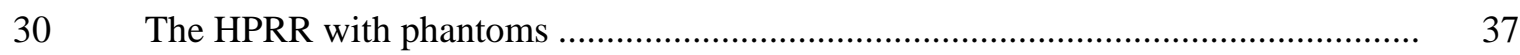

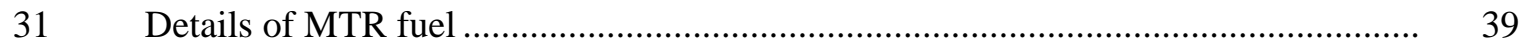

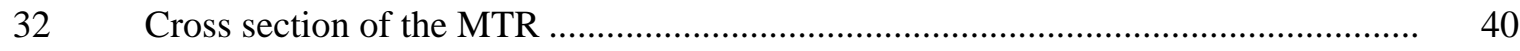

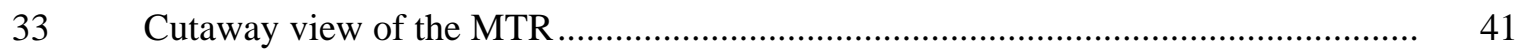

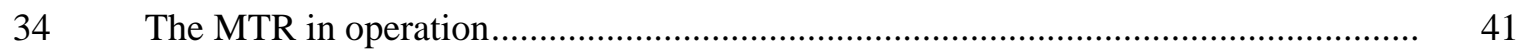

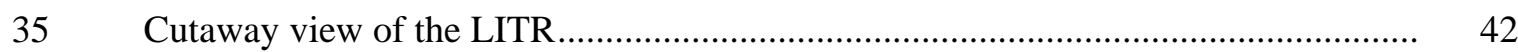


36 The LITR on the cover of Scientific American ........................................................ 43

37 The BSR in its "swimming pool" ......................................................................... 44

38 Sketch of the BSR, showing the forced cooling piping........................................... 45

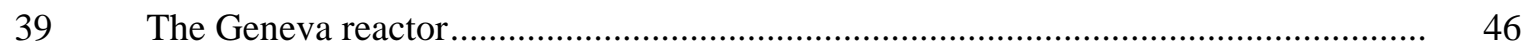

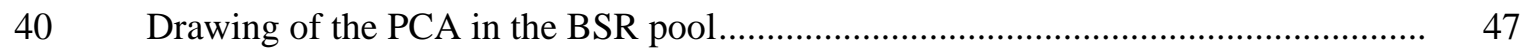

$41 \quad$ A reactor and shield suspended at the TSF ........................................................... 48

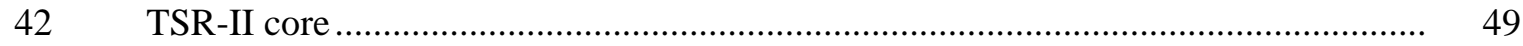

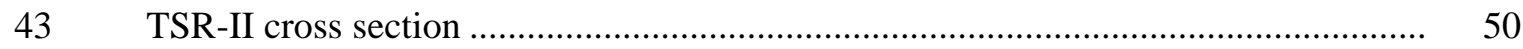

$44 \quad$ TSR-II suspended from the TSF towers ...................................................................

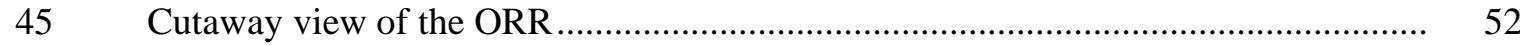

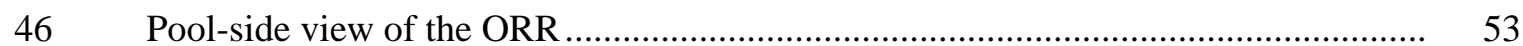

$47 \quad$ The ORR in its “confinement” building .................................................................... 54

48 The HFIR and other facilities in Melton Valley ..................................................... 55

$49 \quad$ HFIR fuel element with target rods in the flux trap................................................ 56

$50 \quad$ Cross section of the HFIR at the horizontal midplane............................................... 57

$51 \quad$ Replacement of HFIR fuel element .................................................................... 58

52 The operating gallery of the Transuranium Processing Facility ................................ 58

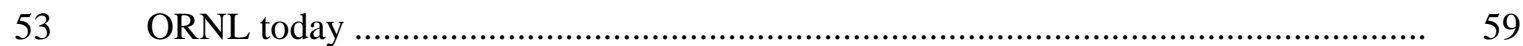




\section{LIST OF TABLES}

Table $\quad$ Page

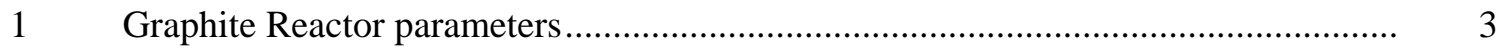

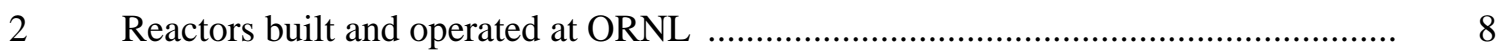

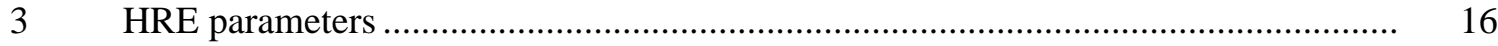

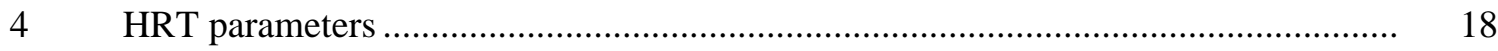

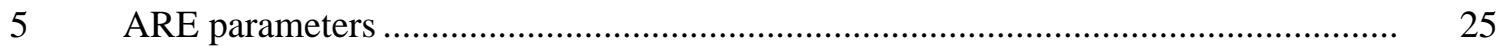

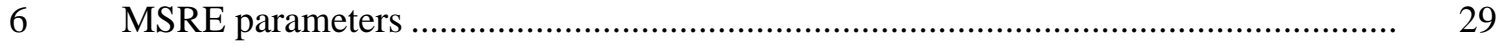





\section{FOREWORD}

The Oak Ridge Institute for Continued Learning has sponsored a series of lectures in honor of Alvin Weinberg, former director of Oak Ridge National Laboratory (ORNL). In 2008 I was asked to give one of those lectures on ORNL's nuclear reactors. In preparing for the lecture, I realized that there is no single publication that covers all of the reactors. Since I had collected a lot of material, I decided to fill the gap with this report.

The best single source of information on ORNL reactors is Weinberg's enjoyable autobiography, The First Nuclear Era. In it he tells how each one came about and describes its accomplishments. Another very useful account is A Brief History of the Research Reactors Division, compiled by D. R. Stapleton. It describes all of the research reactors.

To go deeper requires reading in many reports and papers, and for the big programs, their quarterly reports. The bibliography lists many of the books, papers, and reports that I dug into. While this report is principally about reactors built at ORNL, I briefly describe roles that the Laboratory played in reactors built elsewhere. I also mention some earlier events and, consequently, list in the bibliography several books that are sources of pre-ORNL history, including especially Richard Rhodes’ prize-winning book, The Making of the Atomic Bomb.

The design and construction of the reactors, and particularly the power-reactor experiments, were preceded and accompanied by essential supporting research and development programs that spanned a wide range of scientific and engineering disciplines. Everything from basic chemistry to the testing of valves was carried out by multidisciplinary teams who worked together to develop solutions to critical problems. I concentrate on the reactors themselves and say little about the programmatic support, but it is covered in many publications, including the periodic reports of the programs and divisions. I also omit any discussion of the removal of reactors and the cleanup of their sites after they were shut down. The U.S. Department of Energy established a separate program to manage this task, and it is far along, although not entirely finished.

The reader will notice that I mention few names. There are far too many for me to have listed them all, and often I did not have enough personal knowledge to single out those most deserving of credit. However, the histories of ORNL divisions in the bibliography do list the people and what they did, and Weinberg's book calls attention to a number who played key roles.

Many readers will be aware that the Laboratory was originally called Clinton Laboratories, then Clinton National Laboratory, and in 1948 it became ORNL. I use Laboratory and ORNL interchangeably but not the earlier titles. Readers may also know that the Laboratory's sponsor was originally the U. S. Army, then the Atomic Energy Commission, next the Energy Research and Development Administration, and finally the U.S. Department of Energy. 


\section{ACKNOWLEDGMENTS}

I owe thanks to a number of people who provided help to me in preparing this history: John Auxier, Sam Beall, Roger Carlsmith, Dick Cheverton, Bob Costner, Dick Engel, Mike Farrar, Paul Haubenreich, John Hill, Leo Holland, Gene McNeese, Harold McCurdy, Bud Perry, Norman Schaeffer, and Jerry Swanks reviewed sections about reactors with which they had been involved. I consulted Bill Appleton, Bill Burch, Fritz McDuffie, Randy Nansted, Jack Richard, and Al Trivelpiece about specific items. Bud Perry helped me understand several issues involving reactor physics. Dale Claflin of Idaho National Laboratory dug out old sketches of the Materials Test Reactor.

I am indebted to Bonnie Nestor, Special Assistant to the Director of Oak Ridge National Laboratory (ORNL), for assistance in preparing the report for publication, and to Joy Anderson, ORNL Communications and External Relations, for help in finding photographs. Thanks also go to Jim Roberto, former ORNL Deputy for Science and Technology, for supporting the publication of this report. 


\begin{abstract}
The Oak Ridge National Laboratory has built and operated 13 nuclear reactors in its 66-year history. The first was the graphite reactor, the world's first operational nuclear reactor, which served as a plutonium production pilot plant during World War II. It was followed by two aqueoushomogeneous reactors and two red-hot molten-salt reactors that were parts of power-reactor development programs and by eight others designed for research and radioisotope production.

One of the eight was an all-metal fast burst reactor used for health physics studies. All of the others were light-water cooled and moderated, including the famous swimming-pool reactor that was copied dozens of times around the world. Two of the reactors were hoisted 200 feet into the air to study the shielding needs of proposed nuclear-powered aircraft.

The final reactor, and the only one still operating today, is the High Flux Isotope Reactor (HFIR) that was built particularly for the production of californium and other heavy elements. With the world's highest flux and recent upgrades that include the addition of a cold neutron source, the 44-year-old HFIR continues to be a valuable tool for research and isotope production, attracting some 500 scientific visitors and guests to Oak Ridge each year.

This report describes all of the reactors and their histories.
\end{abstract}





\section{THE BEGINNING AT CHICAGO}

In 1941, Arthur Holly Compton, a physics professor at the University of Chicago, was put in charge of the U.S. effort to develop a plutonium bomb. He quickly collected many of the people who were involved in the program to work together in Chicago at what for security reasons was called the Metallurgical Laboratory. They included Enrico Fermi, Leo Szilard, Eugene Wigner, and Alvin Weinberg, a 26-year-old biophysics post-doctoral associate.

Fermi had been building a series of sub-critical stacks of graphite and uranium that he called piles. In the winter of 1942, he and his team assembled the 30th in the series in a squash-racquets court at the university. It was large enough and the graphite and uranium were pure enough for it to go critical, and on December 2 it became the world's first nuclear reactor. However, it had no shielding or cooling, so the power level had to be kept very low.

As shown in Fig. 1, the pile was made from graphite slabs with arrays of uranium lumps in alternate layers. Figure 2 reproduces a 1957 painting by Gary Sheahan that was commissioned by the Chicago Tribune to commemorate the achievement of criticality.

The Chicago Pile was a key step in a chain that led to the creation of the Oak Ridge National Laboratory (ORNL), a chain that can be thought of as starting in 1932 with the discovery of the neutron by James Chadwick. Chadwick's discovery was followed by a series of events that are summarized in Appendix A.

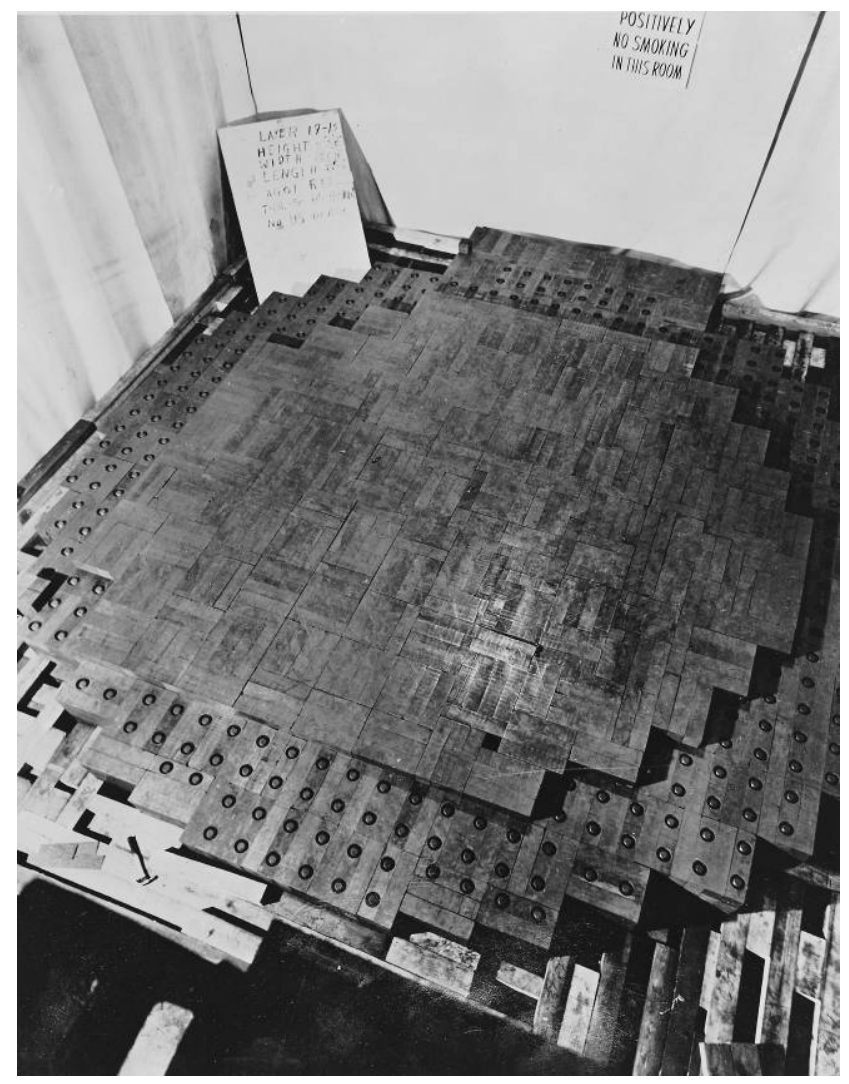

Fig. 1. Final layer of the Chicago Pile. The sign identifies the 19th layer of graphite; portions of layer 18, which contained slugs of uranium oxide, are also visible. (Courtesy of Argonne National Laboratory) 


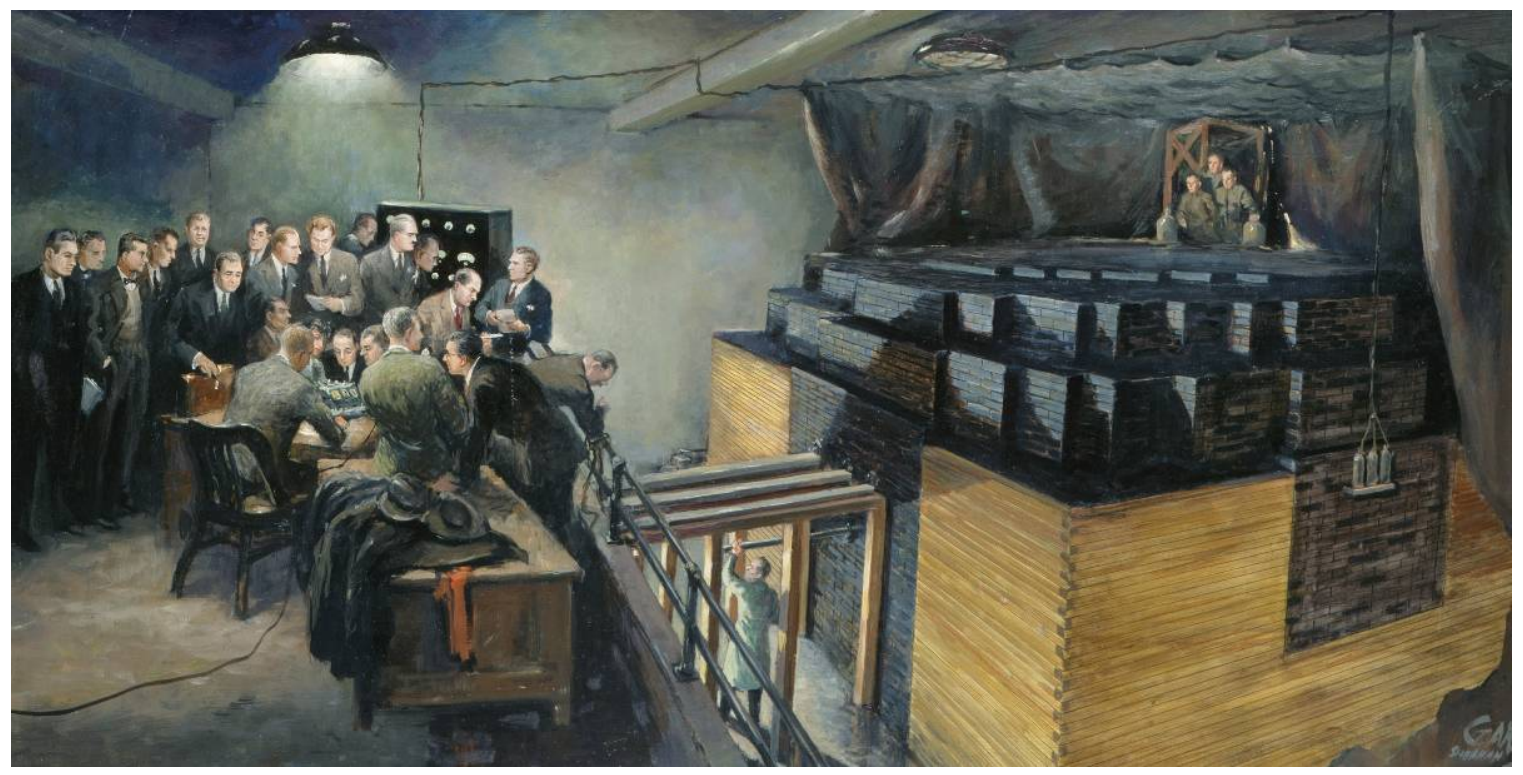

Fig. 2. The Chicago Pile at the approach to criticality. No photographs exist of the experiment on December 2, 1942. This 1957 painting by Gary Sheahan is based on written reports, drawings, and interviews with the participants. Enrico Fermi is seen on the balcony, directing the operation. (Courtesy of the Chicago History Museum) 


\section{THE OAK RIDGE GRAPHITE REACTOR}

General Leslie Groves took charge of the Manhattan Project in September 1942 and immediately made the decision to buy 59,000 acres of land in East Tennessee for the Clinton Engineer Works.

Early plans called for this area, later known as Oak Ridge, to be the site of the plutonium production reactors, but in December, DuPont recommended that these reactors be constructed at a more remote site with more cooling water, and the Hanford site in Washington was selected. However, a month later Groves expanded DuPont's contract to include the building of a smaller reactor and a plutoniumseparation pilot plant in Oak Ridge. Work in Oak Ridge began almost immediately and in a few months was well along, as shown in Fig. 3.

Wigner favored water cooling for the Oak Ridge reactor to make it more of a pilot plant for Hanford, but air cooling seemed easier and quicker, with less potential for corrosion of the fuel cladding, and it was chosen. As indicated in Table 1, the Oak Ridge pile was a $24 \mathrm{ft}$ graphite cube surrounded by a $7 \mathrm{ft}$ thick shield of highdensity concrete. Passing through the graphite were 1248 diamond-shaped channels on 8 in. centers that at criticality contained 44,000 aluminum-clad uranium "slugs" measuring 1 in. by 4 in. A sample slug is shown in Fig. 4. As

Table 1. Graphite Reactor parameters

\begin{tabular}{ll}
\hline Power (heat) & $1000 \mathrm{~kW} / 4000 \mathrm{~kW}$ \\
Fuel elements & $\begin{array}{l}44,0001 \times 4 \mathrm{in} \text {. aluminum-clad } \\
\text { uranium-metal cylinders }\end{array}$ \\
Coolant & Air \\
Moderator & Graphite \\
Core & $24 \mathrm{ft}$ cube with 1248 fuel channels \\
Shield & $7 \mathrm{ft}$ thick high-density concrete \\
Critical & November 4, 1943 \\
Shut down & November 4, 1963 \\
\hline
\end{tabular}
seen in Fig. 5, cooling air entered and left the

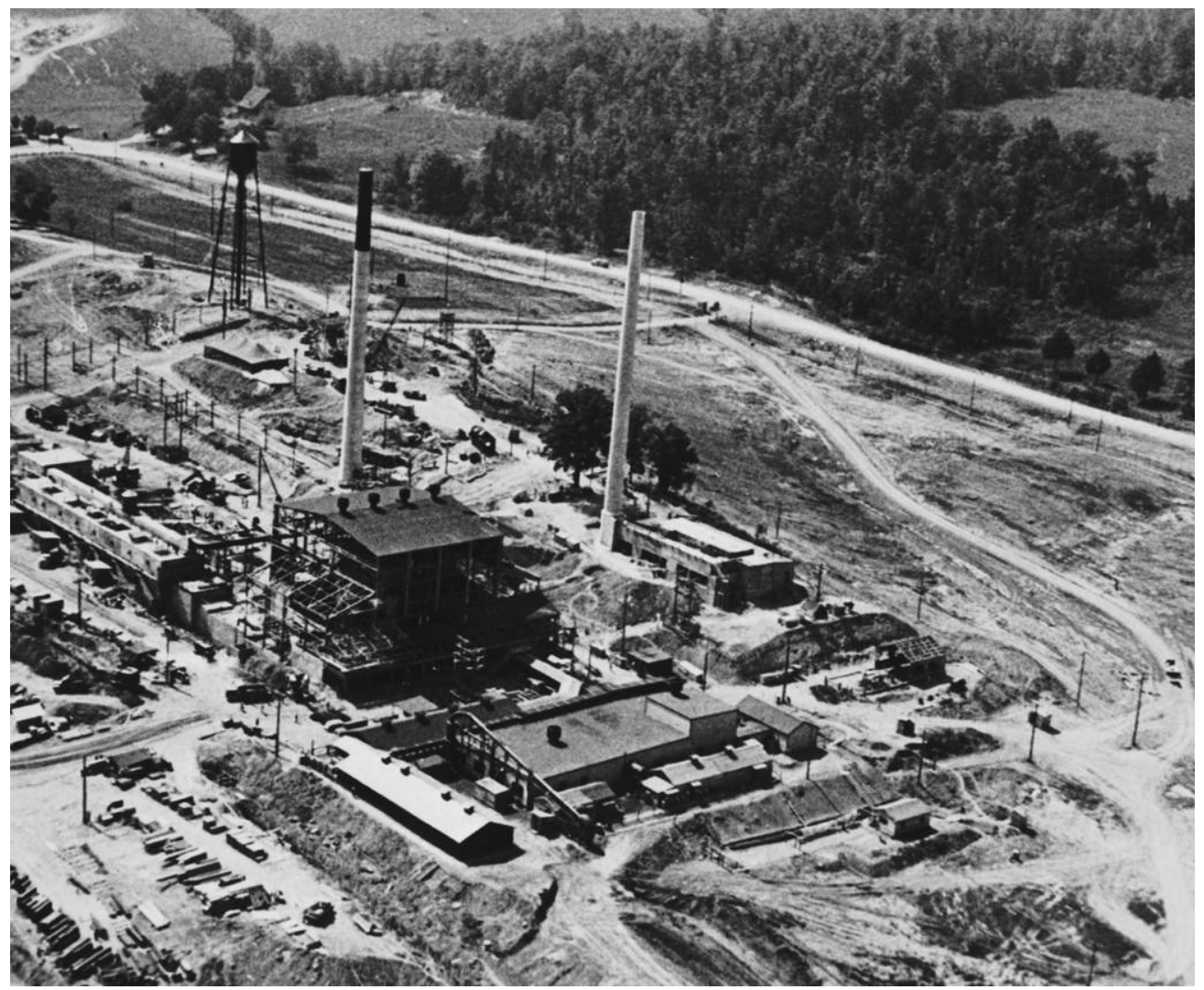

Fig. 3. The Graphite Reactor and the concrete cells of the chemical processing pilot plant under construction in August 1943. (ORNL History Photo 152) 
channels through gaps between the core and shield. The heated air passed through filters and then was blown up a tall stack.

Passages through the front shield matched the channels through the core, and the gap between them was spanned by steel tubes. After removal of shield plugs, crews standing on an elevator at the front face pushed fresh slugs into the core of the shutdown reactor with long rods, as shown in Fig. 6. The irradiated slugs dropped into the air gap at the rear of the core, where a chute guided them to a $20 \mathrm{ft}$ deep canal filled with water. Here they were loaded into buckets using long poles and transported underwater to a cell in the adjacent chemical processing plant

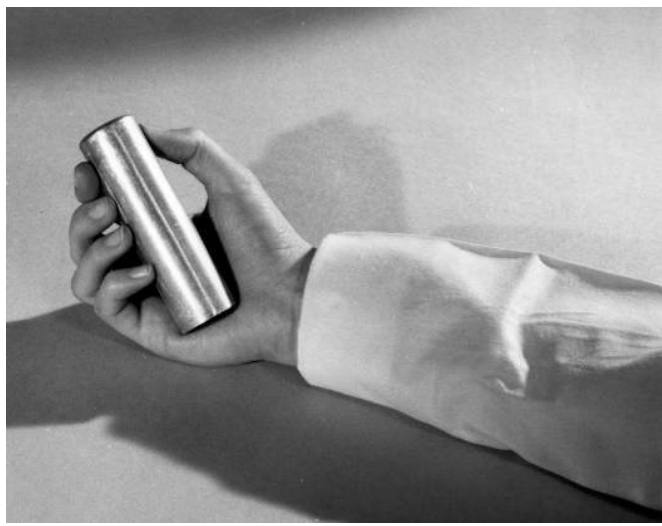

Fig. 4. Graphite Reactor fuel slug. shown in Fig. 7.

Almost all of the steps involved in separating and purifying plutonium had to be performed behind thick shielding, so the equipment at the pilot processing plant was contained in a set of six

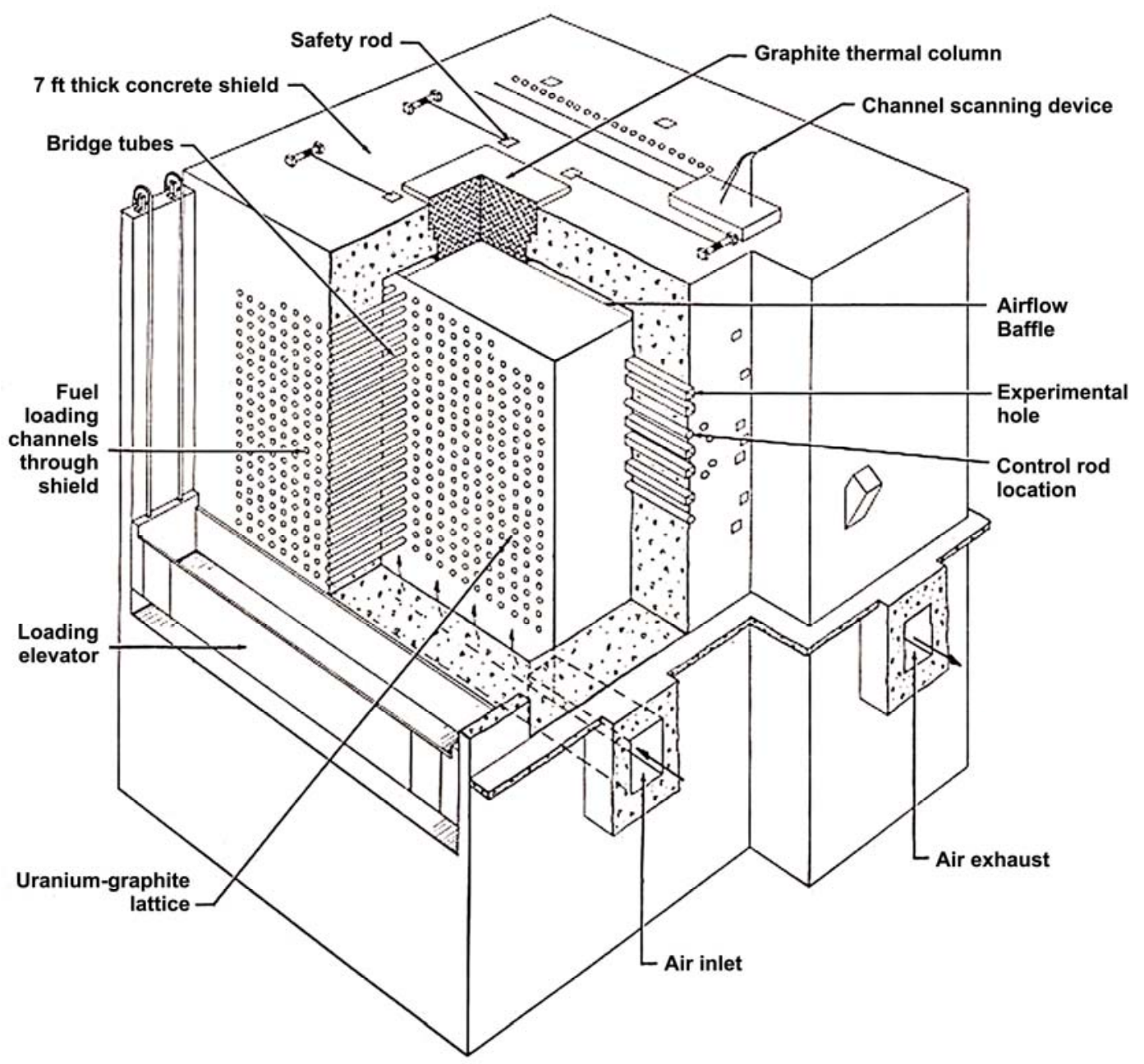

Fig. 5. Cutaway view of the Graphite Reactor. 
cells with $5 \mathrm{ft}$ thick concrete walls. These cells can be seen to the left of the reactor in Figs. 3 and 8. Television was used to view one part of the separation process, but most operations were controlled by observing instruments in the operating gallery shown in Fig. 7.

Fabricating and testing the fuel elements turned out to be one of the most acute problems. Initially bare uranium metal billets were inserted into deep-drawn aluminum cans onto which end caps were welded. Later the billets were coated with an aluminum-silicon alloy that formed a diffusion barrier and provided a thermally conducting bond. The test of the slugs that proved adequate was heating them at $500^{\circ} \mathrm{C}$ for 10 days and then weighing them to detect any oxidation of the fuel. A review in 1948 showed that of 163,661 slugs loaded into the reactor by then, only 48 (representing $0.03 \%$ ) had failed in operation.

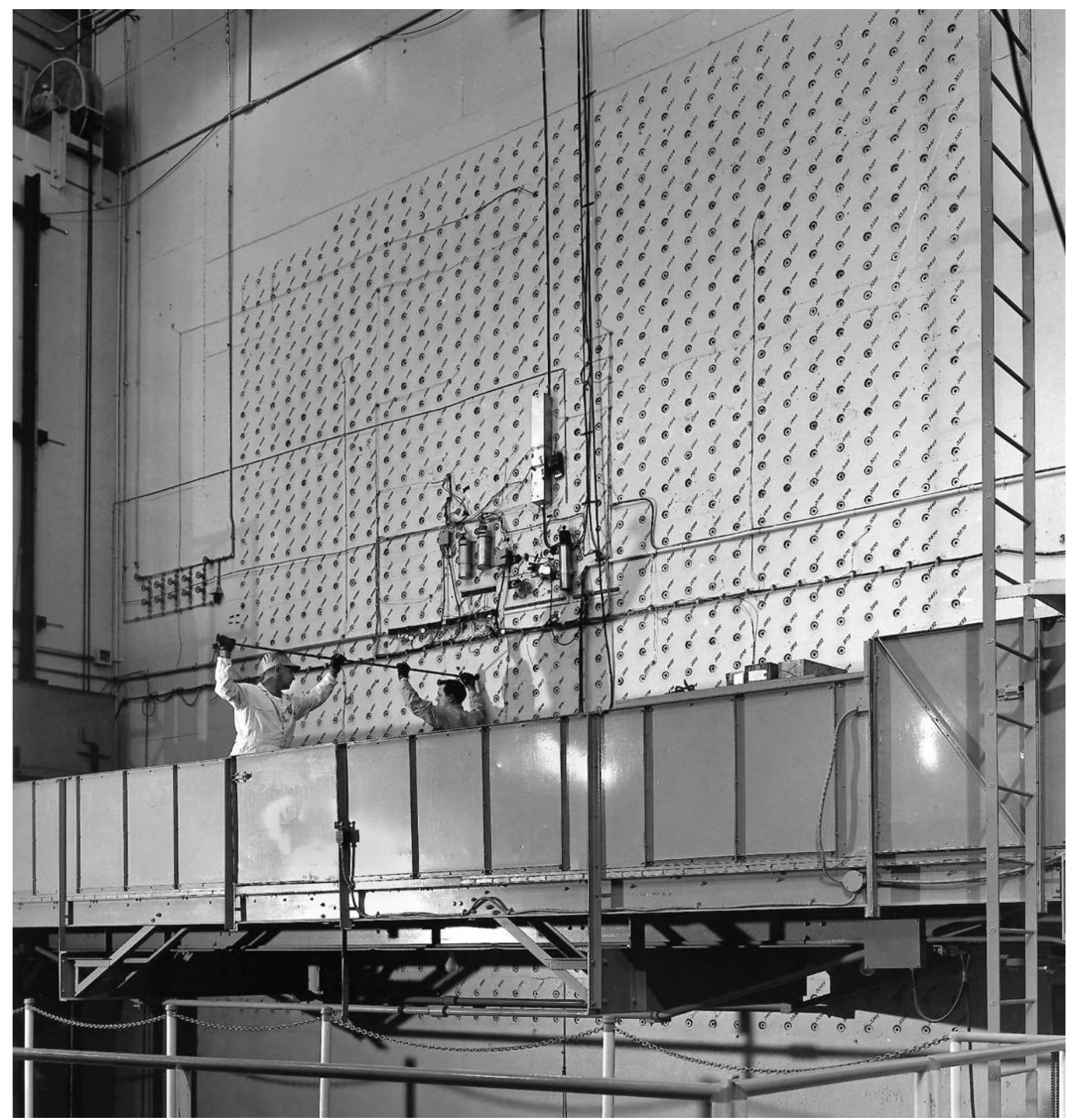

Fig. 6. Loading fuel into the Graphite Reactor. (ORNL History Photo 69) 


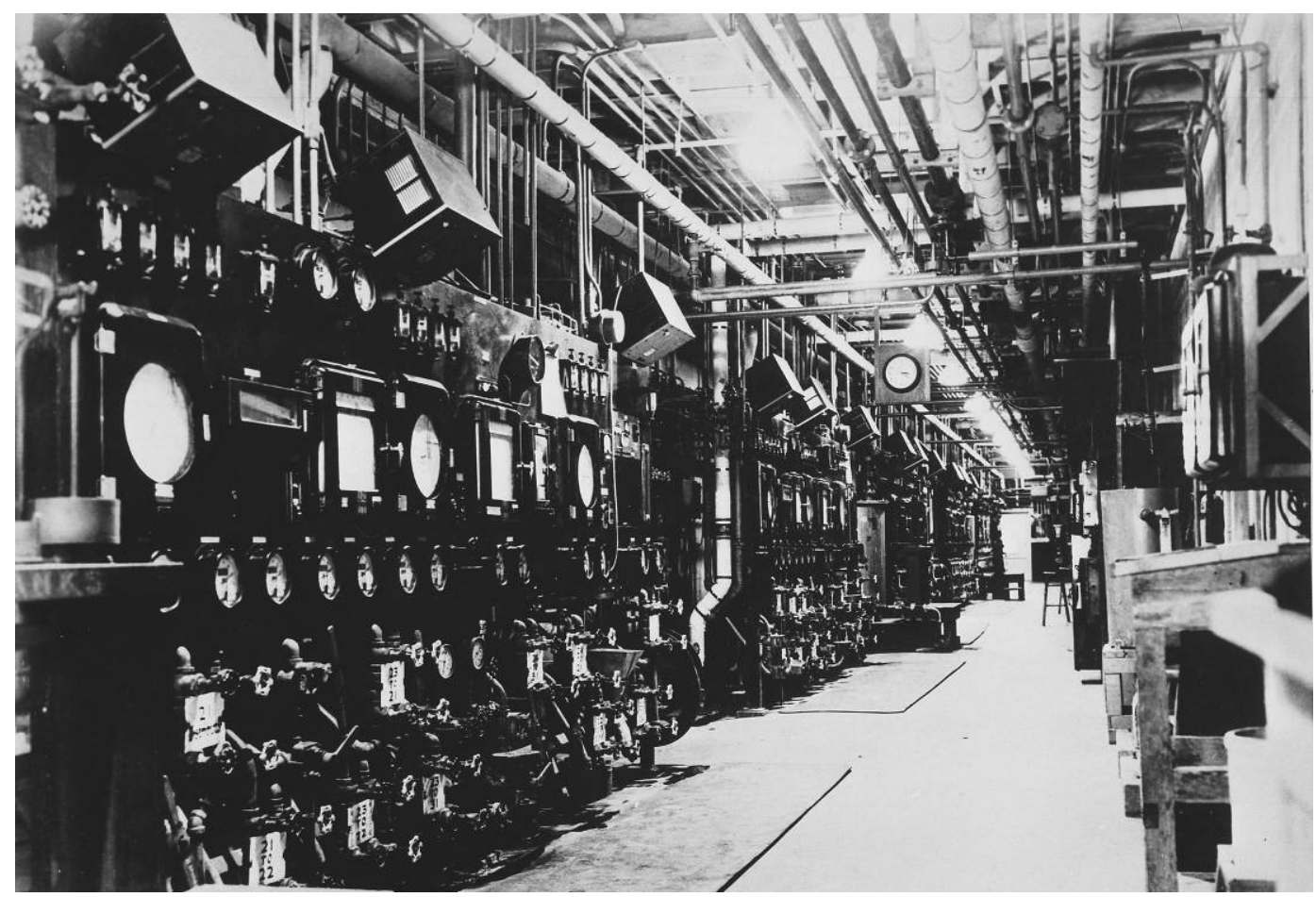

Fig. 7. Operations area of the chemical separations pilot plant. (ORNL History Photo 185)

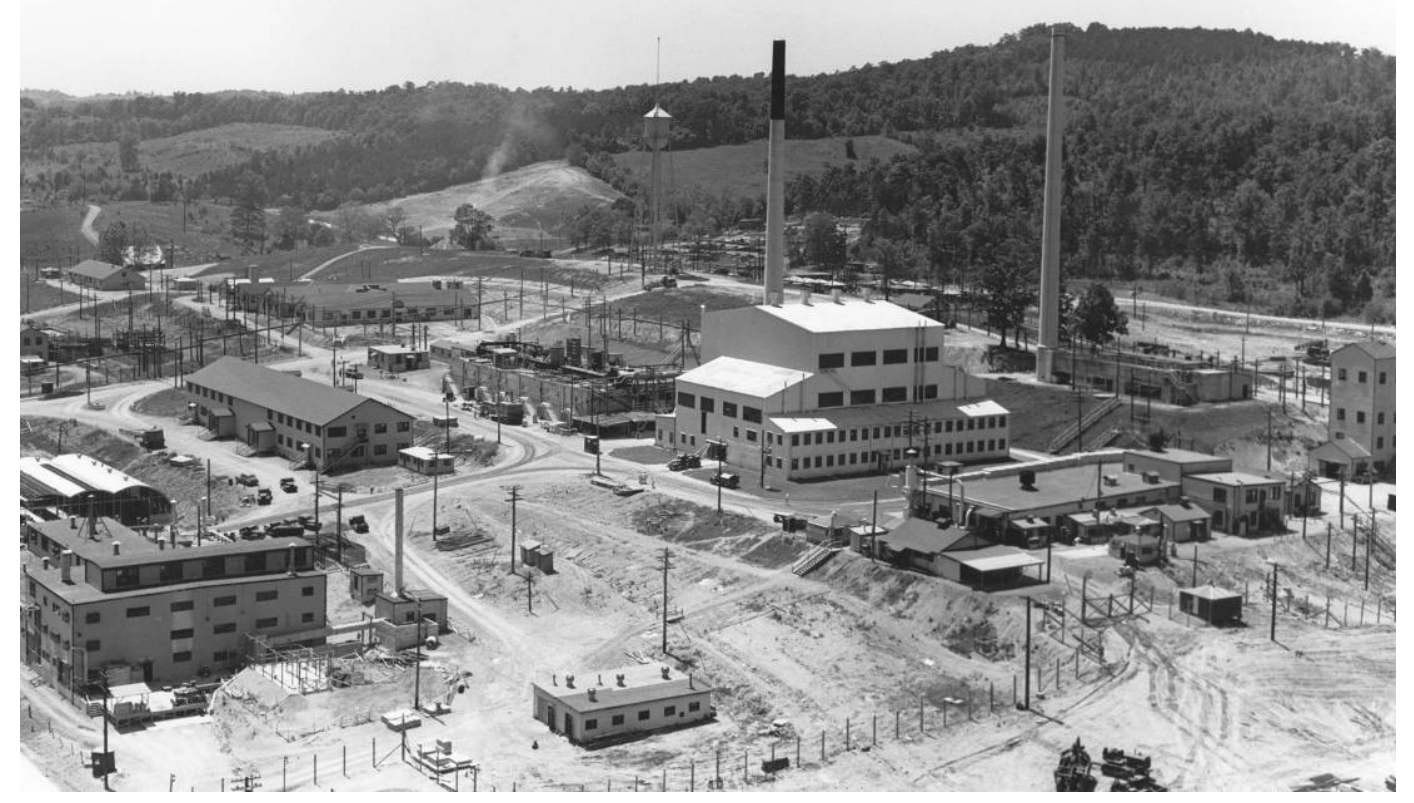

Fig. 8. The Graphite Reactor in 1947. (DOE Oak Ridge Operations Photo 3537)

Sets of "regulating," "shim," and "safety" rods containing neutron poisons were inserted into the core from the top and sides. Radiation detection and measurement instruments, many of them newly developed in Oak Ridge, were located in and around the reactor. 
The Pile, which came to be known as the Oak Ridge Graphite Reactor, was completed in 9 months. Criticality occurred at 5 a.m. on November 4, 1943, after Fermi and Compton had been awakened and brought in from town. The design power was $1000 \mathrm{~kW}$, but by blocking unused channels, reducing the amount of uranium near the center, and adding additional blowers, it was possible over time to increase it to $4000 \mathrm{~kW}$.

Nearly 2 grams of plutonium was produced in 2 months and shipped to Los Alamos, where tests revealed a high spontaneous fission rate of $\mathrm{Pu}-240$. The neutrons emitted were concluded to be capable of causing premature detonation, an important discovery that had a major effect on the design of the plutonium bomb.

Research facilities were created in the Pile by leaving out some of the graphite blocks, thus forming chambers that were used for the exposure of test materials. Beam holes were provided as well, and in addition a $6 \mathrm{ft}$ section of the shield on top of the Pile was replaced with a column of graphite to create a large radiation source for special experiments.

These facilities were used to determine the effects of radiation on materials to be used at Hanford, to measure cross sections and fission product yields and half-lives, to irradiate mice to determine health effects, and to conduct other urgent tests. A simulated Hanford fuel channel was installed to investigate the effects of radiation on the corrosion of aluminum.

The large facility on top of the reactor was used for tests of the laminated steel and Masonite radiation shields planned for Hanford. Then it was used for measuring nuclear properties in an experiment involving 35 tons of uranium slugs. Afterwards, responding to Weinberg's interest, the fuel elements were arranged in lattices in water and the multiplication factors determined. This was an early step along the path that led to the Materials Test Reactor (MTR) family of research reactors and to pressurized-water reactors.

In early 1945, Los Alamos urgently requested large quantities of radioactive lanthanum-known as RaLa - for flash radiographic measurements of implosions. A quickly assembled facility separated $12.8 \mathrm{~d} \mathrm{Ba}-140$ (which decays into $40 \mathrm{~h} \mathrm{La}-140$ ) from the fission products and met the request. This was the first large-scale production of radioisotopes.

Key people from the staff who would operate the Hanford reactors and processing plant spent time in Oak Ridge where special training programs were provided for them. The 1945 Smyth report stated, "Besides the proving of the pile and the separation plant and the production of several grams of plutonium for experimental use at Chicago, Clinton, and elsewhere, the Clinton Laboratories have been invaluable as a training and testing center for Hanford, for medical experiments, pile studies, purification studies, and physical and chemical studies of plutonium and fission products.”

The Pile was run to generate plutonium for processing until early 1945, producing a total of $326 \mathrm{~g}$. During this period it was also used for research and for production of other radioactive materials; these activities continued after the plutonium production mission ended. Other notable work included the pioneering production of radioisotopes; pioneering studies of radiation damage in materials; the determination that hafnium-free zirconium has a very low neutron capture cross section, which led to its being widely used as a reactor cladding material; and the development, by Ernest Wollan and Clifford Shull, of neutron diffraction as a research tool, for which Shull received a Nobel Prize in 1994.

The Pile was shut down in 1963 and designated a National Historical Landmark in 1966. It also received a Historical Landmark Award in 1973 from the American Society for Metals for its contributions to the advancement of materials science and technology. And in 2008, the production and distribution of radioactive isotopes for peacetime use that began at the Graphite Reactor was designated a National Historic Chemical Landmark by the American Chemical Society. 


\section{THE EVOLUTION OF ORNL}

Alvin Weinberg moved to Oak Ridge in 1945. Eugene Wigner came 6 months later to be Research Director and began to make the Laboratory into a broad research facility with emphasis on the technology needed for nuclear reactors. Wigner left in 1947 to return to Princeton University and 16 years later received a Nobel Prize; he maintained a continuing relationship with the Laboratory for many years. In 1948 Weinberg became Research Director.

Under Weinberg's leadership, the Laboratory built and operated another 12 reactors that are listed in Table 2 and shown on the bar chart in Fig. 9, where they are grouped by category: gas cooled, aqueous homogeneous, molten-salt, fast burst, and water cooled. Note that the reactors overlap and sometimes several of them were being built at the same time. In this report, they are treated by type, in the order given in Table 2. As a result, the narrative jumps back and forth in time.

Table 2. Reactors built and operated at ORNL

\begin{tabular}{|c|c|c|}
\hline Name & $\begin{array}{c}\text { Thermal } \\
\text { power, MW }\end{array}$ & $\begin{array}{c}\text { Years } \\
\text { operated }\end{array}$ \\
\hline \multicolumn{3}{|c|}{ Air-cooled, graphite-moderated } \\
\hline Graphite Reactor (Oak Ridge Pile, X-10 Pile) & 3.5 & 1943-63 \\
\hline \multicolumn{3}{|c|}{ Aqueous homogeneous } \\
\hline Homogeneous Reactor Experiment (HRE) & 1.6 & 1952-54 \\
\hline Homogeneous Reactor Test (HRT) & 5.0 & 1957-61 \\
\hline \multicolumn{3}{|c|}{ Molten salt } \\
\hline Aircraft Reactor Experiment (ARE) & 2.5 & 1954-55 \\
\hline Molten Salt Reactor Experiment (MSRE) & 7.4 & 1965-69 \\
\hline \multicolumn{3}{|c|}{ Fast burst } \\
\hline Health Physics Research Reactor (HPRR) & & 1963-87 \\
\hline \multicolumn{3}{|c|}{ Water cooled } \\
\hline Low-Intensity Test Reactor (LITR) & 1.5 (later 3.0) & 1950-68 \\
\hline Bulk Shielding Reactor (BSR) & 2.0 & $1950-87$ \\
\hline Geneva Conference Reactor & 0.1 & 1955 \\
\hline Tower Shielding Reactor I (TSR-I) & 0.5 & 1954-58 \\
\hline Tower Shielding Reactor II (TSR-II) & 1.0 & 1958-92 \\
\hline Oak Ridge Research Reactor (ORR) & 30 & 1958-87 \\
\hline High Flux Isotope Reactor (HFIR) & 100 (now 85) & 1965- \\
\hline
\end{tabular}

With the exception of the HFIR, all of the reactors listed in Table 3 and shown in Fig. 9 have been shut down: the Pile and the Low-Intensity Test Reactor (LITR) in part because of funding restraints and in part because they were superseded by other reactors; the homogeneous, molten-salt, and tower shielding reactors because they had served their purposes and no longer had program support; and the Health Physics Research Reactor and the other research reactors because of U.S. Department of Energy (DOE) concerns about reactor safety and the safeguarding of enriched uranium.

The safety concerns were triggered in 1986 by the disastrous nuclear plant accident at Chernobyl in the Soviet Union. Following it, DOE initiated a massive reexamination of reactor safety, and numerous reviews were conducted at ORNL and the other DOE installations. In March 1987, DOE directed the shutdown of many of its reactors, including all of those at ORNL.

Only the HFIR and the Tower Shielding Reactor II (TSR-II) were eventually authorized to return to operation. The Laboratory had discovered a potentially serious issue at the HFIR and dealt with it 


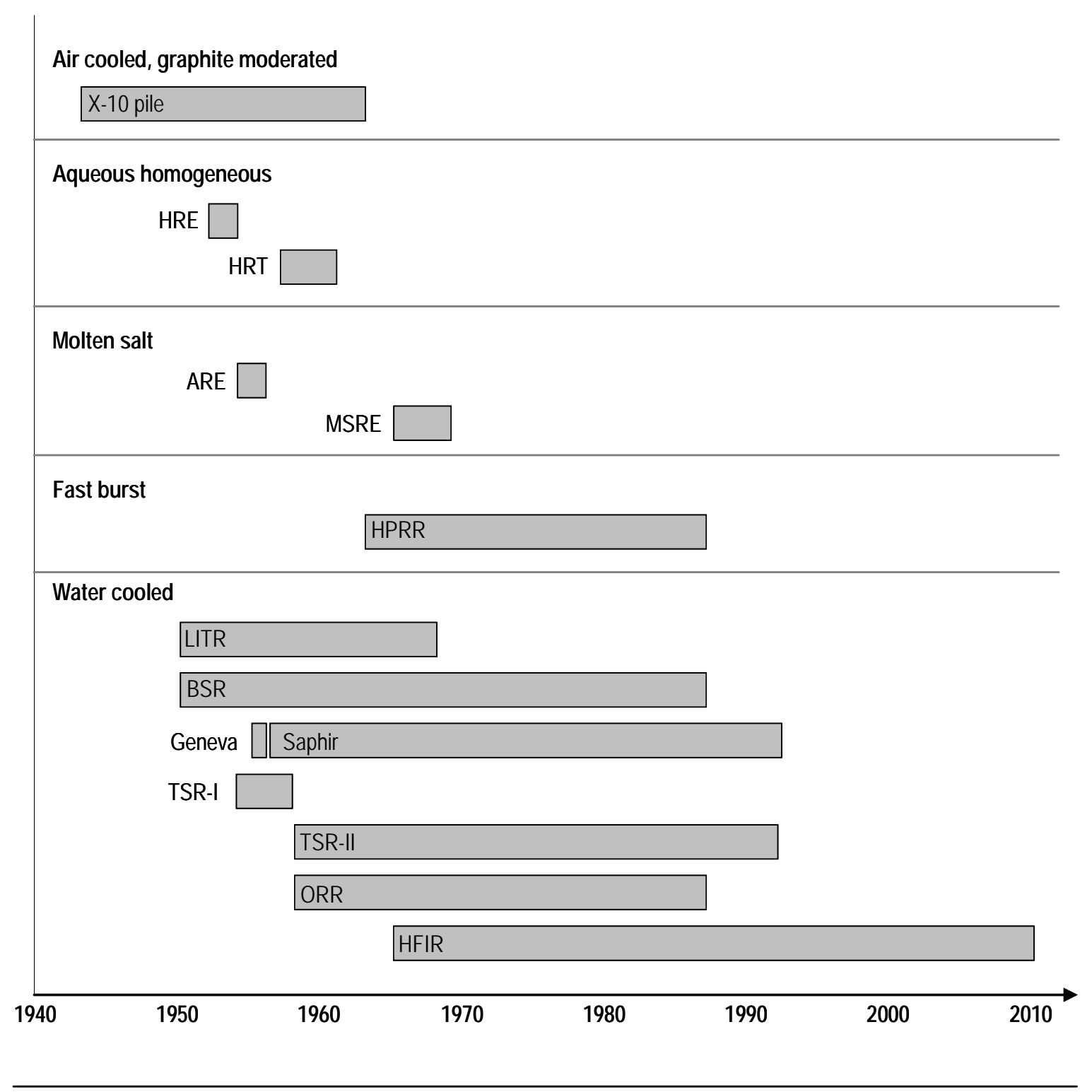

Fig. 9. ORNL's nuclear reactors, from criticality to shutdown.

but felt that the problems of the other reactors were mostly organizational and procedural and were being corrected. The research staff was particularly distressed by the loss of some special research capabilities and the interruption of valuable investigations that were in progress and could have been completed with extended operation. Nevertheless, the shutdowns were permanent, and the Laboratory was reduced to two operating reactors and eventually to one with the final shutdown of the TSR-II in 1992.

In the late 1980s and early 1990s, ORNL developed a concept for a new and higher capability reactor that would replace the HFIR when it reached the end of its life. With a power of several hundred megawatts, the Advanced Neutron Source (ANS) would have far surpassed the research capability of any other reactor and was expected to regain for the United States the world leadership in neutron scattering that was slipping away. But because of cost, and possibly because the ANS would have used fully enriched uranium at a time when the United States was urging other nations not to do so, the idea for a new reactor was abandoned. Instead, construction began in 1999 on the 
accelerator-based Spallation Neutron Source (SNS), which provides the world's most intense pulsed neutron beams for scientific research and industrial development. While the SNS lacks the isotope production and materials testing ability of a steady-state neutron source, the HFIR continues to fill that need and is expected to remain in operation for many more years.

The 13 reactors that were designed, built, and operated by ORNL are discussed in individual sections. The Laboratory also had important roles in reactors built by other organizations, making major contributions to research and technology in materials, chemistry, chemical processing, shielding, instrumentation, remote handling, radiation protection, and many other areas. In two cases, however, the Package Power Program and the Gas-Cooled Reactor Program, ORNL's role extended further and included contributions to the development of concepts and assistance in the design and construction of the reactors themselves. The Materials Test Reactor was also built elsewhere, but it is included with ORNL's water-cooled reactors because it originated at the Laboratory. 


\section{SUPPORT OF NON-ORNL REACTORS}

\section{Package-Power Program}

In the early 1950s, the U.S. Army became interested in compact reactors that could be transported to remote locations where other fuels would not be readily available. A joint program was established by the Army and the U.S. Atomic Energy Commission (AEC), and a study group was assembled at ORNL. This group prepared the conceptual design for a fully enriched $10 \mathrm{MW}$ (th) pressurized water plant called the Army Package Power Reactor. The concept was used by the Army to solicit bids for a prototype that was constructed at Fort Belvoir, Virginia.

The American Locomotive Company (Alco) received the contract and in April 1957, the reactor, called the SM-1 by the Army, went critical. ORNL developed the fuel elements and control rods, reviewed the design, performed critical experiments and materials irradiations, and provided other support. Fully enriched $\mathrm{UO}_{2}$ powder dispersed in stainless steel plates and clad with stainless steel was chosen for the fuel elements; $\mathrm{B}_{4} \mathrm{C}$ powder was also dispersed in the plates as a burnable poison. The fuel elements and control rods for the first core were fabricated by the Laboratory.

The reactor performed very well and was pioneering in many ways. It was the first reactor secured by bids on a fixed-price contract, the first with a pressure-containment structure, and the first to use stainless steel for fuel cladding

Following the success of the Fort Belvoir prototype, the Army went on to build eight other compact reactors of various designs The one that attracted the most public attention provided heat and electricity at McMurdo Sound in the Antarctic from 1962 until 1972 and thereby avoided the need for more than 25,000 barrels of diesel fuel a year that an oil-fired plant would have consumed.

Nevertheless, the Army program eventually found small power reactors to be too costly to operate and ended their use.

\section{N.S. Savannah}

The ORNL group that had worked on the Army reactor took on one other assignment. A nuclearpowered passenger/cargo vessel, the Nuclear Ship (N.S.) Savannah, was authorized in the Atoms for Peace program as a joint project of the AEC and the Maritime Administration (then part of the U.S. Department of Commerce). Babcock and Wilcox built the reactor, and ORNL provided substantial technical assistance to the program.

The Savannah was a beautiful ship with a $69 \mathrm{MW}(\mathrm{th})$ pressurized-water reactor that propelled it over 300,000 miles before refueling. It made more than 300 visits to ports all over the world, where it was toured by about 1.5 million visitors. The ship performed well and met all of its objectives but was taken out of service for budgetary reasons in 1970 after eight years of operation. The Savannah was named a Nuclear Engineering Landmark by the American Nuclear Society in 1991.

\section{Gas-Cooled Reactors}

After the Clinton Pile and the Hanford reactors were under way, a number of scientists and engineers who had been involved in their designs turned their attention to ideas for power reactors. The studies at Oak Ridge narrowed down to a helium-cooled, beryllium-oxide-moderated reactor that was known as the Daniels Pile. When Wigner moved to Oak Ridge, among the roles he considered for the Laboratory was the development of power reactors based on the Daniels Pile. But as recounted later, he decided to give priority to a high-flux reactor that became the Materials Test Reactor (MTR), and afterwards Weinberg chose to follow the MTR with efforts to develop an aqueous homogeneous breeder. Consideration of gas-cooled power reactors at Oak Ridge thus ceased.

Hyman Rickover and his crew came to Oak Ridge in 1946 for training in nuclear engineering and while here chose water cooling over gas cooling for submarines. The course of U. S. power reactors 
was thus set. The technology developed in the Navy program gave pressurized and boiling water reactors a lead that was hard to overcome.

The United Kingdom, however, followed a different route. The British wanted to produce plutonium for bombs and simultaneously generate nuclear power, and the $50 \mathrm{MW}(\mathrm{e})$ Calder Hall power plants that they built used dual-purpose reactors that could do both. The British did not yet have enriched uranium and had no domestic source of helium, so the Calder Hall reactors were restricted to natural uranium and used carbon dioxide as the coolant. The metal fuel was clad in a magnesium alloy called Magnox, and from that they came to be called Magnox reactors. The Calder Hall reactors were the first to supply commercial amounts of power to a utility grid.

The dual-purpose Magnox reactors were followed in the United Kingdom by larger gas-cooled power reactors. They were still cooled with carbon dioxide but used low-enriched uranium in stainless-steel-clad $\mathrm{UO}_{2}$ fuel elements that enabled higher temperatures and thus higher thermal efficiency.

Members of the Congressional Joint Committee on Atomic Energy noted what the British were doing and thought the United States might be missing out on something. Consequently, in 1956 they directed the AEC to build a gas-cooled reactor and investigate its potential. The AEC eventually assigned responsibility for this effort to its Oak Ridge Operations Office, which in turn arranged for the Tennessee Valley Authority (TVA) to participate and to operate the power plant as part of its grid. Outside contractors were hired for design and construction, and ORNL was called on for technical support.

The Laboratory and others studied the various possibilities and recommended a helium-cooled graphite core which, like the British advanced reactors, used oxide fuel pellets clad with stainless steel. The power output was $30 \mathrm{MW}(\mathrm{e})$, and the site was on the Clinch River near ORNL.

ORNL supplied advice and assistance for the Experimental Gas-Cooled Reactor (EGCR), but its major responsibility was the design of the fuel elements and their qualification by irradiation testing. Doing that involved the testing of fuel capsules and eventually the construction and operation of a large helium-cooled loop in the Oak Ridge Research Reactor (ORR).

By 1966, the fuel elements had been fabricated and the reactor was nearly complete. But just before the fuel was to be loaded, the AEC decided that reactors of the type that would be most directly tested by the EGCR had no future in the United States. Consequently, it ended the program before the reactor became radioactive. Many saw justification in the AEC decision, but those who had devoted years to the reactor, and particularly those who had developed the fuel elements, were disappointed that their efforts were never tested. The EGCR offices and generator hall were eventually put to use as development space for other programs, but the large containment dome shown in Fig. 10 still stands as the most visible symbol of nuclear reactors in Oak Ridge.

At the time the EGCR program was in progress, a group centered on Germany’s Jülich Research Center was undertaking the development of helium-cooled reactors in which the core was a bed of $6 \mathrm{~cm}$ diam fuel-containing graphite spheres. The all-ceramic core permitted operation at high temperature, and the spherical fuel elements could be assayed and recycled or replaced while the reactor was at power. Funding was secured for a $15 \mathrm{MW}(\mathrm{e})$ pebble-bed reactor, the AVR (for Arbeitsgemeinschaft Versuchsreaktor), to be built at Jülich.

The AEC asked ORNL to take a new look at pebble-bed reactors (they had been considered by the Daniels Pile group earlier) and develop ideas for a reactor experiment that would be built in Oak Ridge. Following an optimistic report, the Laboratory was asked to prepare a conceptual design of what was called the Pebble-Bed Reactor Experiment (PBRE). In addition, the United States and Germany established an agreement to cooperate. Both parties benefited: Germany was ahead in developing reactor hardware, but did not have fuel-testing facilities, and ORNL had better capability for physics calculations. 


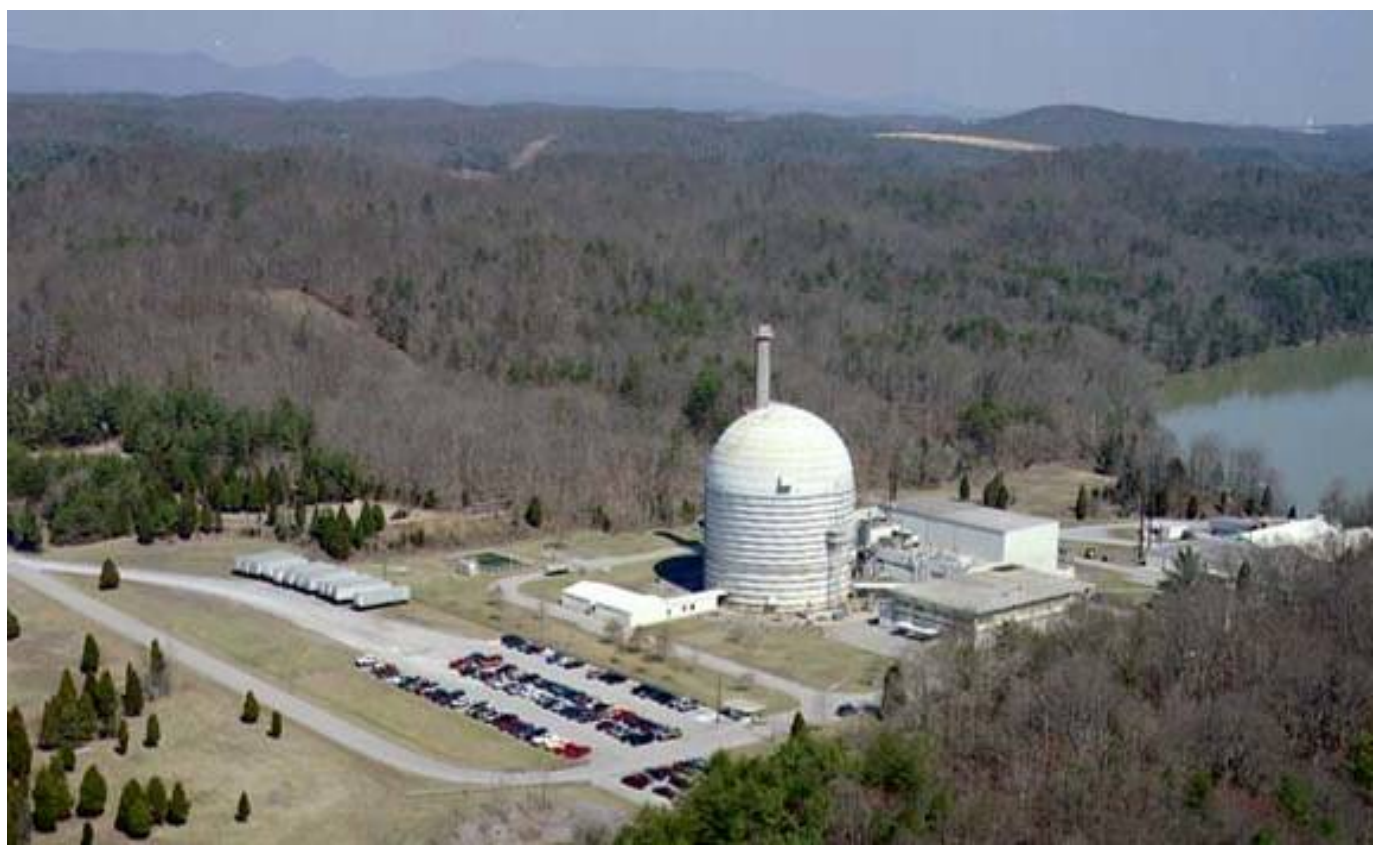

Fig. 10. The Experimental Gas-Cooled Reactor. (ORNL Photo 02144-95)

The original idea was to use graphite spheres that contained bare particles of uranium dioxide or uranium carbide. In-pile tests at ORNL revealed, however, that not only did volatile fission products escape, but also the fuel elements swelled and became distorted. Fortunately, several installations were demonstrating that pyrolytic-carbon coatings on tiny spherical fuel particles could absorb fission recoil and contain fission products. Both the Germans and ORNL adopted coated-particle fuel dispersed in graphite for their reactors, and ORNL proceeded to develop multiple-layer coatings and demonstrate in-pile that they worked well.

When ORNL's conceptual design for a reactor was completed, the AEC changed its mind and cancelled the project. One reason was that the Laboratory found that PBRE would cost about twice the amount estimated in its earlier report. Another was that General Atomics was proceeding with construction of the Peach Bottom high-temperature reactor, and no need was seen for two graphitefuel reactor programs.

The Germans completed the AVR in 1966 and operated it successfully for 21 years. At Oak Ridge, pebble-bed reactor work ended, but a very successful program to develop coated-particle fuel for reactors and other applications continued. 


\section{AQUEOUS HOMOGENEOUS REACTORS}

As noted earlier, after the conceptual designs for the Oak Ridge and Hanford piles were completed, Wigner's group at Chicago began to think about concepts for power plants. A series of meetings of what was called the New Piles Committee, held in the spring of 1944, was attended by Fermi, Wigner, Szilard, Walter Zinn (who became director of the Argonne National Laboratory), and others including Weinberg. At that time, the amount of uranium available was thought to be small, and it was concluded that for the production of large amounts of power, it would be necessary either to convert U-238 into plutonium or to convert thorium into U-233.

So among the ideas discussed by the committee were reactors that would produce more fissionable fuel than they consumed. Szilard called these reactors "breeders," and the name stuck. Several alternatives were considered, particularly fast reactors operating on plutonium. Wigner, however, liked the idea of a homogeneous thermal breeder in which a slurry of U-233 oxide in heavy water in the core generated neutrons to convert thorium in a surrounding blanket into U-233. The neutron economy would be very good, and the reactor was said to be just "a pot, a pipe, and a pump."

The possibility of forming reactors from a slurry or solution of uranium in water had been recognized early following the discovery of fission. In 1940, Hans von Halban and Lew Kowarski, who had brought the entire French supply of heavy water (112 liters) with them when they fled to England ahead of the advancing German army, tried it at the Cavendish Laboratory in England. They put the heavy water in a $60 \mathrm{~cm}$ sphere surrounded by a reflector, suspended varying amounts of $\mathrm{U}_{3} \mathrm{O}_{8}$ powder in it, and determined the multiplication factor. But there was no more heavy water to be had, and the idea was not pursued further in England.

However, by 1943 American and Canadian efforts to produce large quantities of heavy water were proceeding well, and concepts for production reactors using heavy water, including homogenous reactors, were considered at Columbia and Chicago. But with the design of graphite reactors now well along, the heavy water concepts for production reactors were dropped

In 1944, after enriched uranium had become available, a group at Los Alamos built LOPO (for low power), an unshielded homogeneous "water boiler" with a light-water solution of uranyl sulfate in a $1 \mathrm{ft}$ stainless steel sphere. To get useful neutron fluxes, shielding and cooling were soon added in a modification called HYPO (for high power), and the uranyl sulfate was replaced with uranyl nitrate. A 1949 upgrade called SUPO took the power to $45 \mathrm{~kW}$.

Proposals were developed in Oak Ridge in 1944 and 1945 for building aqueous homogenous reactors for research or radioisotope production, but a number of serious problems were recognized. They included solution stability, corrosion, and questions of nuclear instability from bubbles formed by radiolytic decomposition of water. So work on homogeneous reactors was stopped and was replaced by Wigner's concept of a water-cooled solid-fuel reactor that became the MTR.

\section{Homogeneous Reactor Experiment}

Alvin Weinberg says in The First Nuclear Era that he continued to be attracted by the advantages of aqueous homogeneous reactors, and in 1950 he initiated a review of the overall situation with regard to what in Oak Ridge came to be simply called homogeneous reactors. The conclusion was positive, and he persuaded the AEC to fund a small reactor, the Homogeneous Reactor Experiment (HRE), referred to by the AEC as HRE-1. It was constructed in Melton Valley, to the south of the original X-10 location in Bethel Valley, and completed in 1952.

The core of the HRE was a thin 18 in. stainless steel vessel enclosed in a larger pressure vessel with a 10 in. gap for a $\mathrm{D}_{2} \mathrm{O}$ reflector. The reflector pressure vessel is shown during construction in Fig. 11, and a sketch of the reactor is shown in Fig. 12. Additional details are provided in Table 3. 


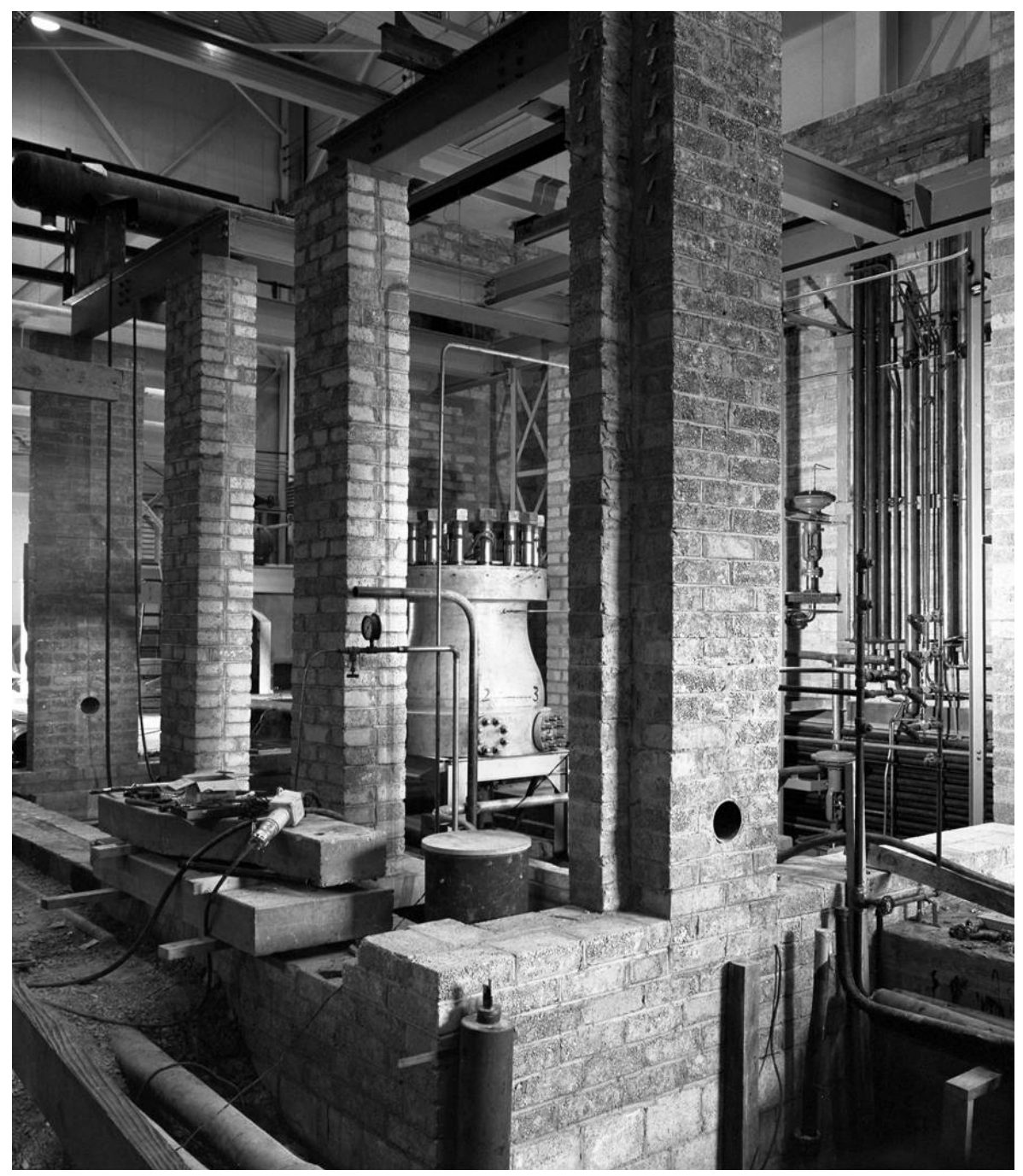

Fig. 11. The HRE pressure vessel during construction. (ORNL Photo 8614)

The fuel was a solution of 93\%-enriched uranium as uranyl sulfate dissolved in water, and it operated at $250^{\circ} \mathrm{C}$ and 1000 psi. The design power was $1000 \mathrm{~kW}$ of heat, but a maximum of $1600 \mathrm{~kW}$ was attained.

As can be seen in Fig. 13, a canned-rotor pump circulated the fuel solution from the core through a heat exchanger. Saturated steam produced in the heat exchanger powered a turbine generator, producing $140 \mathrm{~kW}$ of electricity that was fed to the grida first. The heavy water in the reflector was pumped through a heat exchanger that served as a boilerfeedwater preheater.

The recoiling fission products decomposed water in the fuel solution to hydrogen and oxygen, and a small

Table 3. HRE-1 parameters

\begin{tabular}{ll}
\hline Power (heat) & $1000 \mathrm{~kW}(1600 \mathrm{~kW}$ maximum) \\
Fuel & $\mathrm{UO}_{2} \mathrm{SO}_{4}$ (93\% enriched) in $\mathrm{H}_{2} \mathrm{O}$ \\
Fuel inlet temperature & $210^{\circ} \mathrm{C}$ \\
Fuel outlet temperature & $250^{\circ} \mathrm{C}$ \\
Pressure & $1000 \mathrm{psi}$ \\
Core vessel & 18 in. diam, stainless steel \\
Pressure vessel & 39 in. inside diameter \\
Reflector & $\mathrm{D}_{2} \mathrm{O}, 10$ in. thick \\
Turbine generator & $140 \mathrm{~kW}, 200 \mathrm{psi}, 382^{\circ} \mathrm{F}$ \\
Critical & April 15,1952 \\
Shut down & February 1954 \\
\hline
\end{tabular}




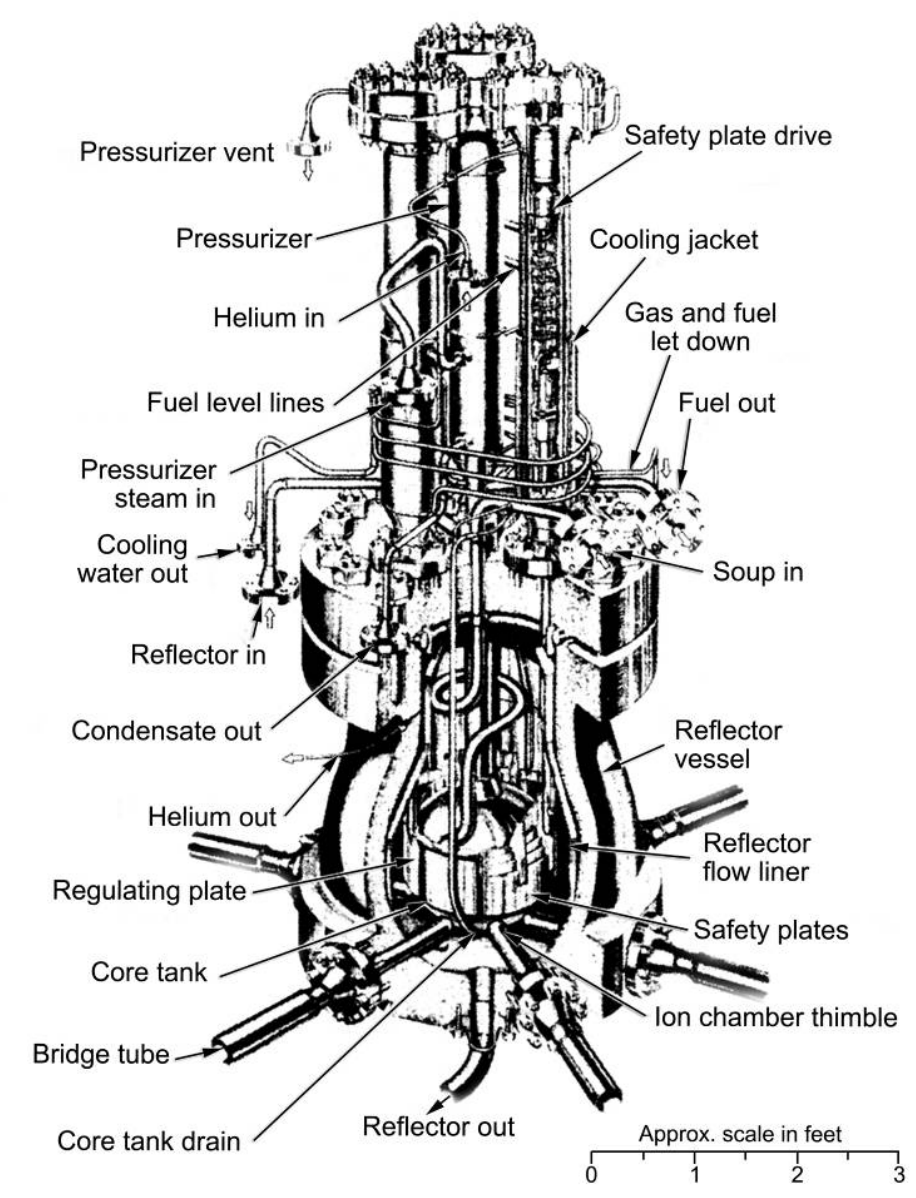

Fig. 12. Sketch of the HRE reactor vessel. (ORNL Drawing D-9065A)

volume of fission gases was also produced. To prevent these gases from accumulating in the core, the fuel solution was fed in tangentially near the equator, causing it to swirl and generate a stable vortex about 0.25 in. in diameter. The centrifugal action swept out the gases, which were withdrawn at the top through a nozzle centered in the outlet line.

These gases, with the liquid that accompanied them, were passed through a cooler and a gas separator. The separated gas then flowed through a flame recombiner followed by a catalytic recombiner, and the highly radioactive fission gases that remained went on to water-cooled activated carbon beds buried outside the reactor building. Other systems visible in Fig. 13 provided for fuel storage, concentration control, and other functions.

After the HRE was designed, chemists at the Laboratory found that copper ion added to fuel solution serves as a homogeneous catalyst that causes hydrogen and oxygen to recombine, an important discovery. Consequently, copper sulfate was added to the HRE fuel solution several times and its effect studied over a range of operating conditions. It was found to prevent bubble formation and had no deleterious chemical effects.

A key operating and safety feature of aqueous homogeneous reactors is a very strong negative temperature coefficient. As a result, an increase in steam demand by the turbine that would have lowered the fuel solution temperature was automatically offset by an increase in power that kept it constant. And experiments with rapid reactivity additions showed that the HRE was extremely fast acting in limiting power surges. In two experiments in which the power reached a peak of $10 \mathrm{MW}$ in 1.0 second, it returned to near the equilibrium power level in just 0.2 second. The calculated peak 


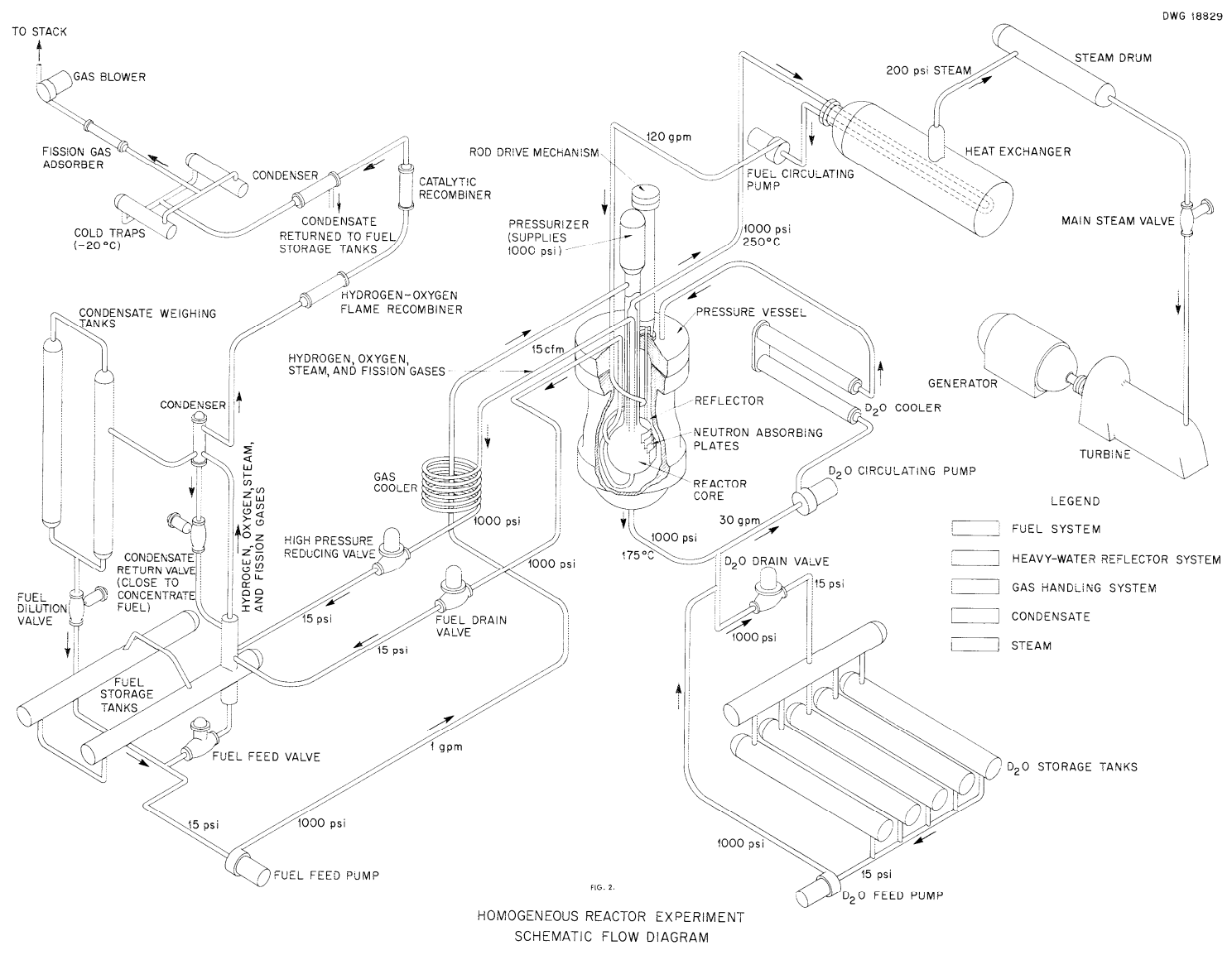

Fig. 13. Schematic flow diagram for the HRE. (ORNL Drawing 18829)

pressure rise was only 5 psi. Magnetically coupled safety plates could be dropped between the core and reflector of the HRE, but the rapid self-regulation obviated the need for them.

Because of the high radioactivity in the fuel solution, leakage from the reactor had to be kept very low. This was achieved by the use of canned-rotor pumps, bellows-sealed valves, and double tube sheets in the heat exchangers. Oval cross-section metal gaskets in flanged joints formed inner and outer seals and allowed monitoring for leakage to the space between. Several leaks occurred during the startup period but none during the final months of operation.

One of the most pressing questions about liquid-fuel reactors is the ability to perform maintenance in the presence of the high radioactivity that is deposited in many parts of the systems. Maintenance on the radioactive parts of the HRE was usually done with long-handled tools from behind temporary shields, and often the reactor components were decontaminated before work began. By these means, all necessary repairs were accomplished, including replacing or repairing the main circulating pump three times and the diaphragm feed pumps twice. However, maintenance under these conditions took much longer than would be needed in the absence of the radioactivity.

The HRE was operated for 24 months and was shut down in 1954 after a run of 40 days at full power. By then it had demonstrated that:

- a small homogeneous reactor can be operated reliably at a significant temperature and pressure,

- leak tightness can be maintained,

- nuclear stability is excellent,

- copper ions suppress evolution of hydrogen and oxygen, and

- maintenance is feasible in spite of the circulating fission products. 


\section{Homogeneous Reactor Test}

Various ideas for follow-on experiments, including a 150-kW boiler, were being considered while the HRE was being built and operated. In 1953, ORNL joined Los Alamos in performing boiling experiments on SUPO, which showed that it automatically compensated for sudden additions of reactivity. This and other ideas were put off, however, by the conclusion that the next step in homogeneous reactors should be further development of features that would be needed for a power reactor. Important among them were improved provisions for maintenance and methods for the continuous removal of fission and corrosion products.

Consequently, the HRE was removed and another homogeneous reactor was installed in the same building. In Oak Ridge the second reactor was known as the Homogeneous Reactor Test (HRT), but it was called HRE-2 by the AEC, and both names appear in the literature.

The HRT was completed in 1956. Its core diameter was 32 in., nearly twice that of the $18 \mathrm{in}$. HRE, and it generated four times the power. The fuel was still uranyl sulfate but in $\mathrm{D}_{2} \mathrm{O}$. And to provide the potential for higher thermal efficiency and (as discussed later) lower corrosion, it was hotter than the $\mathrm{HRE}$, operating at $300^{\circ} \mathrm{C}$ vs $250^{\circ} \mathrm{C}$. A 14 in. gap between the core tank and a pressure vessel provided space for a heavy water reflector. Other details are given in Table 4.

With the HRE having demonstrated that copper ion will recombine hydrogen and oxygen in the fuel solution, flow straight through the core was selected rather than the vortex-generating swirl of the HRE. As shown in Fig. 14, the fuel solution entered through a tapered section at the bottom into which zirconium diffuser screens were welded to even out the flow. From the core, it passed through a centrifugal gas separator that removed fission gases and any uncombined hydrogen and oxygen. Then it went through a U-tube steam generator and on to a circulating pump that returned it to the core. The steam generated in the heat exchanger was routed to the turbinegenerator originally used for the HRE, and the excess went to an air-cooled condenser.

Figure 15 is a schematic flow diagram of the HRT fuel and blanket systems. Also shown are the systems provided for fuel storage, concentration control, and other functions.

The core vessel, shown in Fig. 16, was made of Zircaloy-2, an alloy that was Table 4. HRT parameters

\begin{tabular}{ll}
\hline Power (heat) & $5000 \mathrm{~kW}$ \\
Fuel & $\begin{array}{l}\mathrm{UO}_{2} \mathrm{SO}_{4} \text { in } \mathrm{D}_{2} \mathrm{O} \\
(\sim 10 \mathrm{grams} \text { of } \mathrm{U}-235 \text { per liter })\end{array}$ \\
$\begin{array}{l}\text { Fuel circulation rate } \\
\text { Fuel inlet temperature }\end{array}$ & $\begin{array}{l}400 \mathrm{gal} / \mathrm{min} \\
265^{\circ} \mathrm{C}\end{array}$ \\
Fuel outlet temperature & $300^{\circ} \mathrm{C}$ \\
Pressure & $2000 \mathrm{psi}$ \\
Core vessel & 32 in. diam, 0.3125 in. thick, \\
& Zircaloy-2 \\
Pressure vessel & 60 in. inside diameter \\
Reflector & $\mathrm{D}_{2} \mathrm{O}, 14$ in. thick \\
Turbine generator & $140 \mathrm{~kW}, 200$ psi, 382 ${ }^{\circ} \mathrm{F}$ \\
Critical & December 27, 1957 \\
Shut down & April 21, 1961 \\
\hline
\end{tabular}
made available by advances in technology after the HRE was built. The rest of the system was 347 stainless steel. Both materials had been shown to corrode less at $300^{\circ} \mathrm{C}$ than at $250^{\circ} \mathrm{C}$ in fuel solution. No mechanical control devices were provided, because experience with the HRE had shown them to be unnecessary.

One of the key attractions anticipated for liquid fuel reactors is ease of reprocessing the fuel to remove fission products. The volatile products from the HRT were removed by the gas separator in the core exit line. After passage through the steps shown in Fig. 15, they were adsorbed on beds of activated charcoal. 


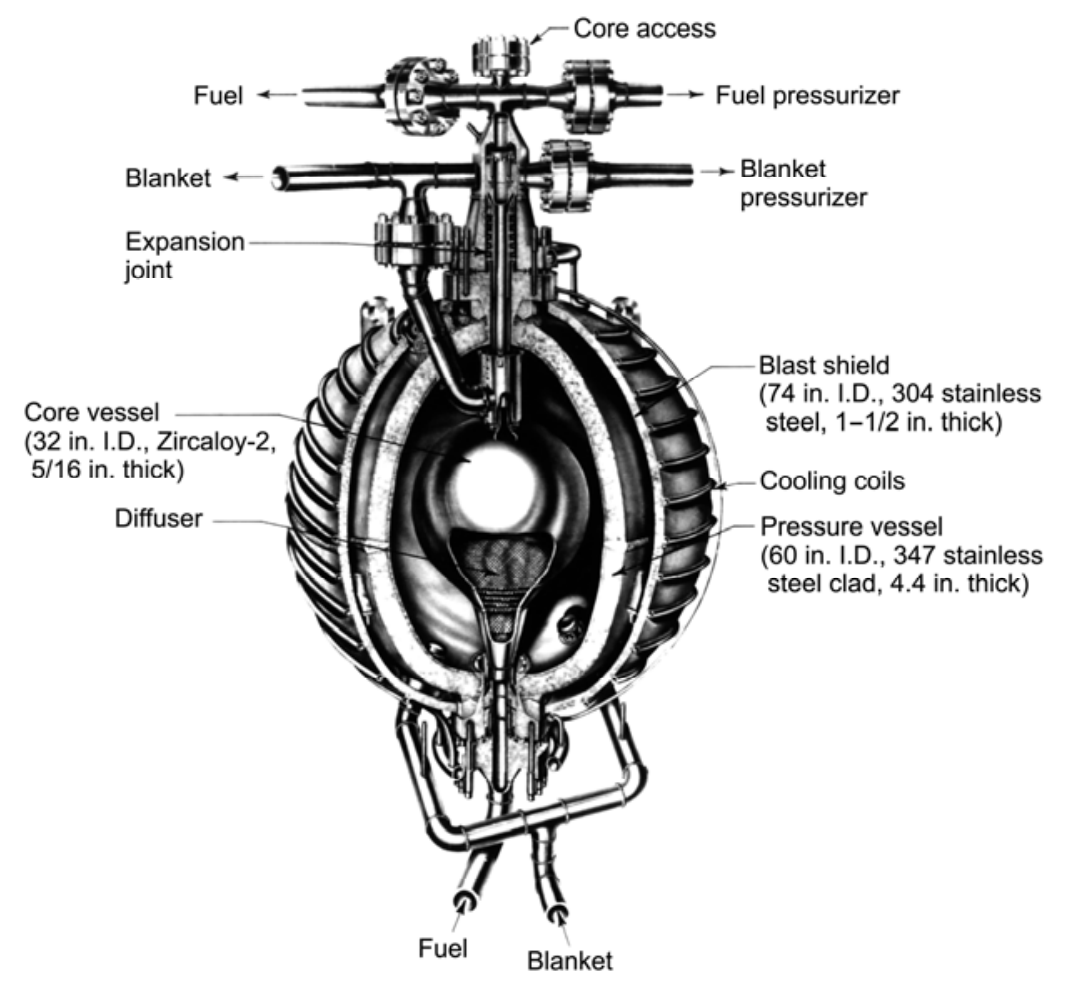

Fig. 14. HRT core and pressure vessels. (ORNL Photo 23459)

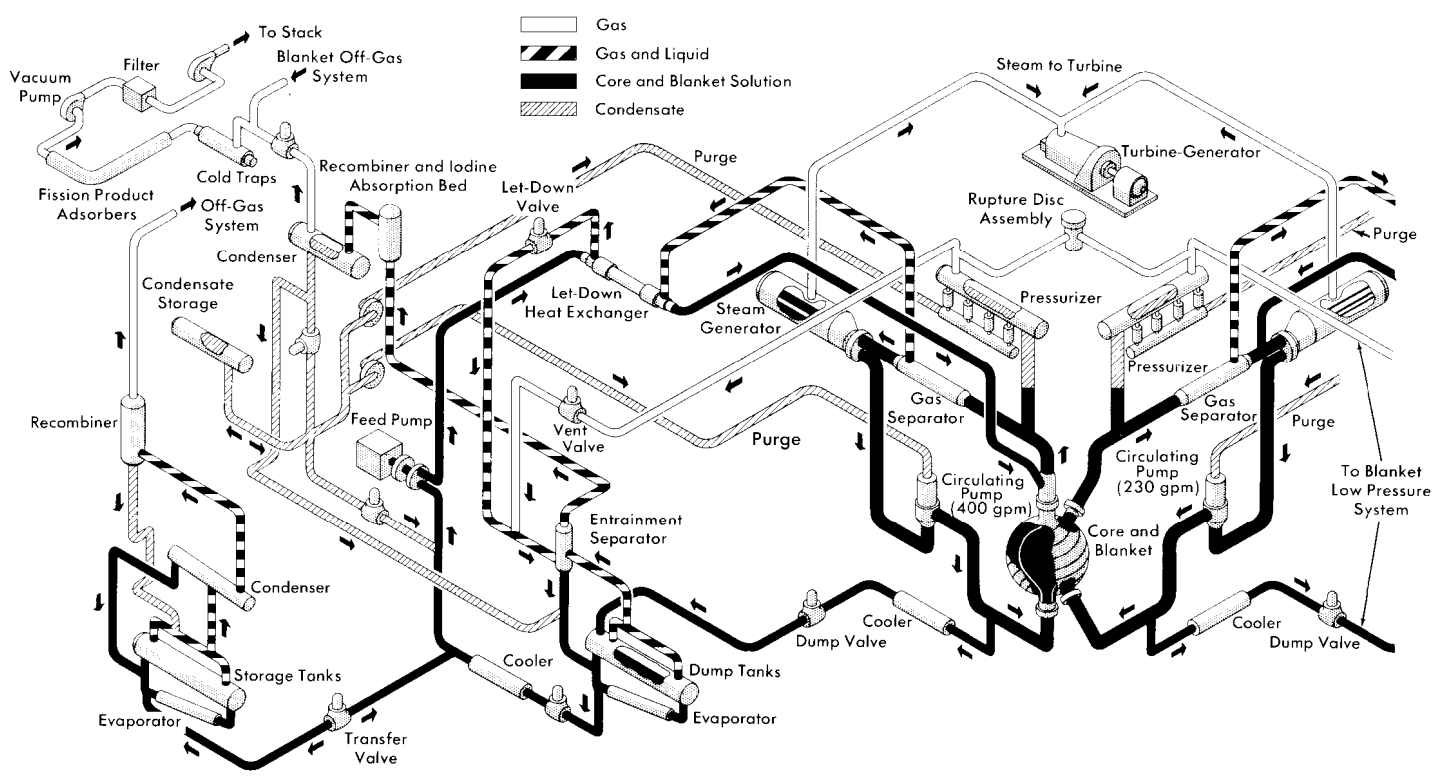

Fig. 15. Schematic flow diagram for the HRT.

A liquid centrifugation process was provided for removal of those solid fission products and corrosion products that are insoluble in the fuel solution. This was done in an adjacent cell by 2.5 in. high cyclone separators ("hydroclones") in a $1.5 \mathrm{gal} / \mathrm{min}$ liquid sidestream that was continuously withdrawn from the primary system. The solids dropped into an underflow pot from 


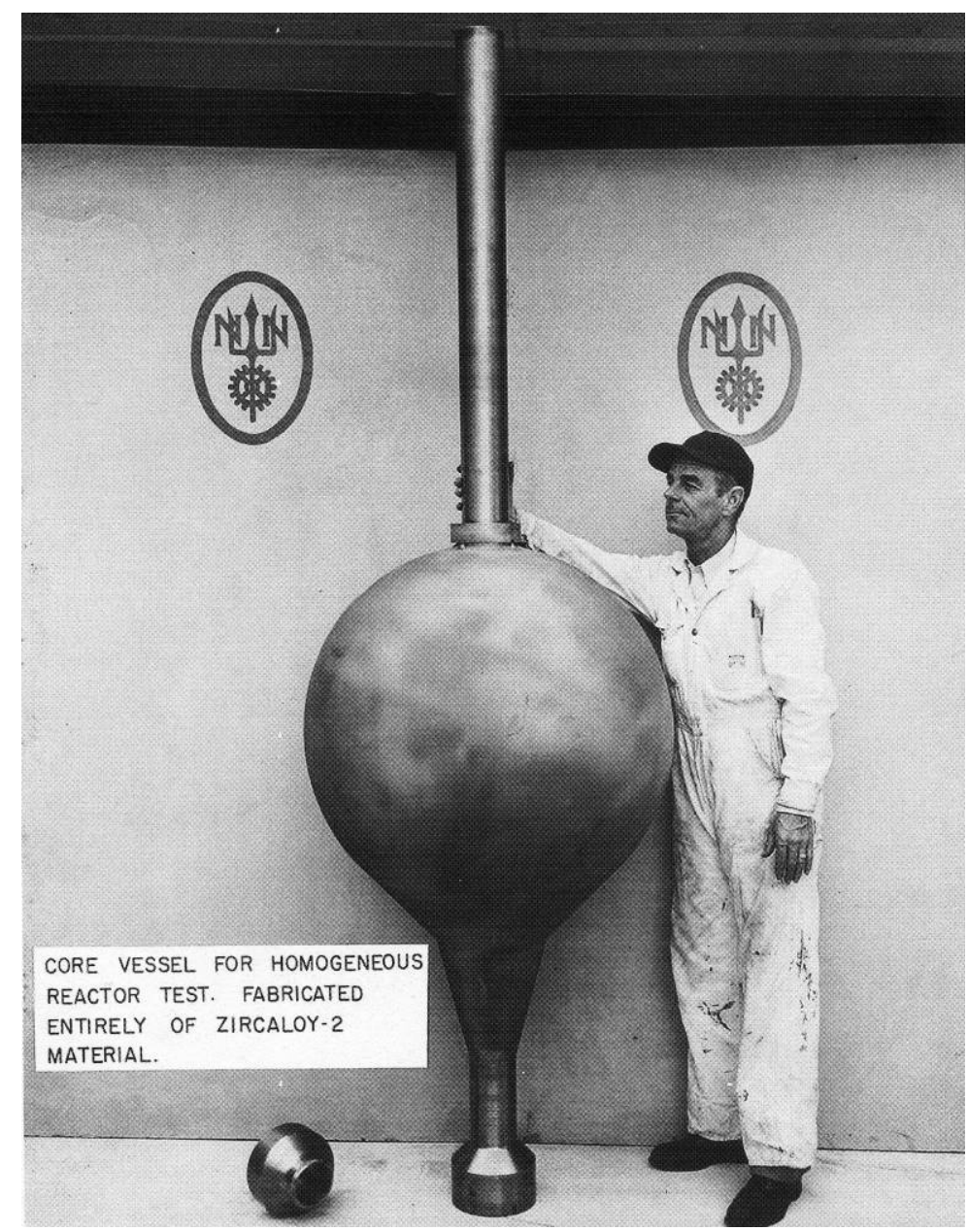

Fig. 16. Core vessel for the HRT. The vessel was fabricated by Newport News Shipbuilding and Drydock Company of Newport News, Virginia. (ORNL Photo 24103)

which they could be drained at intervals for $\mathrm{D}_{2} \mathrm{O}$ recovery, sampling, and removal for further processing and disposal. The hydroclones did remove some solid fission products and a larger amount of corrosion products, but material balances and radiation scans of components showed that most were deposited in the heat exchanger and other components.

Provisions for maintenance were given careful attention in the design. The reactor was surrounded by a $2 \mathrm{ft}$ thick neutron-absorbing shield to reduce activation of equipment. All of the primary system was below grade in a cell with a steel lining that could be flooded to lower the radiation level during maintenance. The top shield, as seen in Fig. 17, was made in sections that could be removed and replaced with a work shield when maintenance was to be done. The equipment was made accessible from above with provisions for ease of removal, such as all bolts pointing up and the number of separate parts minimized. And tools and procedures were tested on mock-ups before being used in the reactor cell. (The cell wall was heavy enough to contain the contents of the entire primary system if it were unintentionally released at full operating pressure.)

Preoperational testing was interrupted by the discovery of chloride-ion-induced stress corrosion cracking that required replacement of 132 high-pressure flanges. The chloride was found to have resulted from the fabricator's incomplete removal of a chloride-containing drawing compound from long stainless-steel tubes that were attached to flanges for leak detection. 


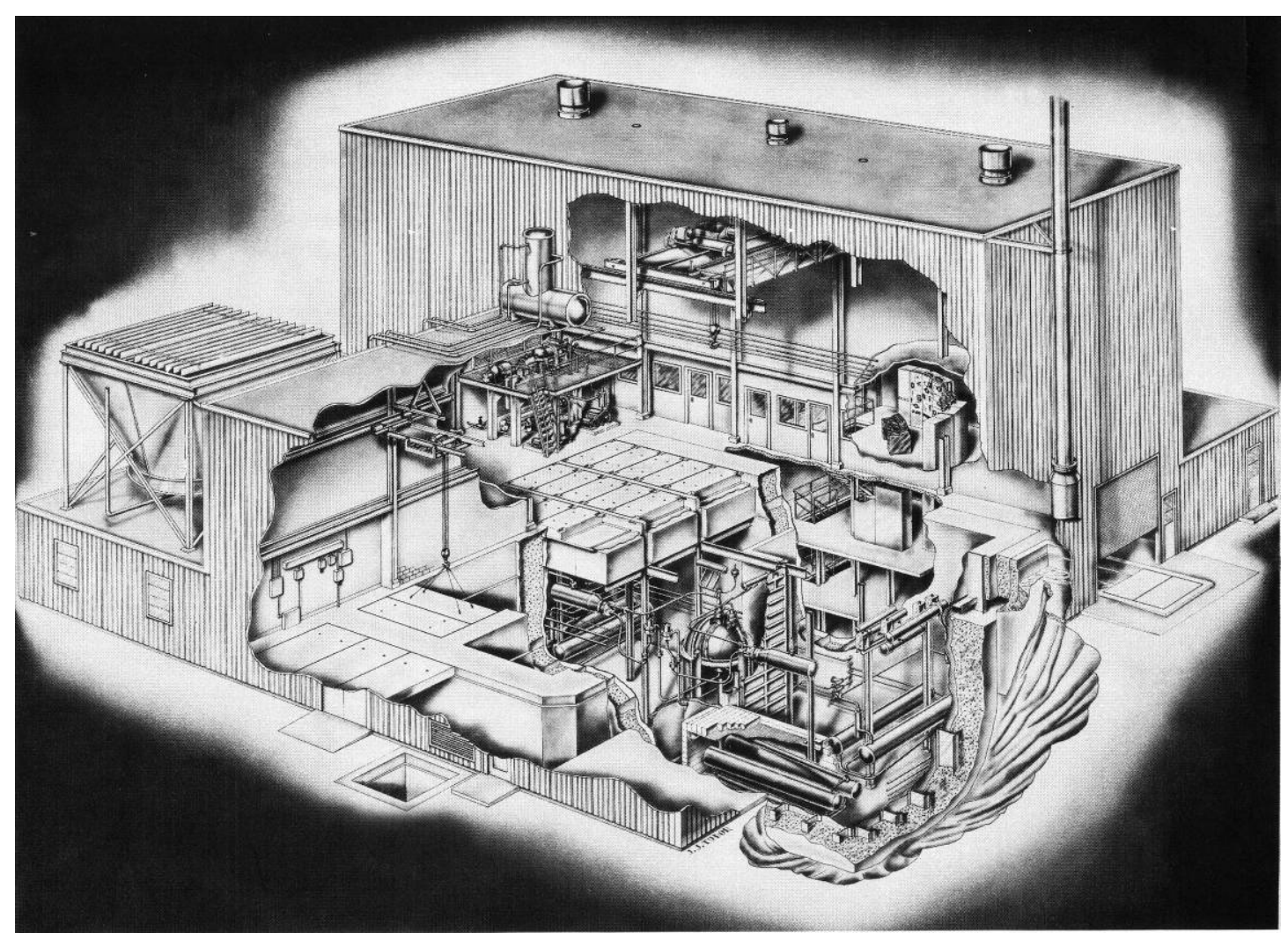

Fig. 17. HRT building, showing upper shield blocks.

All seemed well when operation finally began, and the power was raised progressively to more than 5 MW. Suddenly a change in liquid level and an increase in the power generated in the reflector indicated that a leak had developed in the core tank. Investigation by raising and lowering the liquid levels showed that the leak was in the lower part of the core, but an examination of the vessel from both sides with periscopes did not detect it. (The hole was seen later.) However, piles of solids were found at the junction of the upper diffuser screen and the wall. General corrosion of the stainless steel was low except for one day at the beginning of power operation, when the dissolved oxygen became depleted and corrosion equivalent to about 0.5 mil occurred before it was corrected. Presumably most of the solids seen in the core came from that event.

Tests showed that by distilling heavy water from the fuel solution drained into the dump tank and continuously pumping it into the blanket, the uranium concentration in the blanket could be kept lower than in the core. Operation was resumed with $40 \%$ of the power being produced in the blanket.

Operation was continued over the next 21 months until another hole developed in the vessel. The last part of that period of operation was 105 days without interruption until the second hole was detected. During shutdowns, arrays of small corrosion specimens with several thermocouples in them were inserted and removed from the core.

A number of surprising things had been discovered since the beginning of operation. Power excursions, called "pips" and "poops," were found to be occurring about twice an hour whenever the reactor was at a significant power level—most up but some down. Generally they lasted much less than a minute, and on average the power rose about 20\%, then fell back. But some pips were bigger, and in one the power rose from 3.7 to $25 \mathrm{MW}$. Calculations indicated that most of the excursions were caused by the movement of less than 10 grams of uranium through the core, and the largest by about 100 grams. 
The pressure and temperature changed during the excursions, but as would be expected from the experiments performed earlier on the HRE, the surges were not big enough to cause problems or threaten safety. However, at one point, two of the thermocouples on the corrosion specimen array registered temperatures up to $1500^{\circ} \mathrm{C}$ and then failed.

Early in operation, continuing small power fluctuations were seen on the nuclear power trace. A sensitive recorder allowed them to be examined in detail, and they were found to have a frequency of 8 to $16 \mathrm{~Hz}$ and an average height of about 1\% of the power level. Analysis of the frequency and shape led to the conclusion that they resulted from boiling of the fuel solution somewhere in the core.

Chemical analysis of the fuel solution revealed that at significant power levels, part of the uranium was missing, sometimes as much as $25 \%$. But there was no corresponding decrease in critical temperature, which indicated that part of the missing uranium must have been somewhere in the core. Some of the uranium went in and out of solution when the power was changed, but some of it did not. An extensive investigation was made of the effects of power level, pressure, temperature, fuel-solution acidity, and other operating conditions.

After the second hole formed, the maintenance staff again removed a flange above the core and inserted periscopes through the 2 in. opening. One of the holes was found to be where the top diffuser grid intersected the wall; the other was near the equator. Manipulators were inserted and the holes reamed out; impressions of them were made in plastic, and matching plugs held in place by toggle bolts were inserted.

The interior of the core was thoroughly examined, and the thickness of the wall was measured with ultrasonic equipment to determine the extent of corrosion ( 0.03 in. near the bottom but less further up). The top two grids were found to be loose, and three more were easily broken out by pulling on them. Torches were used to cut all of them into strips narrow enough to be lifted out through the top of the vessel. Several of the corrosion specimens were found on the grids, and metallurgical examination showed them to have been momentarily at very high temperature, accounting for the high temperature readings and subsequent failures of the thermocouples. Some areas of the screens also had been very hot.

What was going on finally seemed clear. Uranium was being lost from the fuel solution in two ways. The part that did not reappear when the power was lowered was in or on corrosion and fission product solids. The power-dependent part was concluded to have been in a heavy phase of uranyl sulfate that separates from the solution when its temperature rises above about $340^{\circ} \mathrm{C}$. The heavy phase would have formed and been deposited at low-velocity points where the fuel overheated. Once formed, its high concentration of uranium could cause it to be heated even more. Film boiling probably occurred at points and resulted in the melting of the wall, screens, and corrosion specimens. Blobs of the heavy phase with its high uranium content must have accumulated in places in the core and dropped through at intervals causing the power excursions. The small fluctuations seen on the power trace could have been caused by boiling on the accumulations of solids seen on the screens.

In addition to the potential for fuel instability, the basic problem was the low velocity in the core, less than $0.2 \mathrm{ft} /$ second at the midplane. The low velocity had two results: trapping of solid particles in the core and low heat-transfer coefficients that led to high temperatures.

The HRT had been designed with a larger core than the HRE to permit the use of a dilute fuel that would be representative of a power reactor. However, the power was limited to avoid higher cost, and the flow rate was made low to match the power and produce a representative rise in temperature across the core. The outcome was the low core velocity.

The plugs that were installed did not make perfect seals but did limit the leakage, and reactor operation was started again at lower temperature and pressure and higher acidity, with the flow reversed to flush solids from the core. The reactor was run at full power for 4 months with no signs of fuel instability. However, the bolt on the upper plug failed (believed to be from fuel deposited on the blanket end) and the plug fell out. With that, operation was ended. 
Weinberg urged the AEC to continue funding the program, but after a review of fluid fuel reactors that is discussed later, the program was brought to an end.

The instability of the fuel, the power excursions, and the holes in the core vessel overshadowed other results from the HRT. However, in spite of these difficulties, the homogeneous reactor program did show the feasibility of operating a circulating-fuel reactor. And, importantly, it demonstrated that highly radioactive reactor systems and components can be repaired and replaced without overexposure of personnel. The techniques and tools used to maintain the HRT provided valuable examples for radioactive facilities that followed. 


\section{AIRCRAFT NUCLEAR PROPULSION PROGRAM}

In 1946, the Air Force initiated a program to develop a nuclear-powered airplane and contracted with the Fairchild Engine and Airplane Corporation to evaluate its feasibility. Fairchild set up a project in an unused building near the K-25 gaseous diffusion plant (now the East Tennessee Technology Park) in Oak Ridge. ORNL provided assistance.

There was considerable skepticism, and before getting more deeply involved, the AEC asked staff at the Massachusetts Institute of Technology to perform an independent evaluation. A summer project at Lexington, Massachusetts, concluded after initial doubts that developing nuclear-powered aircraft would cost as much as $\$ 1$ billion and take 15 years but was feasible.

So under Cold War pressure, the AEC directed ORNL to establish the Aircraft Nuclear Propulsion (ANP) Program. It grew to be the Laboratory's largest activity for a number of years.

General Electric (GE) eventually replaced Fairchild and moved its program to Evendale, Ohio. But about 180 people remained in Oak Ridge and joined ORNL's program, which by 1951 filled a big building at the Oak Ridge Y-12 Plant (now the Y-12 National Security Complex). Two approaches to nuclear propulsion were considered. In the direct cycle, air for the jet engine would pass through the reactor and be directly heated to $1700^{\circ} \mathrm{F}$. In the indirect cycle, a molten metal would flow through a reactor and then through a heat exchanger where it would heat the air. GE undertook to develop the direct cycle and ORNL the indirect cycle.

\section{Aircraft Reactor Experiment Development}

ORNL proposed building a small reactor to guide its development program. Funded by the AEC, this reactor was called the Aircraft Reactor Experiment (ARE). To permit high temperature, $\mathrm{BeO}$ was chosen as the moderator. The core was to be a stack of hexagonal blocks with vertical passages for the fuel elements and molten sodium coolant. Because of the time needed for production of the $\mathrm{BeO}$ blocks, they were ordered before the design was completed. The blocks stacked up to form the core are shown in Fig. 18. The fuel elements themselves were to be long, thin stainless-steel tubes containing uranium dioxide. Details are given in Table 5.

An extensive research and development program was undertaken in chemistry, materials, hightemperature sensors, and other areas, and components such as pumps and valves were tested in loops. Protecting the aircraft's crew and components and the public from radiation was critical. Consequently, ORNL launched a broad program on the penetration of gamma rays and neutrons, including measurements of the shielding properties of a variety of materials and the development of calculation methods. That led to reactors built just for shielding studies, about which more will be said later.

As the ARE design progressed, however, two serious questions arose. One came from physics calculations that showed that the cross section of xenon-135 at elevated temperatures could cause a positive temperature coefficient in a high-power solid-fuel reactor. The other was doubts about the reliability of "spaghetti-like" fuel elements operating at the temperatures that would be necessary.

An alternate idea arose in which a uranium compound would be dissolved in a molten salt and solid fuel elements avoided. The salt would flow through the core, where it would be heated by fissions, and then pass through a heat exchanger. The xenon gas was expected to evolve from the salt and be removed, but even if it did not, much of it would be outside the core in the external system. So the fuel rods were replaced by a molten salt.

After considering other salts, the choice of carrier salt was a "relatively" low melting temperature $\left(950^{\circ} \mathrm{F}\right)$ mixture of sodium and zirconium fluorides into which $\mathrm{UF}_{4}$ was dissolved. The fluoride salts when solid look somewhat like green table salt, but as seen in Fig. 19, when molten they resemble water. Alkali fluorides are among the most stable of compounds, which means they do not corrode 


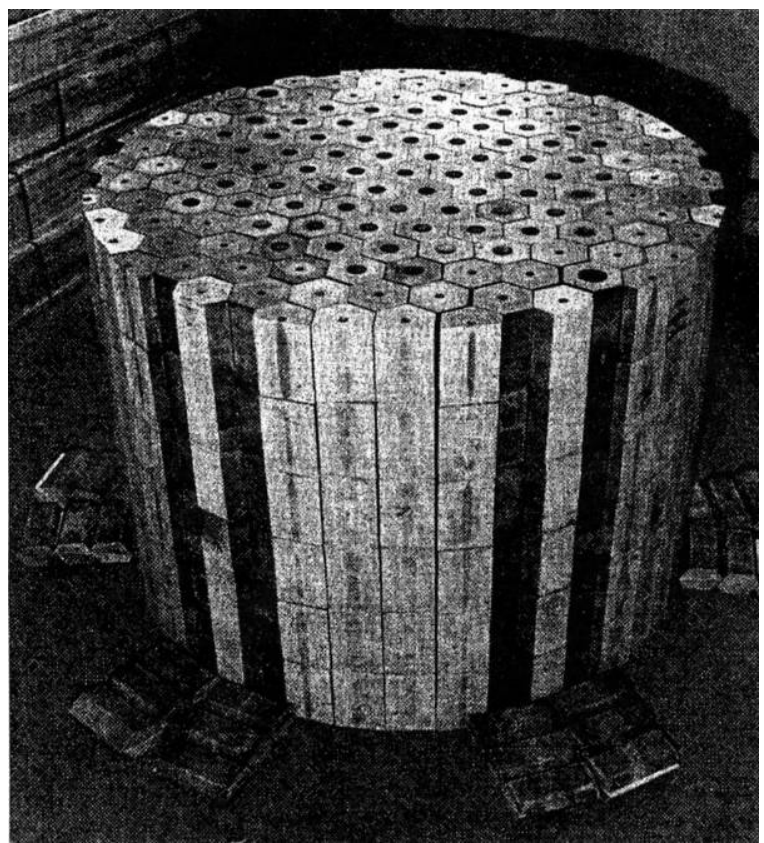

Fig. 18. Stacked BeO moderator blocks for the ARE.

stainless steels and similar alloys. They also have very low vapor pressures, and when molten, they are not damaged by radiation.

The salt would flow through the core in the passages that were designed to hold the solid elements, but in a single pass the velocity would have been too low for turbulent flow. This was dealt with by having the fuel make multiple passes at higher velocity. The core with the multiple-pass tubes is seen in Fig. 20. The salt emerging from the core was pumped through a finned-tube heat exchanger, where it was cooled by helium, which was in turn cooled by water, as shown schematically in Fig. 21.

Heat generated in the moderator and reflector was removed in a sodium system that was similar to the salt system. For safety, the sodium system had two independent circuits, and the fuel salt system contained a standby pump and heat exchanger to ensure continued operation. Sump-type centrifugal pumps with overhung impellers were used, and the sumps served as expansion tanks. The reactor was designed to operate with the fuel salt at around $1500^{\circ} \mathrm{F}$ and at a power of 1 to $3 \mathrm{MW}$ of heat.

The salt and sodium pipes and all major components had double walls to provide a space in which helium was circulated to maintain even temperatures and to provide leak monitoring. Control and safety rods in the core and fission chambers in the reflector were also cooled by the circulating helium. Electrical heaters around the core and the piping raised the temperature before molten salt was added. All salt and sodium-containing systems were made from Inconel, a high-temperature nickelbase alloy.

Table 5. ARE parameters

\begin{tabular}{ll}
\hline Power (heat) & $2.5 \mathrm{MW}$ \\
Fuel salt & $\begin{array}{l}53 \% \mathrm{NaF}, 41 \% \mathrm{ZrF}_{4}, 6 \% \mathrm{UF}_{4} \\
(93 \% \text { enriched })\end{array}$ \\
& $990^{\circ} \mathrm{F}$ \\
Fuel melting point & $1225^{\circ} \mathrm{F}$ \\
Fuel inlet temperature & $1580^{\circ} \mathrm{F}\left(1620^{\circ}\right.$ at peak $)$ \\
Fuel outlet temperature & $45 \mathrm{gal} / \mathrm{min}$ \\
Fuel flow rate & $\mathrm{BeO}$ hexagonal blocks, 3.6 in. \\
Moderator & across $\times 6$ in. high with 1.25 in. \\
& coolant passages \\
& Helium to water \\
Coolant & Inconel \\
Container & November 3, 1954 \\
Critical & November 12, 1954 \\
Shut down &
\end{tabular}




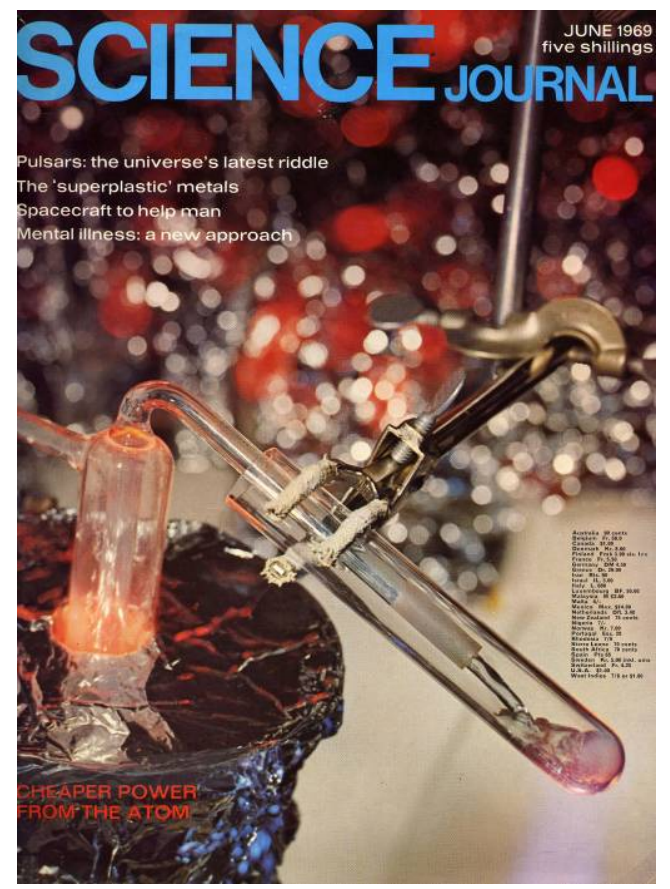

Fig. 19. ORNL photograph of molten salt, featured on the cover of the British Science Journal in June 1969. (Used by permission; Science Journal was incorporated into New Scientist, www.newscientist.com, in 1971)

A mill-type building was constructed in Melton Valley near the homogeneous reactors to house the ARE. All of the reactor systems were located below grade in concrete-lined pits.

\section{ARE Operation}

Operation of the ARE began in early November 1954. First the system was heated with the electrical heaters. Then it was filled with uranium-free carrier salt. And finally, fuel salt as $2 \mathrm{NaF} \cdot \mathrm{UF}_{4}$ was added in increments from a heated pot that emptied into the pump bowl.

The fuel concentrate had a higher melting temperature than the carrier salt and tended to freeze in the fuel addition system. Heating the transfer line and getting the fuel concentrate to flow was the biggest operating problem of the reactor, and much of three days was spent in clearing plugs. Overheating of the line with a welding torch caused a small hole which, however, did not prevent the loading from being completed.

Physics experiments were run at low power for several days, and then the power was raised in steps to full power over 30 hours. The ARE ran very smoothly. However, small amounts of radioactive gas leaked into the reactor compartment from the hole in the loading line and set off alarms. That was handled by hooking up a construction compressor that exhausted air from the compartment and blew it into an uninhabited area about $1000 \mathrm{ft}$ away.

The temperature coefficient of reactivity was negative as expected, and the power level could be raised or lowered by changing the speed of the blower that cooled the heat exchanger. The total power extracted in the fuel salt and sodium reached 2.5 MW with a steady-state fuel temperature of $1580^{\circ} \mathrm{F}$, but the temperature exceeded $1620^{\circ} \mathrm{F}$ in transients. At steady conditions, the temperature rise across the core was $355^{\circ} \mathrm{F}$.

The last experiment conducted was a measurement of xenon retention during a 25-hour run at full power. It indicated that no xenon remained in the salt. After all scheduled tests were completed, the reactor was cycled between full and low power 21 times within 12 hours. 


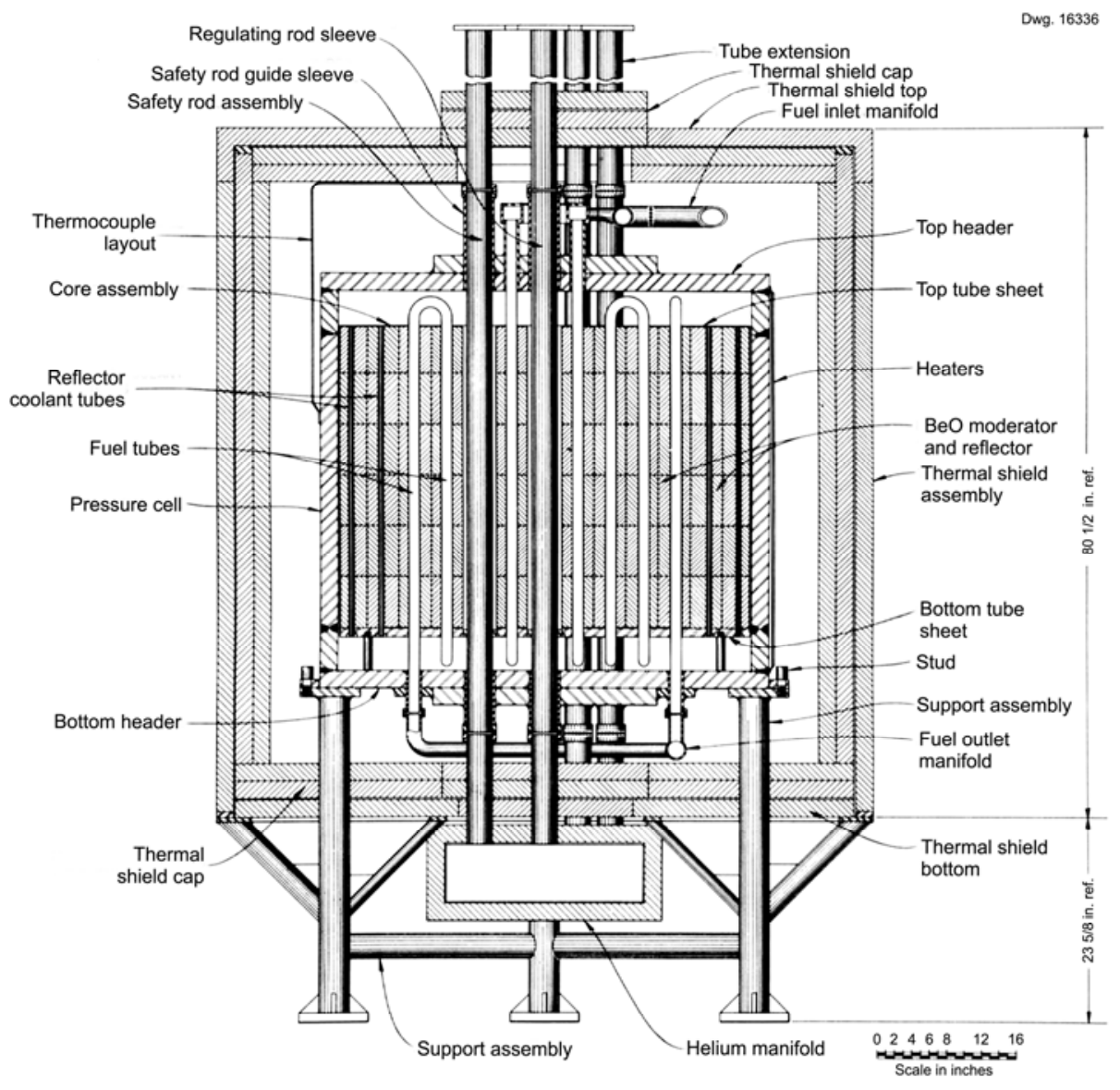

Fig. 20. Elevation view of the ARE core. (ORNL Drawing 16336)

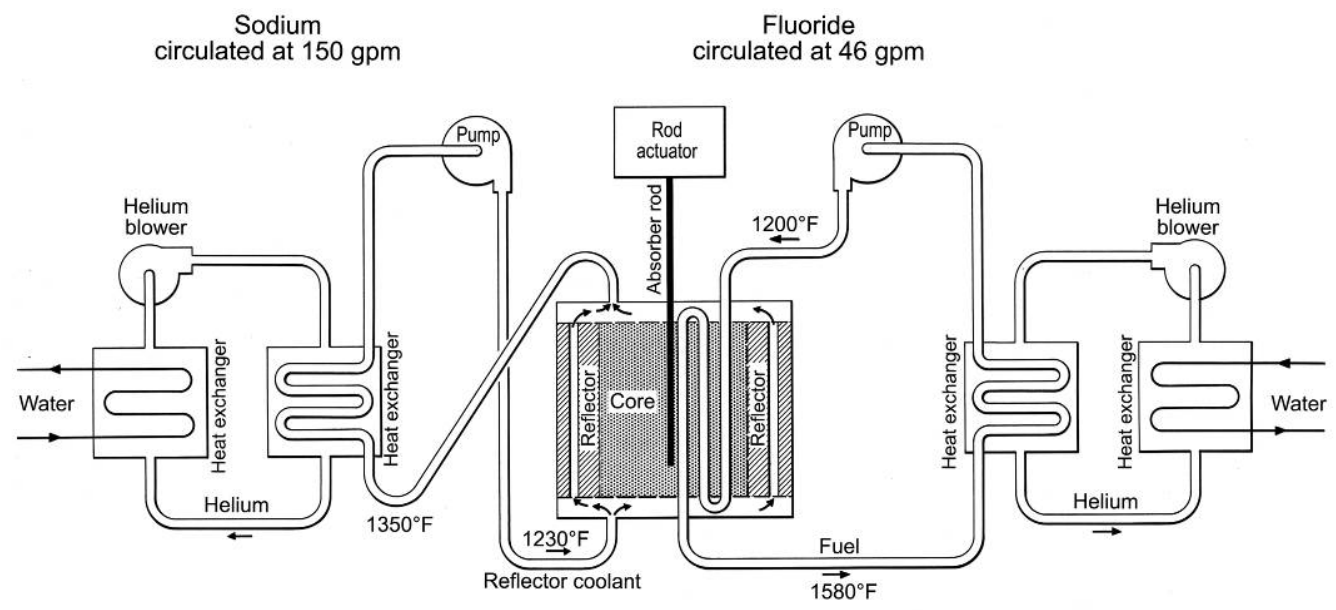

Fig. 21. ARE flow diagram.

The operating plan was to run the ARE for 100 MW-hours; however, when that target was reached, only 9 days of operation had been at power. Running longer was considered, but the experiment was shut down on schedule because of concern about weakness in the overheated fill line. That turned out to be a wise decision, because the line opened completely 5 days later and released radioactive gas into the reactor compartment. 
The Air Force was pleased with the performance of the ARE and brought Pratt and Whitney Aircraft Company aboard to develop the indirect cycle power plant. ORNL began the design of a compact $60 \mathrm{MW}$ reactor. And in spite of growing skepticism about success and the recognition that missiles might substitute for bombers, industrial and political support kept the national program going. But it was killed in March 1961 soon after John Kennedy took office.

Thus ORNL's ANP program came to an end, but in its 12-year run, it greatly expanded knowledge of the chemistry and technology of molten salts and made advances in materials, shield design, and other areas that enlarged the Laboratory's ability to undertake new projects. 


\section{MOLTEN-SALT REACTOR EXPERIMENT}

With the ARE having shown the feasibility of molten-salt fuel, ORNL persuaded the AEC to fund a study of molten-salt power reactors. Two concepts were evaluated, both graphite moderated and based on the U-233/thorium fuel cycle. In one, the uranium and thorium were in the same salt. In the other, a thorium salt that formed a fertile blanket was kept separate from the fuel salt by a graphite barrier. The single-fluid concept was simpler, but a net breeding gain appeared to be possible in a two-fluid reactor.

The results of the study were encouraging. However, the AEC was still funding the homogeneous reactor program as well as a liquid-bismuth reactor program at Brookhaven National Laboratory, and it had more fluid-fuel reactors than it wanted. So a task force was created to evaluate all three programs. It concluded that the molten-salt reactor "had the highest probability of achieving technical feasibility." This led to approval of a program at ORNL to develop molten-salt power reactors and to the demise of Brookhaven's program and, as mentioned earlier, the homogeneous reactor program.

The molten-salt development program proceeded well, and by the end of 1959, the Laboratory felt justified in proposing a small reactor to investigate the technologies needed for civilian power. To keep the reactor simple and inexpensive, it had a single region like a converter, but the salt did not contain thorium and in that sense was similar to the core of a breeder. (Later a concept was developed in which a virtual two-region reactor was created with a single salt by reducing the moderation in the outer region.) The proposed reactor, called the Molten-Salt Reactor Experiment (MSRE), was approved by the AEC. Design began in 1960, and construction started early in 1962. Details are given in Table 6, and a sketch of the reactor is shown in Fig. 22.

The fuel salt chosen for the MSRE was a mixture of the fluorides of lithium-7, beryllium, and zirconium selected to have good physical and nuclear properties. The melting point was $840^{\circ} \mathrm{F}$. Fluoride salts do not wet graphite, so the MSRE was designed with the bare-graphite core shown in Fig. 23. It was 54 in. in diameter and made up of 2 in. square bars of specially produced low-porosity graphite. Flat passages for the salt were machined into the surfaces of the bars.

The molten salt flowed from the core to a heat exchanger where it gave up heat to another fluoride salt that carried it to an air-cooled radiator. As shown in Fig. 24, the salts were stored below the reactor in heated vessels, from

\begin{tabular}{ll}
\hline \multicolumn{2}{c}{ Table 6. MSRE parameters } \\
\hline Power (heat) & $7.4 \mathrm{MW}$ \\
Fuel salt & $65 \% \mathrm{Li}^{7} \mathrm{~F}, 29.1 \% \mathrm{BeF}_{4}$, \\
& $5 \% \mathrm{ZrF}_{4}, 0.9 \% \mathrm{UF}_{4}$ \\
Fuel melting point & $813^{\circ} \mathrm{F}$ \\
Fuel inlet temperature & $1175^{\circ} \mathrm{F}$ \\
Fuel outlet temperature & $1225^{\circ} \mathrm{F}$ \\
Fuel flow rate & $400 \mathrm{gal} / \mathrm{min}$ \\
Coolant salt & $66 \% \mathrm{Li}_{7} \mathrm{~F}, 34 \% \mathrm{BeF}_{4}$ \\
Moderator & Graphite \\
Container & Hastelloy-N (68\% Ni, \\
& $17 \% \mathrm{Mo}, 7 \% \mathrm{Cr}, 5 \% \mathrm{Fe})$ \\
Critical on U-235 & June 1, 1965 \\
Critical on U-233 & October 2, 1968 \\
Shut down & December 1969 \\
\hline
\end{tabular}
which they could be forced up into the various systems by gas pressure. "Freeze valves" formed by air-cooled flattened sections of pipe retained the salts in the core. Figure 25 is a photograph of the core, fuel pump, and heat exchanger. The radiator with its doors open is seen in operation in Fig. 26.

The salt pumps were at the high points in the system and like those on the ARE, were sump type and performed several functions. The sumps served as expansion tanks and were the free surfaces for the salt systems. A spray of salt into the gas space above the sump allowed noble gases to escape and be conducted to charcoal beds. In addition, a "sampler-enricher" tube leading from above provided access to the salt in the sump. With it, capsules of frozen fuel-salt concentrate could be lowered into the sump on a cable for small fuel additions, or thimbles could be lowered to collect salt samples. 


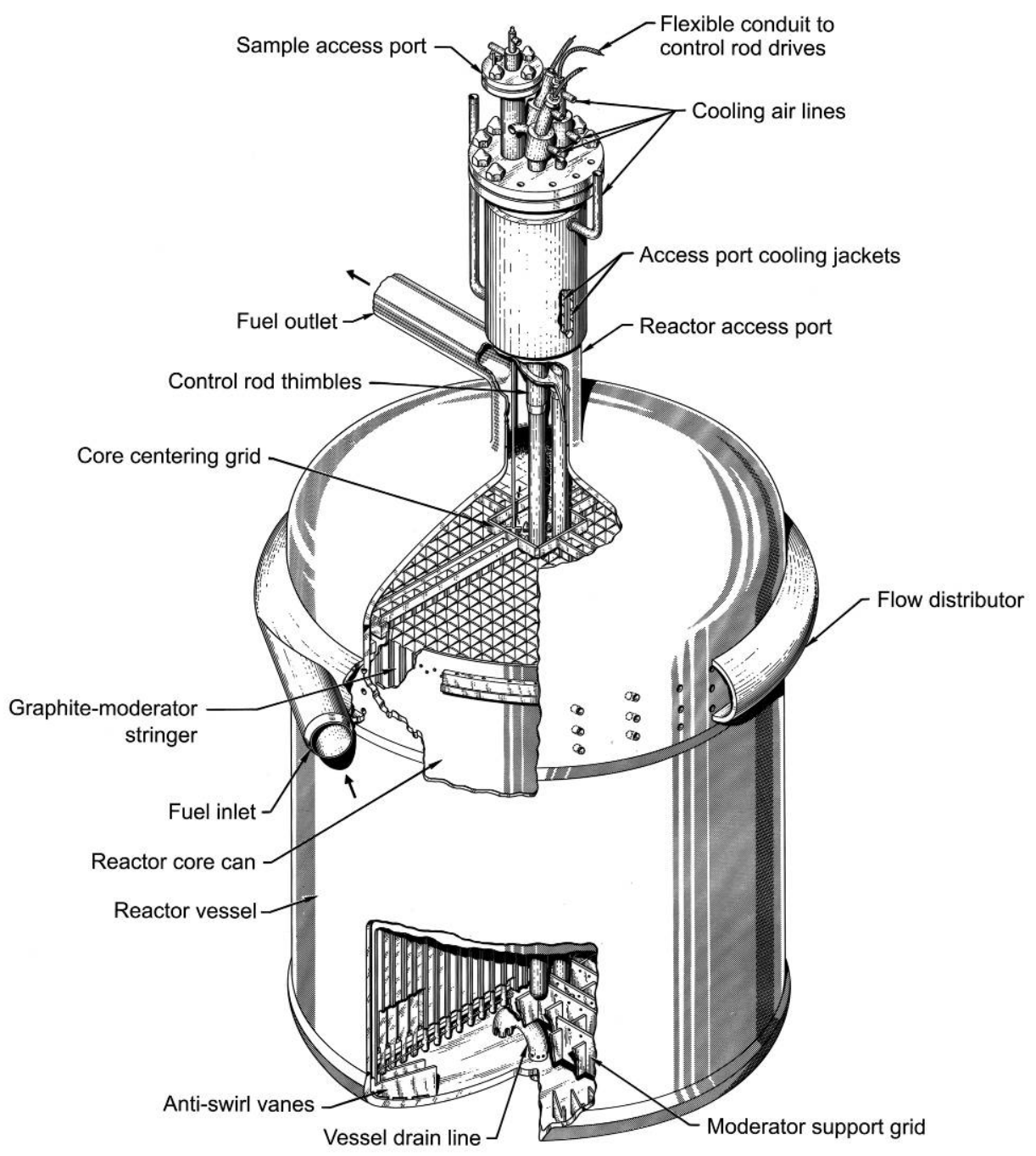

Fig. 22. Sketch of the MSRE. (ORNL-LR-DWG 61097R)

A simple processing facility was installed in a cell near the drain tanks. It contained a tank in which salt could be sparged with hydrogen fluoride to remove water and oxygen or with fluorine to remove uranium.

The reactor and all of the components that contacted salt were made of INOR-8, a nickel-base alloy developed by ORNL and the International Nickel Company for use in molten-salt reactors. It was later commercialized as Hastelloy- $\mathrm{N}$ and is still in use today. All salt piping and vessels were electrically heated.

Careful provisions drawing on HRT experience were made for maintenance, in particular the design and layout of components so that they could be removed from above with long-handled tools. A 16 in. thick shield surrounding the reactor reduced activation of components by neutrons. Effective procedures were devised to control the spread of radioactivity.

Construction of the MSRE was completed in 1964, and critical experiments were run in mid1965. To bring the reactor critical, part of the enriched uranium was added to carrier salt in the drain tank in the form of a $\mathrm{UF}_{4}-\mathrm{LiF}$ eutectic. Then the final additions were made 88 grams at a time using the sampler-enricher. 


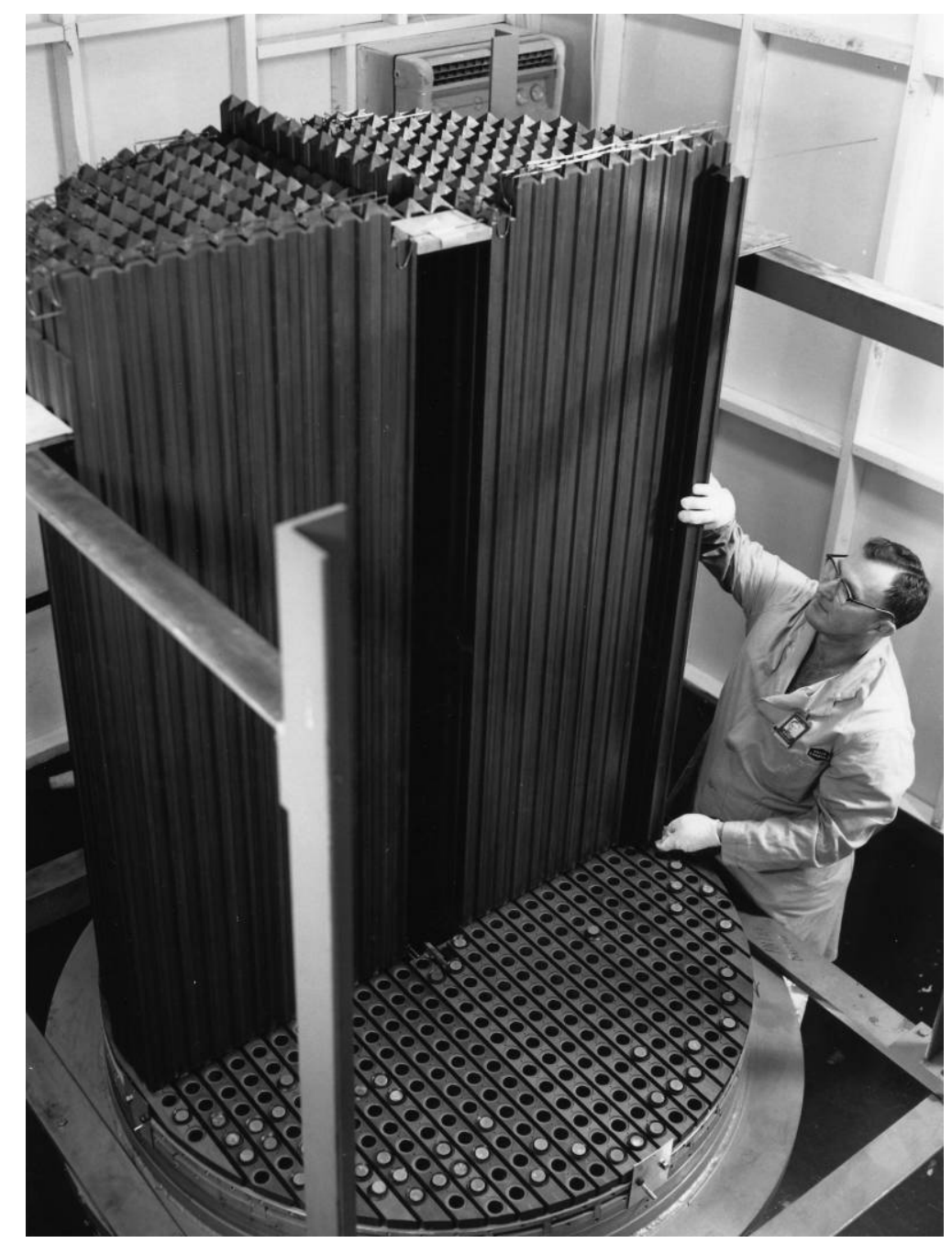

Fig. 23. Graphite core of the MSRE.

Approach to full power began early in 1966, but within a few hours, plugs developed at several points in the fuel off-gas system. Apparently oil vapors that leaked past a gasket in the pump were polymerized by heat and radiation and deposited in small passages. Only a few grams of oil were involved, but three months was required to investigate and remedy the problem.

After full-power operation was resumed, the reactor ran well with only a few small problems until the blades in one of the main blowers that cooled the radiator broke up. Redesigned blowers were procured and installed, but other problems, including recurrences of the off-gas plugs, kept interfering with operation until mid-December when an uninterrupted run of 30 days at full power was achieved. During it the reactor was seen to be stable and load-following as a result of the strong negative temperature coefficient.

The 30-day operation was followed by progressively longer runs; one lasted for 6 months, during which the behavior of fission products was investigated. Xenon-135 poisoning was found to be well below what it would have been if all of the xenon had remained in the core. Between runs, surveillance specimens were removed from the core for examination, tests made of containment and instrumentation, and maintenance operations performed.

Even though numerous problems were encountered during the early months of power operations, they were always overcome in spite of high radiation fields, and the capability for sustained operation 


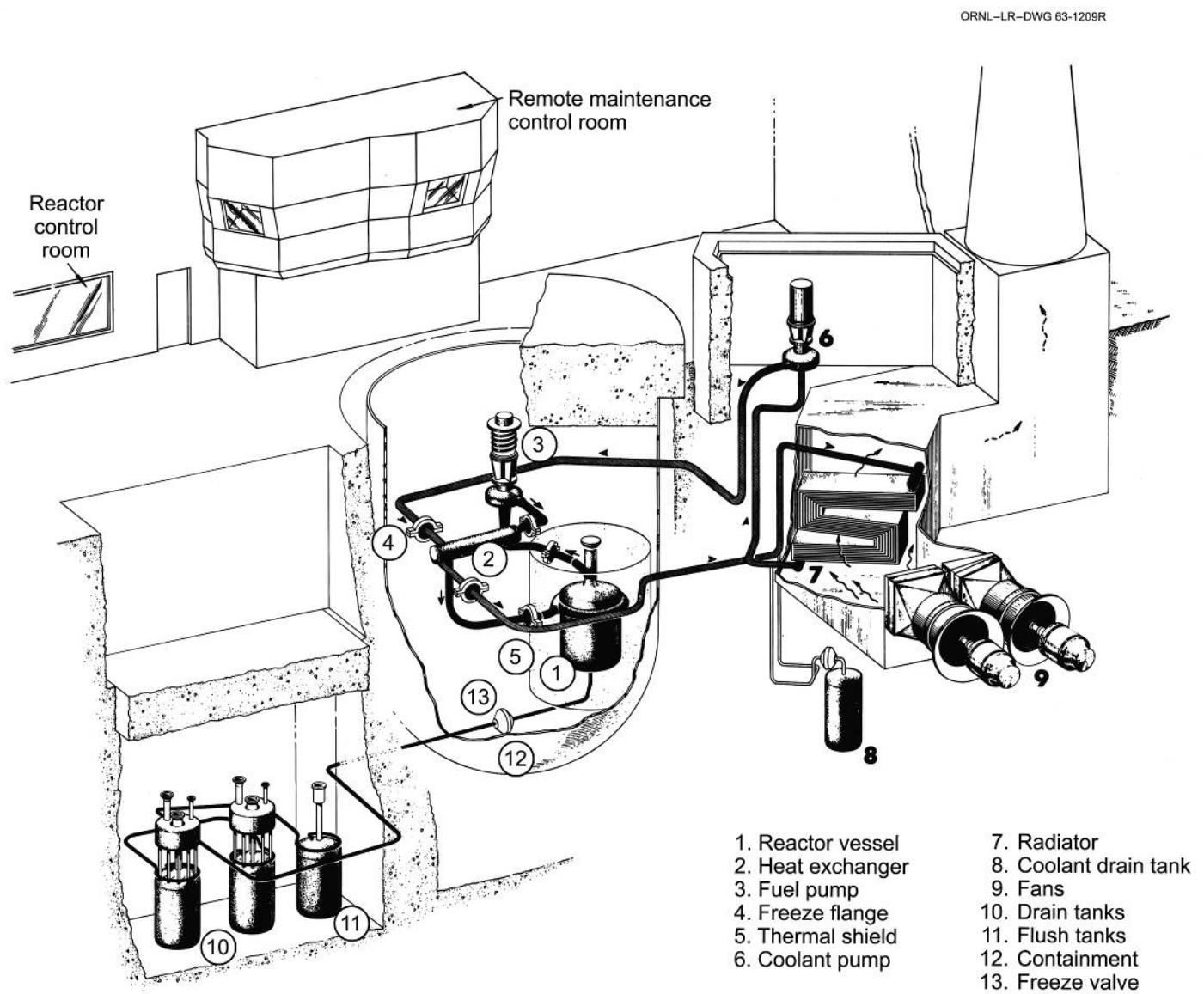

Fig. 24. Schematic of the MSRE. (ORNL-LR-DWG 63-1209R)

was demonstrated. So at the end of the 6-month run, the fuel salt was transferred to the processing tank and the uranium removed from it by treatment with fluorine. The emerging $\mathrm{UF}_{6}$ was passed though a bed of hot sodium fluoride pellets that trapped volatile impurities, then was routed to a series of canisters in the high bay and absorbed on NaF pellets. The fuel-salt fluorination took only 47 hours, and the $\mathrm{UF}_{6}$ that it produced was clean enough that the canisters could be handled without shielding.

Next, some U-233 that had been made in a production reactor was added to the carrier salt, making the MSRE the first reactor ever to operate on U-233. Since Glenn Seaborg, chairman of the AEC, had led the team that first created U-233, he was invited to come to Oak Ridge and start up the reactor. He is seen in Fig. 27 raising the control rod. Although U-233 has a smaller delayed-neutron fraction than U-235, the reactor was quite stable and the dynamic behavior close to predictions. Later a small amount of plutonium was added to show the fissile-fuel flexibility of molten-salt systems.

The MSRE experience had increased confidence in the performance and practicality of moltensalt systems, and the Laboratory was anxious to move ahead with further development that would lead to demonstration of a breeder reactor. Since the budget was quite limited, the reactor was shut down at the end of 1969 and its funds devoted to development, particularly of a processing system that would be needed for breeding in a single-fluid reactor. Two problems that turned up during operation of the MSRE were also investigated. One was the confirmation that tritium produced in the fuel salt by neutron reactions with lithium, while small in amount, had diffused through the heatexchanger tubes and would need to be intercepted in future reactors. The second was the discovery 


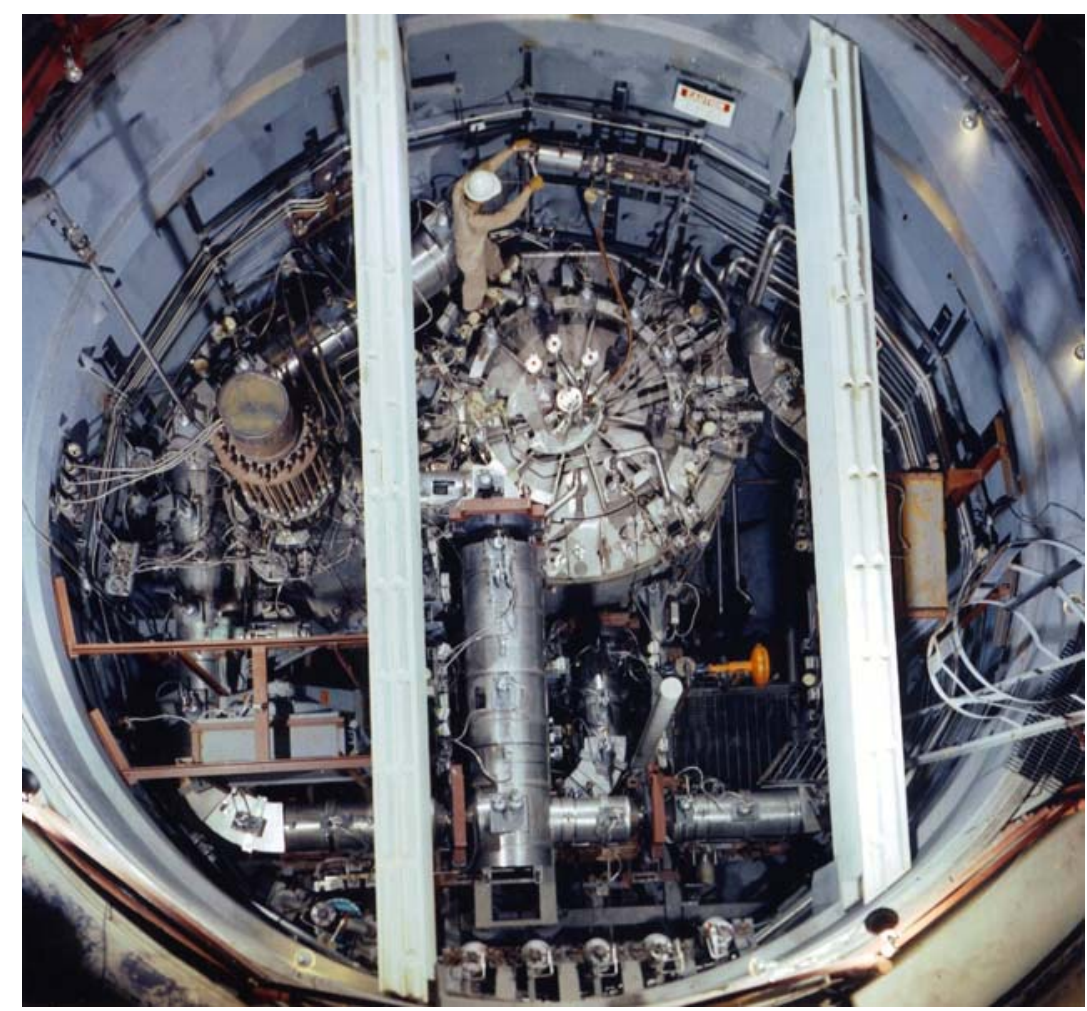

Fig. 25. MSRE core, fuel pump, and heat exchanger in the primary system containment tank. (ORNL Photo 67051-64)

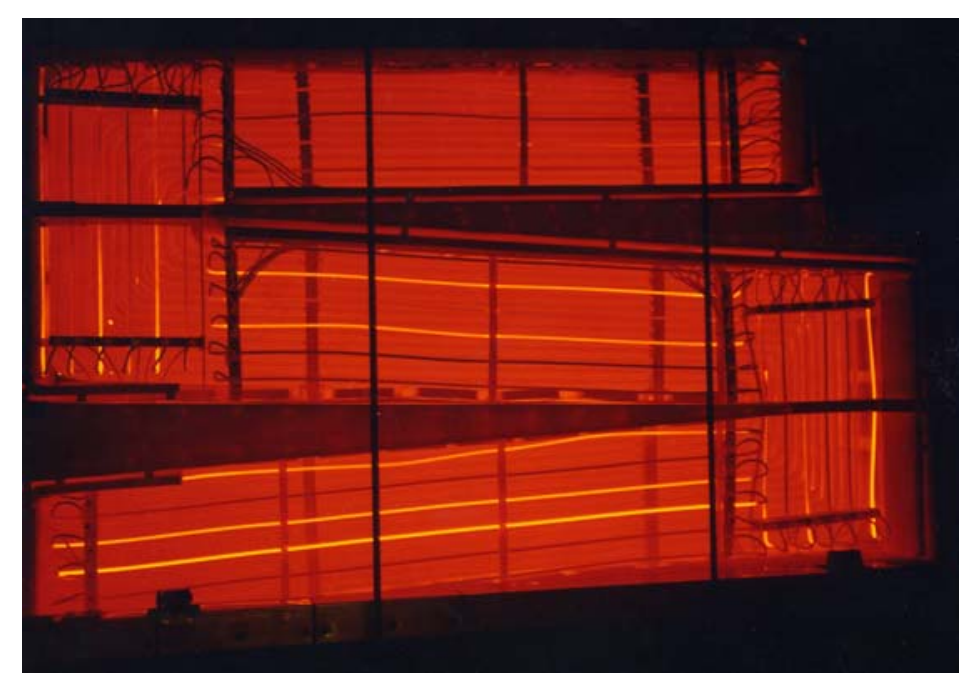

Fig. 26. MSRE air-cooled radiator with its door open.

that although general corrosion was less than expected, fission-product tellurium had caused fine cracks on Hastelloy-N surfaces.

In spite of the technical success of the MSRE, the AEC was strongly committed to sodium-cooled fast breeder reactors and in 1973 gave orders to shut down the molten-salt program. A low-budget extension was soon granted in which solutions of the tellurium and tritium problems were demonstrated, but the program was stopped completely 2 years later. So ORNL's molten-salt adventure came to an end after 20 years. 


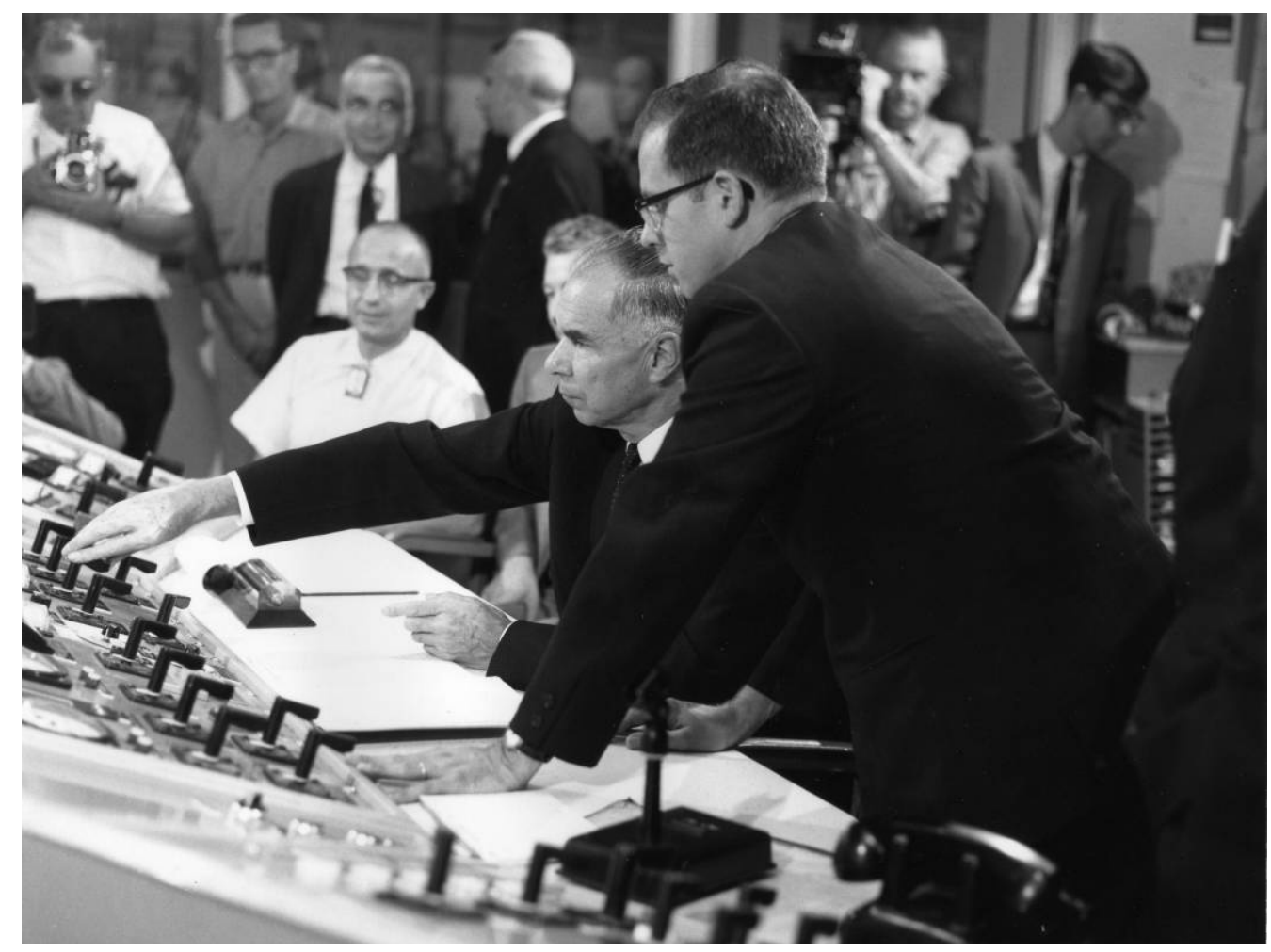

Fig. 27. Glenn Seaborg at the MSRE control panel. 


\section{HEALTH PHYSICS RESEARCH REACTOR}

Health physics arose during the Manhattan Project at the Metallurgical Laboratory in Chicago and at Clinton Laboratories in Oak Ridge as an occupational safety specialty focusing on protecting people and the environment from the harmful effects of radiation. As the Oak Ridge Pile came into operation, physicists and biologists irradiated mice and other animals to establish safe working standards and monitored the areas around the reactor to check for excessive exposure. And in 1944, they trained those who would be responsible for radiation protection at Hanford.

After World War II ended, the ORNL Health Physics Division was established and grew rapidly. It provided radiation protection services and training. It also began to perform research in a number of areas that included radiation tolerance and the development of new methods to measure radiation exposure. Over the years, the scientific staff were leaders in worldwide programs to establish standards for occupational and public exposure.

ORNL scientists participated in programs involving the Godiva fast burst reactors at Los Alamos, and in 1959 the Laboratory was authorized to design and build a fast burst reactor in Oak Ridge. It was housed in the Dosimetry Applications Research Facility (DOSAR) that was built in a hilly area about 2 miles from the center of the Laboratory. DOSAR consisted of a reactor building plus a control and laboratory building located about 900 feet to the southeast, as shown in Fig. 28.

The new reactor, called the Health Physics Research Reactor (HPRR), was completed in 1961, and tests of it were performed in the Critical Experiments Facility at the Laboratory. It was then moved to the Nevada Test Site, where it was operated at different elevations on a $1500 \mathrm{ft}$ tower to provide data to aid in evaluating the radiation doses received by people at Hiroshima and Nagasaki. In 1963, the HPRR was returned to Oak Ridge and installed at DOSAR.

The HPRR was designed to yield a wide range of dose rates without a change in spectrum or geometry. The core, illustrated in Fig. 29, was a bare cylinder of enriched uranium alloyed with 10\%

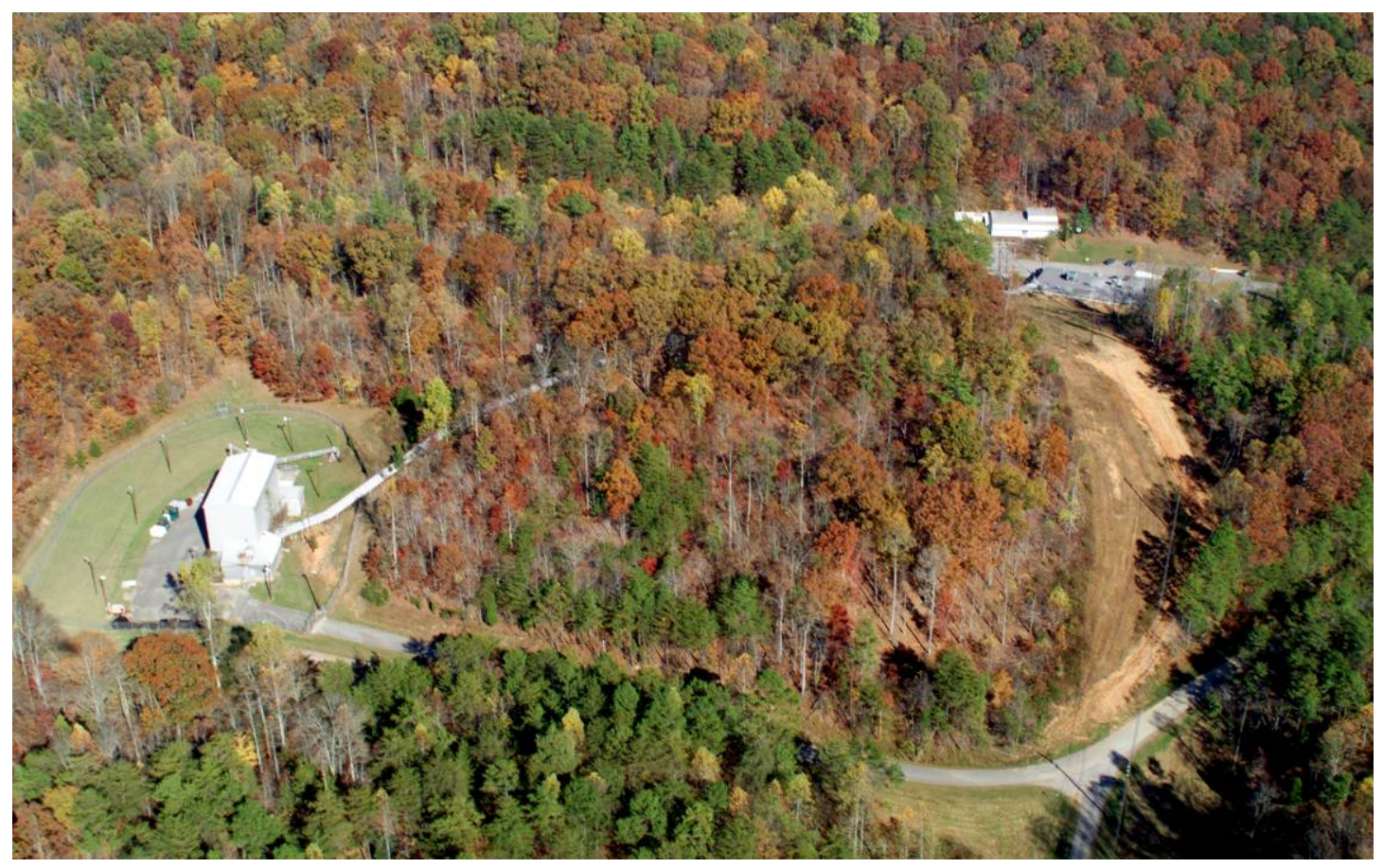

Fig. 28. The DOSAR facility. The HPRR is at lower left, and the control and laboratory building is at upper right. (ORNL Photo 3816-99) 


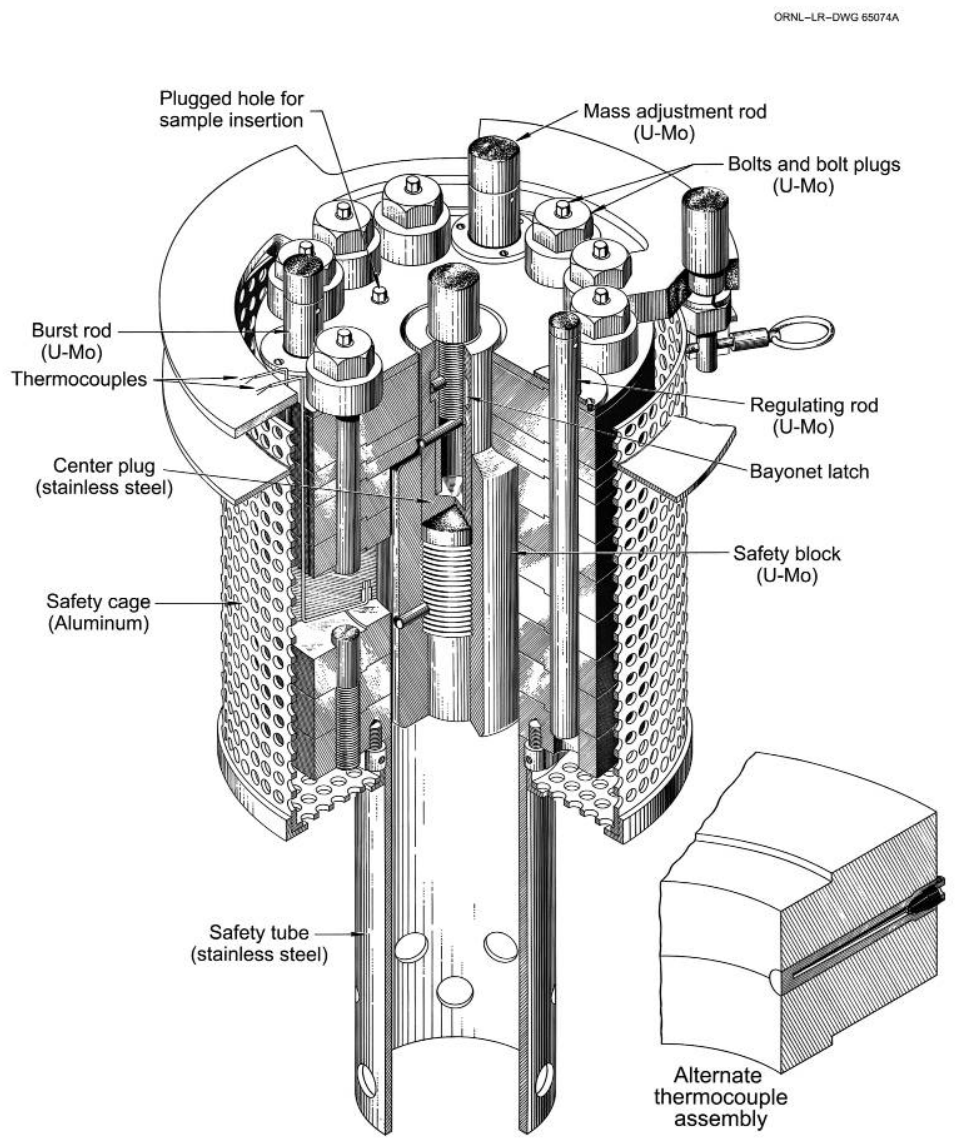

Fig. 29. The HPRR core. (ORNL-LR-DWG 65074A)

molybdenum for strength. It was 8 in. in diameter by 9 in. high, but a 2 in. center section was removed and replaced with a stainless steel cylinder to reduce the peak-to average power and allow bigger bursts. As can be seen in Fig. 29, the stainless steel cylinder was circled by and connected to an annular fuel section, and together they formed a "safety block" that was out of the reactor any time people were present. The reactor contained $97 \mathrm{~kg}$ of U-235.

Three holes that traversed the outer region of the core contained other movable fuel sections: the mass adjustment, burst, and regulating rods. Shim adjustments could be made by adding steel or fuel to the centers of nine hollow bolts that held the core together. An aluminum cage protected the core and a stainless steel cylinder underneath prevented inadvertent insertion of the safety block when it was below the core.

The mass adjustment and regulating rods were motor driven from above. The safety block was also motor driven but was connected to its drive by a magnet that was deactivated for rapid expulsion. To increase the speed of expulsion, a spring above the safety block was compressed when it was raised into position.

The 0.75 in. diam pulse rod was actuated by a pneumatic cylinder that could inject it into the core in about $160 \mathrm{~ms}$. Pulses were terminated by the negative temperature coefficient as the fuel temperature rose, but the safety block also dropped.

The reactor was suspended by the supporting framework, which also held the drive mechanisms, the neutron source and its shield, radiation detectors, and other apparatus. It is seen in Fig. 30 with human-like phantoms used for dosimetry studies. 


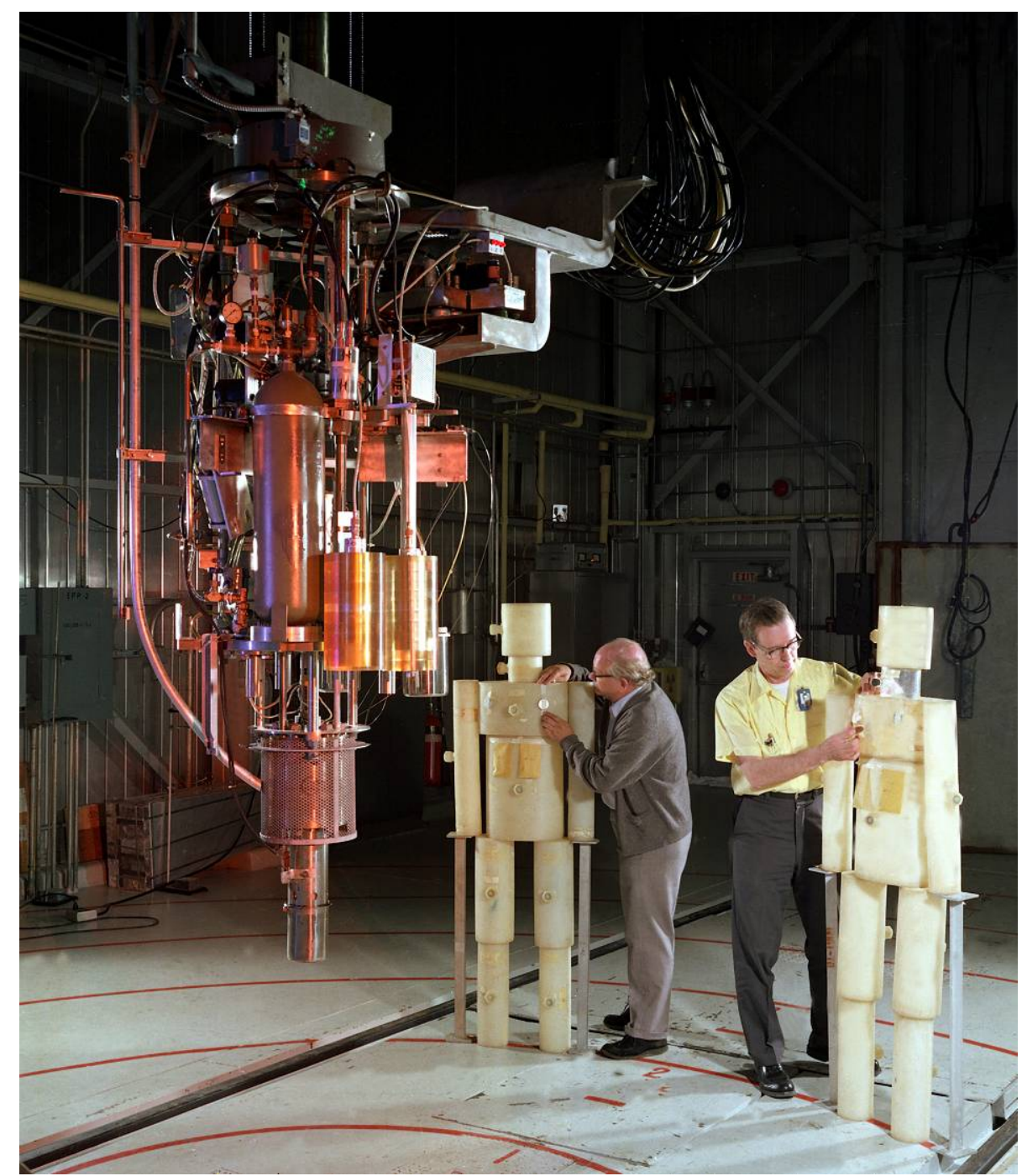

Fig. 30. HPRR with phantoms. (ORNL Photo 1147-77)

The building housing the reactor was a "low-scatter" aluminum-sided structure $30 \mathrm{ft}$ wide and $85 \mathrm{ft}$ long with a concrete pad outside one end. When not in use, the reactor assembly was stored in one of two concrete pits covered with heavy steel doors. It was raised and lowered by hydraulic lifts; when above floor level, it could be transferred to a positioning device that moved on tracks along the building centerline. The positioning device was capable of raising the reactor midpoint to any desired elevation up to $17 \mathrm{ft}$ and to any preset axial position in the building or on the pad outside. The positioning accuracy in each dimension was $\pm 1 \mathrm{~cm}$.

The control building was shielded from direct radiation by a hill and by being partly below grade, and some areas were further protected by heavy concrete walls. Fences surrounded the facility, and additional security was provided for the reactor by a variety of sensor, viewing, alarm, and time-delay systems.

The reactor was capable of operating at steady state in the range of a fraction of a watt to $10 \mathrm{~kW}$, but above $2 \mathrm{~kW}$, heat buildup limited the operating time. In the pulse mode, it could produce bursts of $10^{16}$ to $10^{17}$ fissions. However, the number of shots was restricted to about three per day by requirements for cooling between shots. The peak power in the pulse mode was of the order of 100,000 MW. 
With shields of various materials in front of the targets, the dose rates available to experimenters ranged over 15 orders of magnitude.

The reactor building contained a radioactive source for gamma radiation free of neutrons. A separate building near the control building housed a small accelerator for producing neutrons.

The HPRR was operated in Oak Ridge from 1963 until it was shut down in 1987. During that time, it was used for dosimeter development, simulation of human-body exposure, radiobiology studies with plants and animals, simulation of nuclear weapon and accident spectra, testing of radiation alarms, and training in radiation dosimetry and nuclear engineering. The dosimetry and human-body simulations have been particularly valuable in the setting of radiation exposure limits. 


\section{MATERIALS TEST REACTOR}

As noted earlier, one of Eugene Wigner's goals when he arrived at ORNL in 1946 was to build a high-flux reactor, which he saw as needed to provide a copious supply of neutrons for research and for determining the effects of radiation on materials. After various reactor concepts were considered, Wigner personally stepped in and pointed the way to what became the Materials Test Reactor (MTR).

Wigner's concept was a high-powered enriched-uranium core cooled and moderated by ordinary water. Fast neutrons would escape from the core and be slowed down and "trapped" in a surrounding beryllium reflector, thereby producing a high flux of slow neutrons. Advances in technology were making beryllium use practical.

Weinberg did the physics, but Wigner led the design of the fuel elements. They were formed from aluminum-clad sheets of uranium/aluminum alloy, $3 \mathrm{in}$. wide and about $2 \mathrm{ft}$ long and held by heavier aluminum side plates. The sheets, 18 to an element, were curved so that they would not buckle (Wigner's idea) and when brazed in place formed a rigid unit. Details of a fuel element are shown in Fig. 31. An array of such elements formed a core in which the power density could be very high at acceptable fuel temperatures. Fuel elements based on this concept have been used in most of the world's research reactors.

While the MTR design was under way, Wigner stepped down as research director at Clinton Laboratories and returned to Princeton. Then just before Christmas 1947, the AEC sent word that all reactor work in Oak Ridge, including the MTR, would be transferred to the Argonne National Laboratory near Chicago.

Oak Ridge, led by Weinberg, resisted being kicked out of the reactor business, and the decision never really took effect. However, responsibility for the MTR was transferred to Argonne, and its construction was shifted to the National Reactor Test Site in Idaho (now the Idaho National Laboratory) where other reactors were being built.
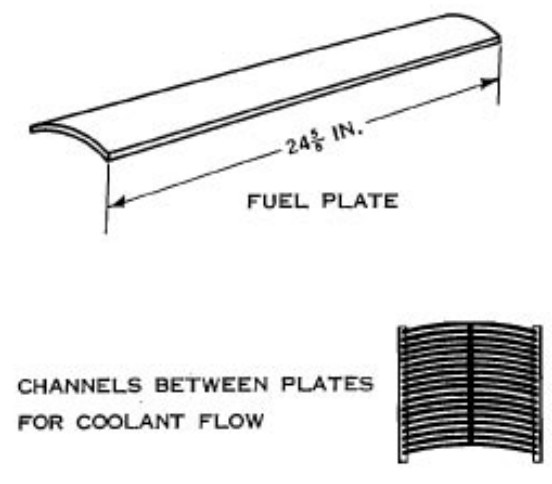

END VIEW OF FUEL PLATES IN ASSEMBLY,

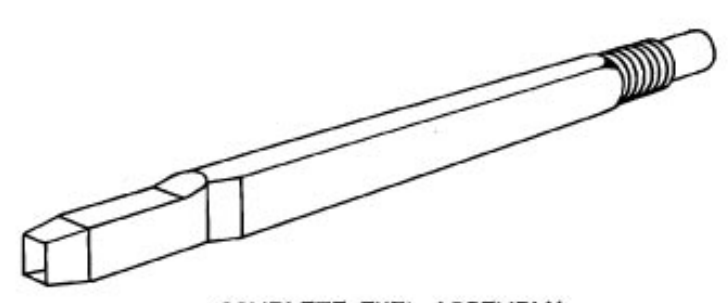

COMPLETE FUEL ASSEMBLY

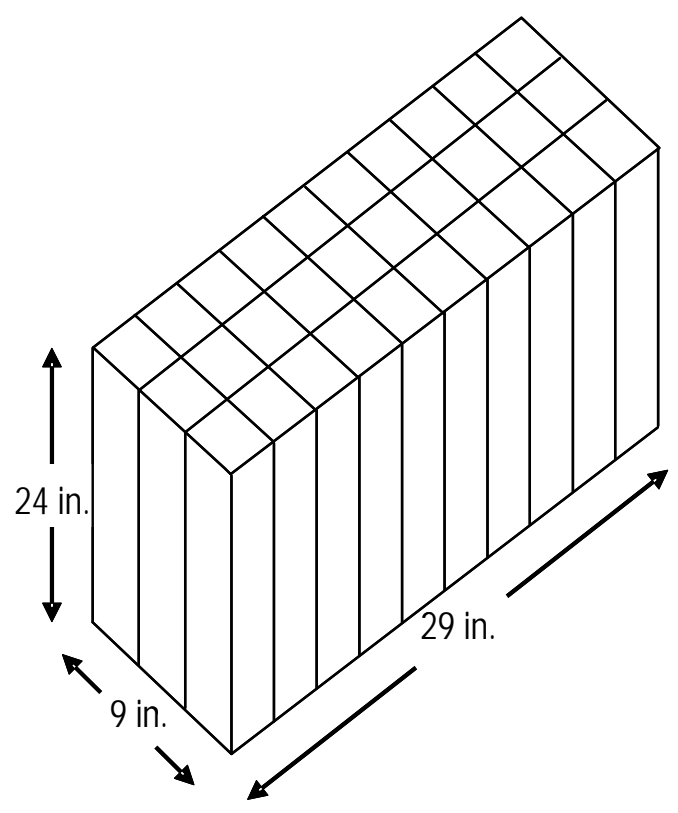

Fig. 31. Details of MTR fuel. Left: Fuel plates and arrangement into fuel assembly. Right: Fuel array. From this core volume comes $40 \mathrm{MW}$ of heat. (Courtesy of Idaho National Laboratory) 
The Oak Ridge people involved were expected to move to Argonne, but many were unwilling to go. Since they were well along with the design, Argonne proposed that ORNL retain responsibility for the core, control systems, and shield. Argonne would handle the balance of the plant. This was an important decision for the Laboratory, for it kept Oak Ridge involved in core physics, fuel development and fabrication, and other critical areas of reactor development.

The core and beryllium reflector, as seen in Figs. 32 and 33, were enclosed in a tank through which the water coolant flowed. Surrounding the tank were zones of replaceable graphite pellets and fixed graphite, a steel neutron-absorbing shield, and a thick concrete biological shield. Penetrating up to the reactor face were a number of tubes into which experiments, including loops containing simulated fuel elements, could be inserted. Control rods entered the core from below. The fuel elements had to be replaced after 24 days at full power, which was done from above with longhandled tools. Figure 34 is an early photo of the reactor with an experimental facility in place. The power originally was $30 \mathrm{MW}$ and later was increased to $40 \mathrm{MW}$.

The MTR was started up at Idaho in 1952 and was used by ORNL and others for about 20 years until it was superseded by more advanced test reactors. It was the progenitor of many reactors built around the world, and Wigner's fuel-element design was copied over and over again.

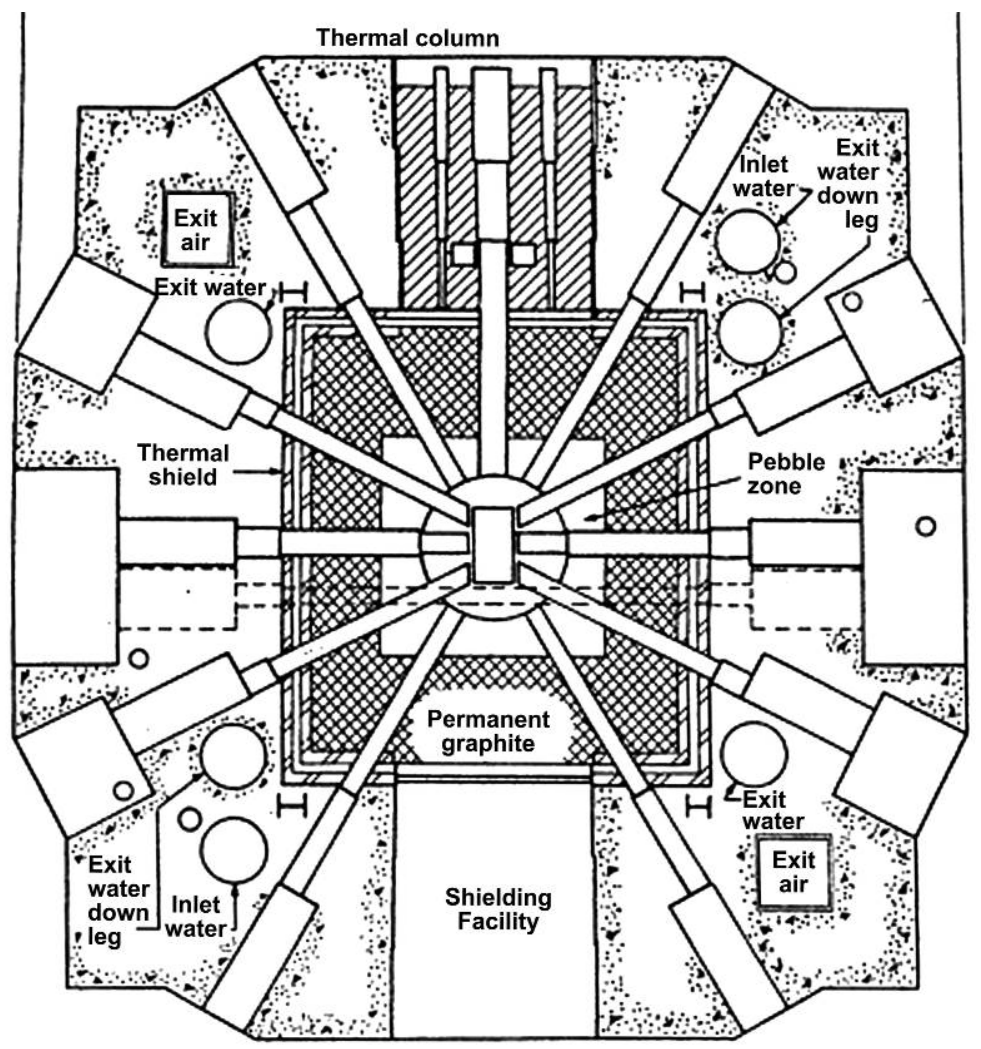

Fig. 32. Cross section of the MTR. (Courtesy of Idaho National Laboratory) 


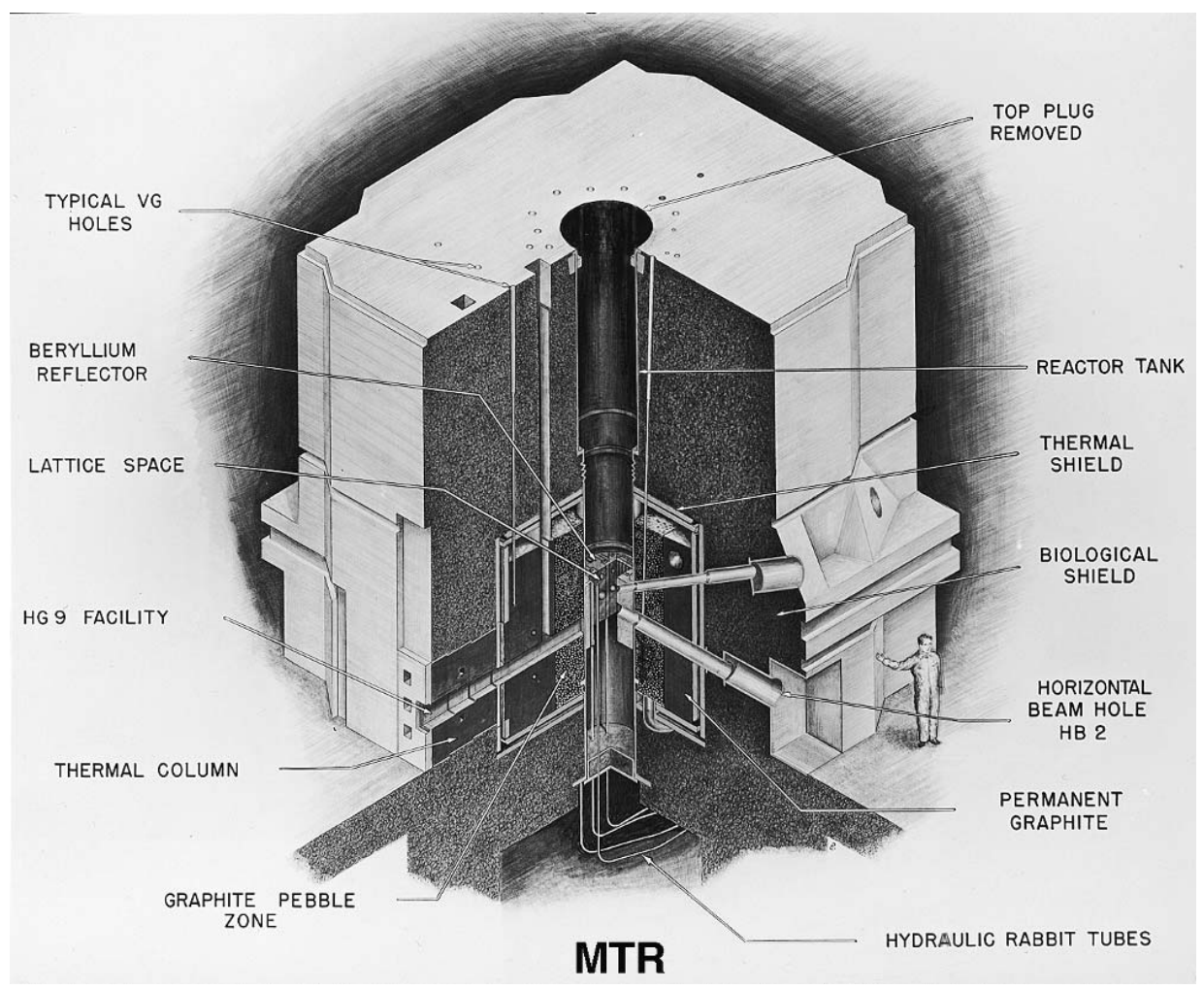

Fig. 33. Cutaway view of the MTR. (Courtesy of Idaho National Laboratory)

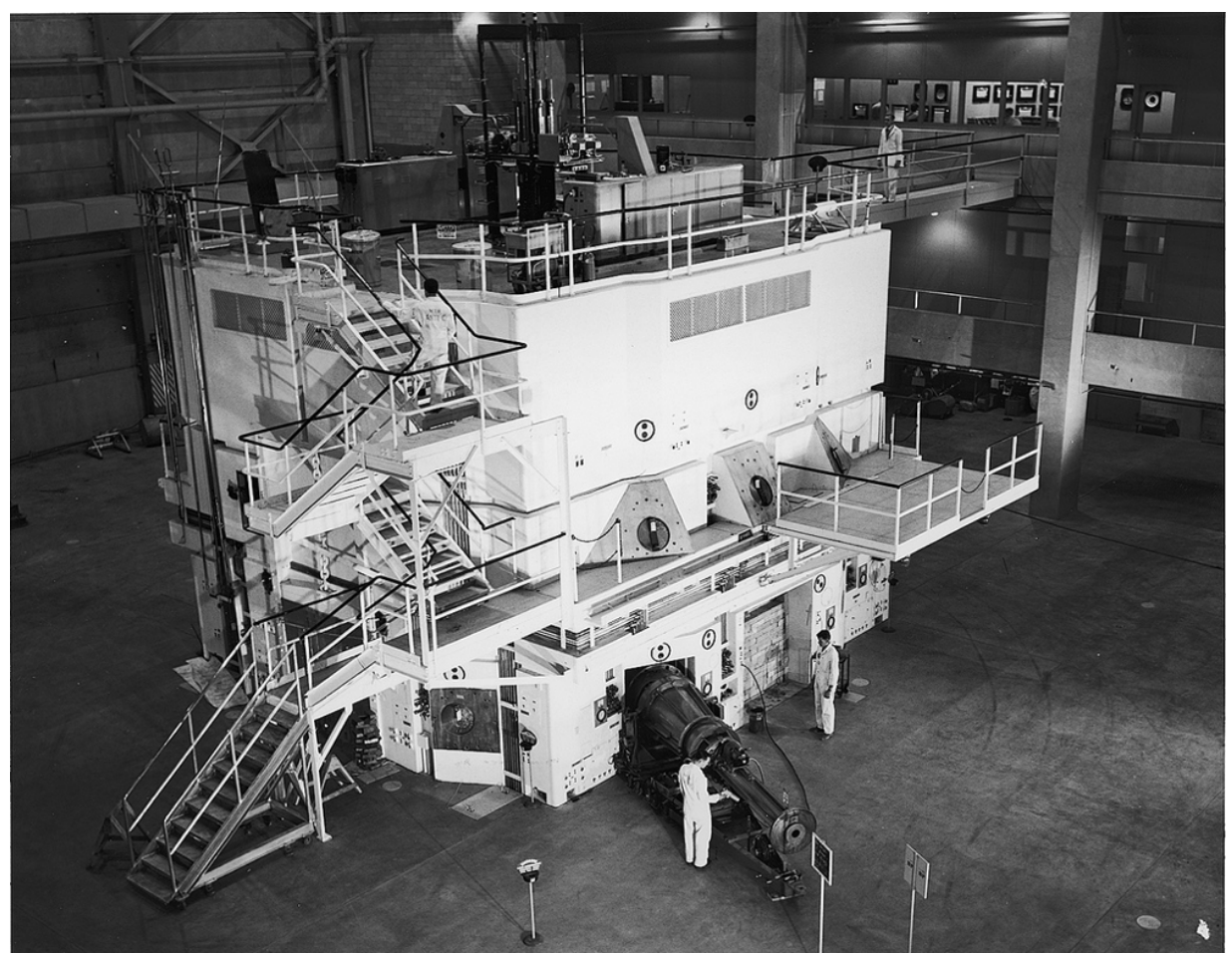

Fig. 34. The MTR in operation. (Courtesy of Idaho National Laboratory) 


\section{LOW-INTENSITY TEST REACTOR}

In 1949, while the MTR was being designed, a full-scale mock-up of its major components was built in the middle of the ORNL campus to check out mechanical and hydraulic operation and provide training for operators. But once the mock-up was running, the Laboratory argued that it should be made critical with real fuel plus beryllium reflector elements, which would allow nuclear measurements and testing of instruments and controls. This was done, and in 1950, many low-power measurements of importance to the final MTR design were made. In 1952, it was a small step to add shielding and a heat exchanger, providing the Laboratory with the $1500 \mathrm{~kW}$ Low-Intensity Test Reactor (LITR). Later, after some modifications, the LITR was operated at $3 \mathrm{MW}$.

As seen in Fig. 35, the reactor tank was surrounded by concrete blocks, and control-rod drives were mounted on the top. Six horizontal beam tubes were added, and some space in the $5 \times 9$ core lattice was available for higher flux experiments. Two pneumatic "rabbit" tubes added and removed samples from the reflector.

In one set of tests, the water flow through the core was reduced and it was allowed to boil to observe the effects on stability and control. Those tests presaged later experiments in Idaho that led to boiling-water power reactors. An important and difficult experiment carried out on the LITR was the measurement of the cross section of intensely radioactive xenon-135 as a function of energy.

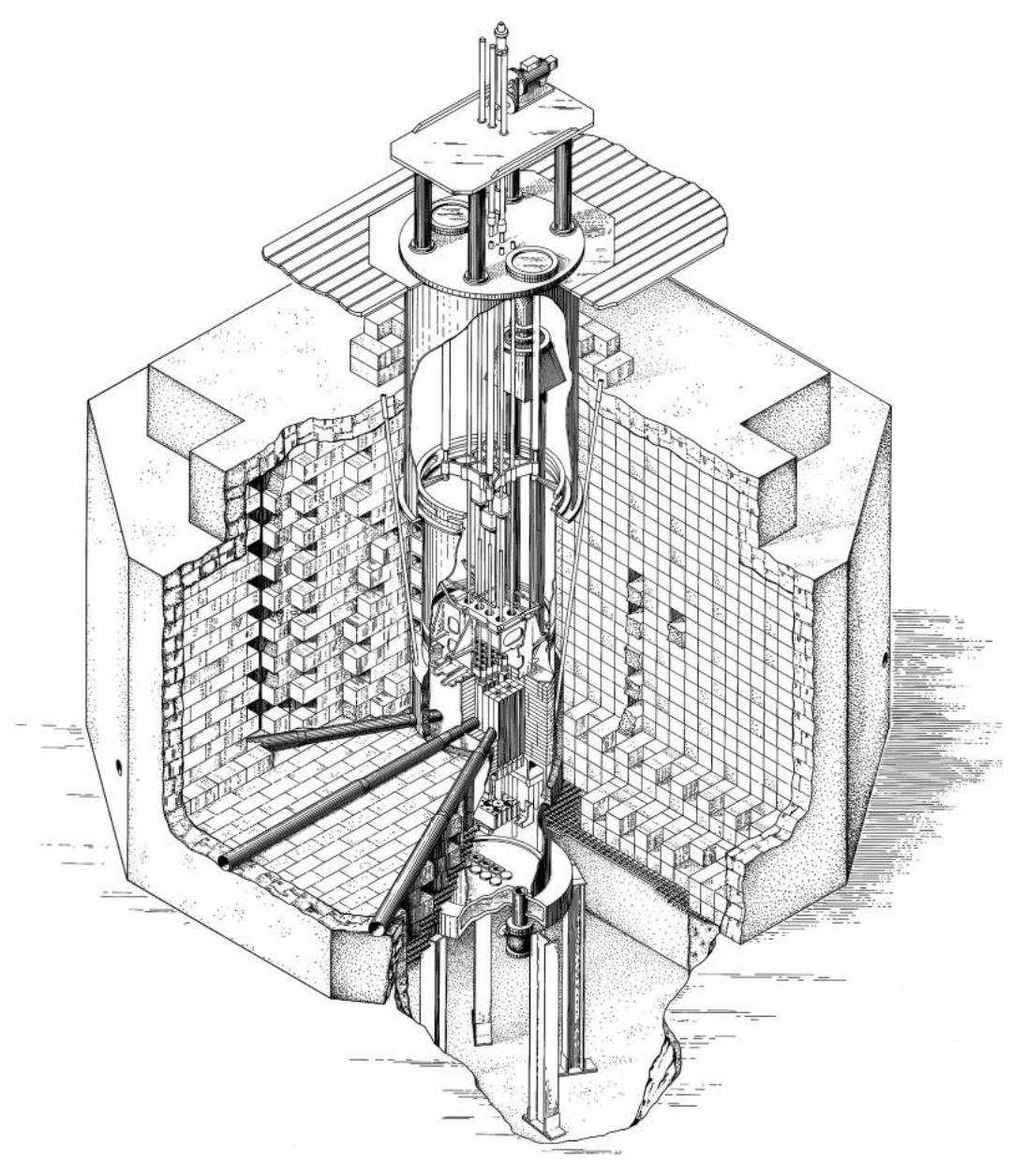

Fig. 35. Cutaway view of the LITR. (ORNL-LR-DWG 11485) 
The LITR attracted world attention because in the pool above it the famous blue glow (Cerenkov radiation) was photographed at a reactor for the first time. As seen in Fig. 36, a copy appeared on the cover of Scientific American. The LITR remained in operation until 1968.

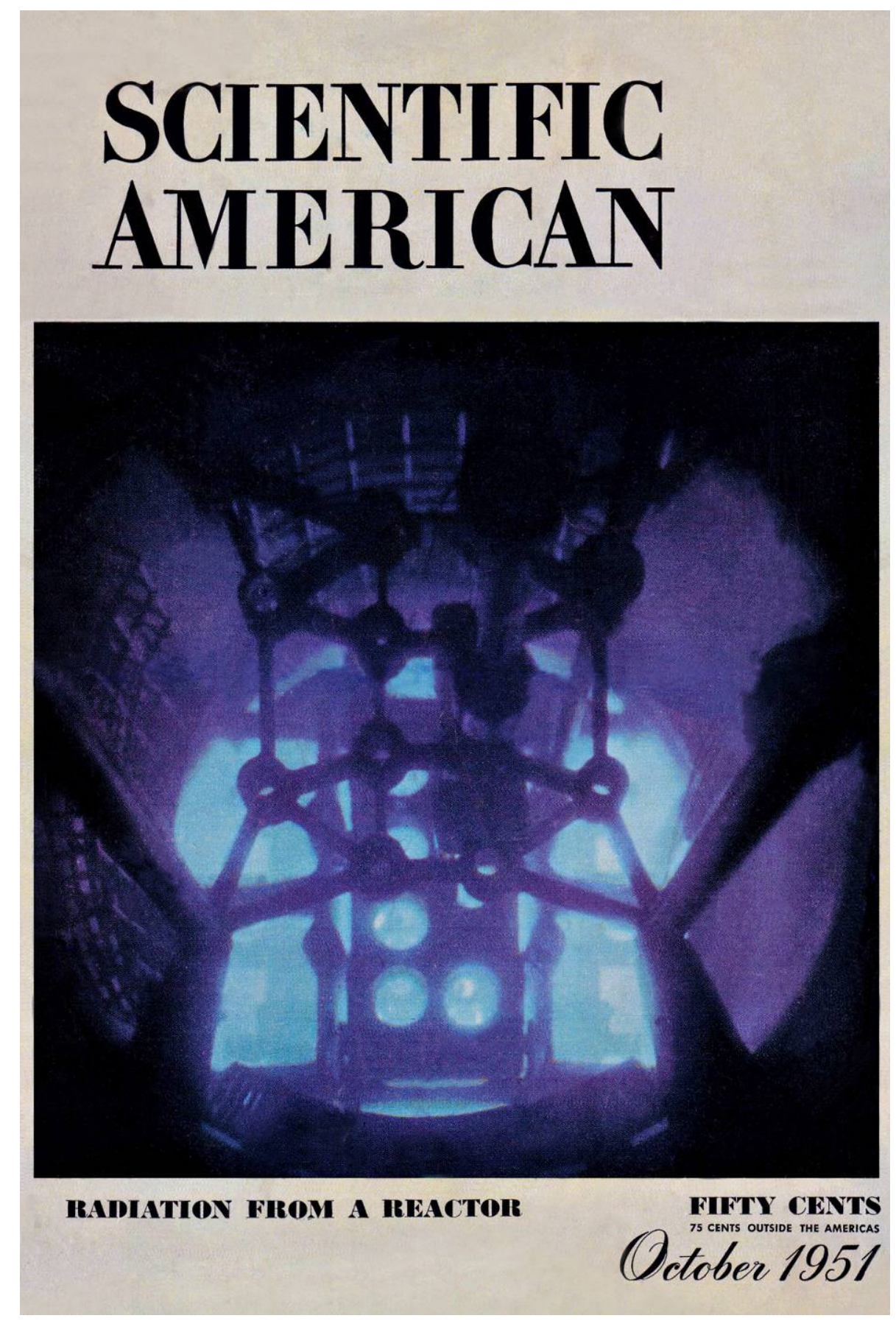

Fig. 36. The LITR on the cover of Scientific American. (Copyright $@ 1951$ by Scientific American, Inc. All rights reserved.) 


\section{THE SWIMMING POOL REACTORS}

Once the nuclear submarine program was initiated in the late 1940s, the design of shielding to protect the crew was an important issue. ORNL had become the lead institution for naval-reactor shielding, and as mentioned earlier, the penetration of neutrons and gamma rays through various materials was being studied at the Graphite Reactor. To get better measurements, however, a special facility called the Bulk Shielding Reactor (BSR) was created by assembling a set of MTR-type fuel elements in a pool at the Laboratory. Because they were inexpensive and simple to operate, such "swimming pool" reactors became a favorite for small research facilities and universities, and dozens were built around the world.

\section{Bulk Shielding Reactor}

The BSR went critical in December 1950. As seen in Fig. 37, the core structure was suspended from a movable bridge that spanned a $20 \times 40 \mathrm{ft}$ pool. A second bridge was available as a working platform and to hold special equipment. Shield assemblies, $\mathrm{D}_{2} \mathrm{O}$ reflectors, and experiments of various kinds could be placed alongside or near the core and measurements easily made.

Initially the reactor was cooled by natural circulation of water and operated at only $100 \mathrm{~kW}$. Over time, several additions were made to broaden the usability of the BSR, and eventually a forcedcooling system, shown in Fig. 38, was added to permit continuous operation at up to $2 \mathrm{MW}$. At the higher fluxes thus made available, the BSR became useful for a wider variety of experiments including studies of the effects of radiation on materials.

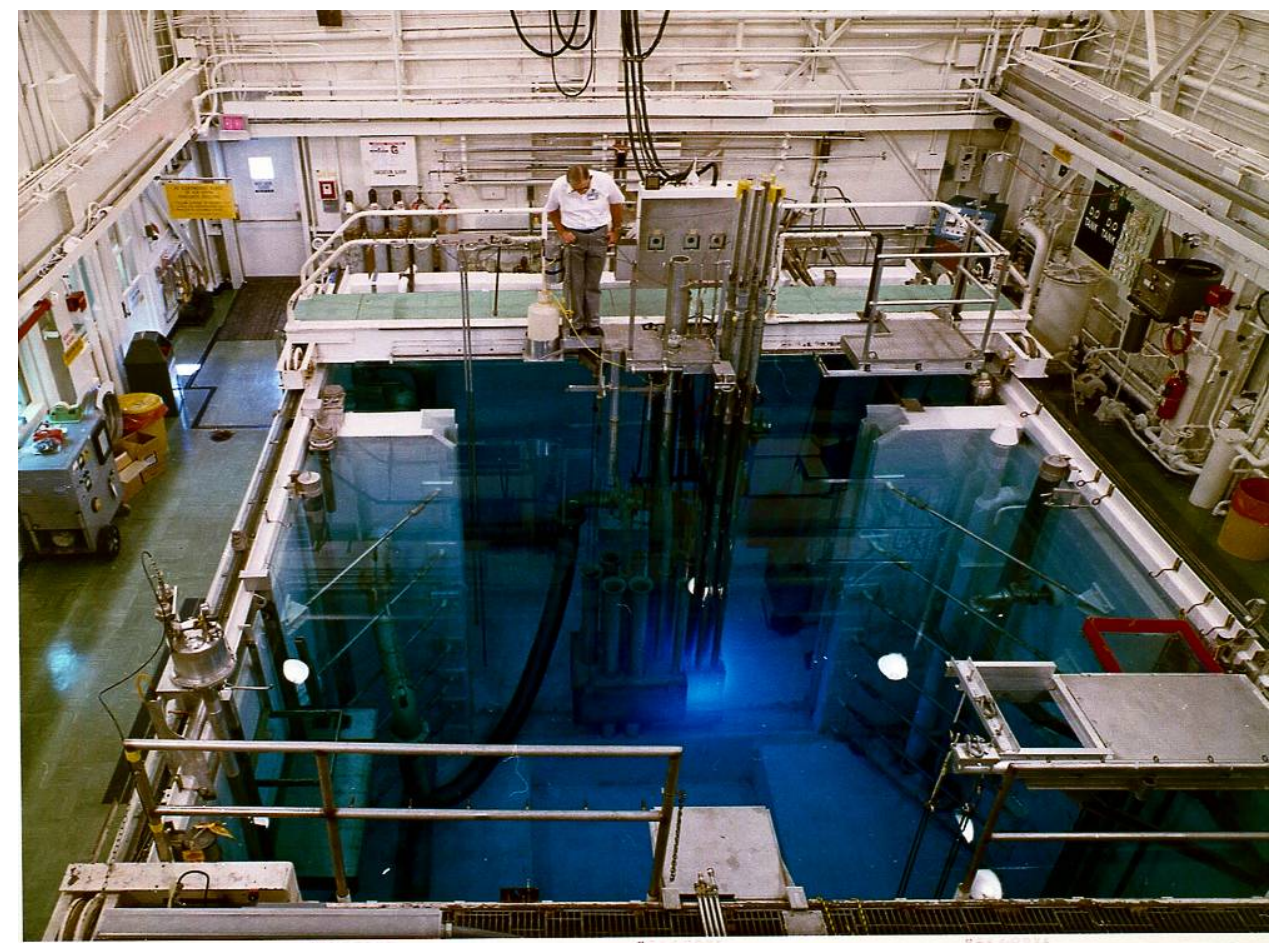

Fig. 37. The BSR in its "swimming pool." (ORNL Photo 4117-96) 


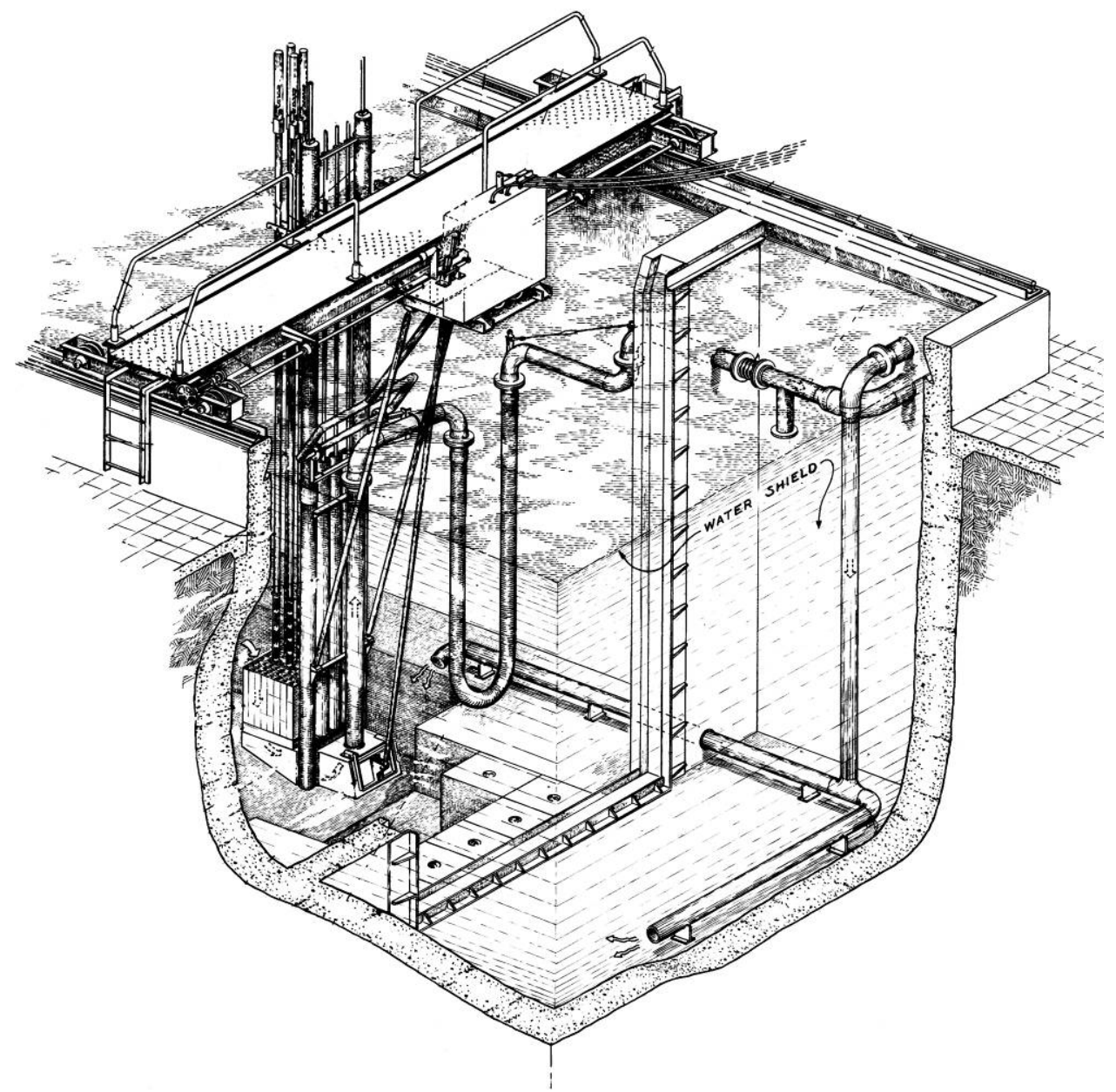

Fig. 38. Sketch of the BSR, showing the forced cooling piping. (ORNL Drawing 67-5973)

\section{Geneva Reactor}

In 1955, the United Nations sponsored the first International Conference on the Peaceful Uses of Atomic Energy in Geneva. It drew participants from 69 countries who presented 1132 papers, many of them describing activities that up to then had been treated as secret.

The meeting offered countries the opportunity to show off their accomplishments, and the AEC invited ideas. ORNL proposed that the United States display an actual operating reactor. The AEC went for it, and in 5 months, ORNL assembled and tested a reactor and shipped it by air to Geneva.

The reactor, shown in Fig. 39, was almost a replica of the BSR, but there was one important difference. The BSR fuel elements contained 93\%-enriched uranium, but only 20\% enriched (which will not make a bomb) could be shipped abroad. Hence nearly 5 times as much uranium had to be included in each fuel plate. That turned out to be difficult, but it was done using plates of specially prepared $\mathrm{UO}_{2}$ particles in an aluminum matrix, thereby becoming the prototype for other research reactors fueled with low-enriched uranium. With the fuel element problem solved, the reactor was assembled, tested in the BSR pool, and loaded on an Air Force plane in time to meet the deadline.

The reactor with its blue glow was the hit of the conference, and many dignitaries from around the world visited it. Afterwards it was sold to the Swiss government and moved to a research institute at Würenlingen, where it was named Saphir for its blue glow. A series of upgrades over the years, 


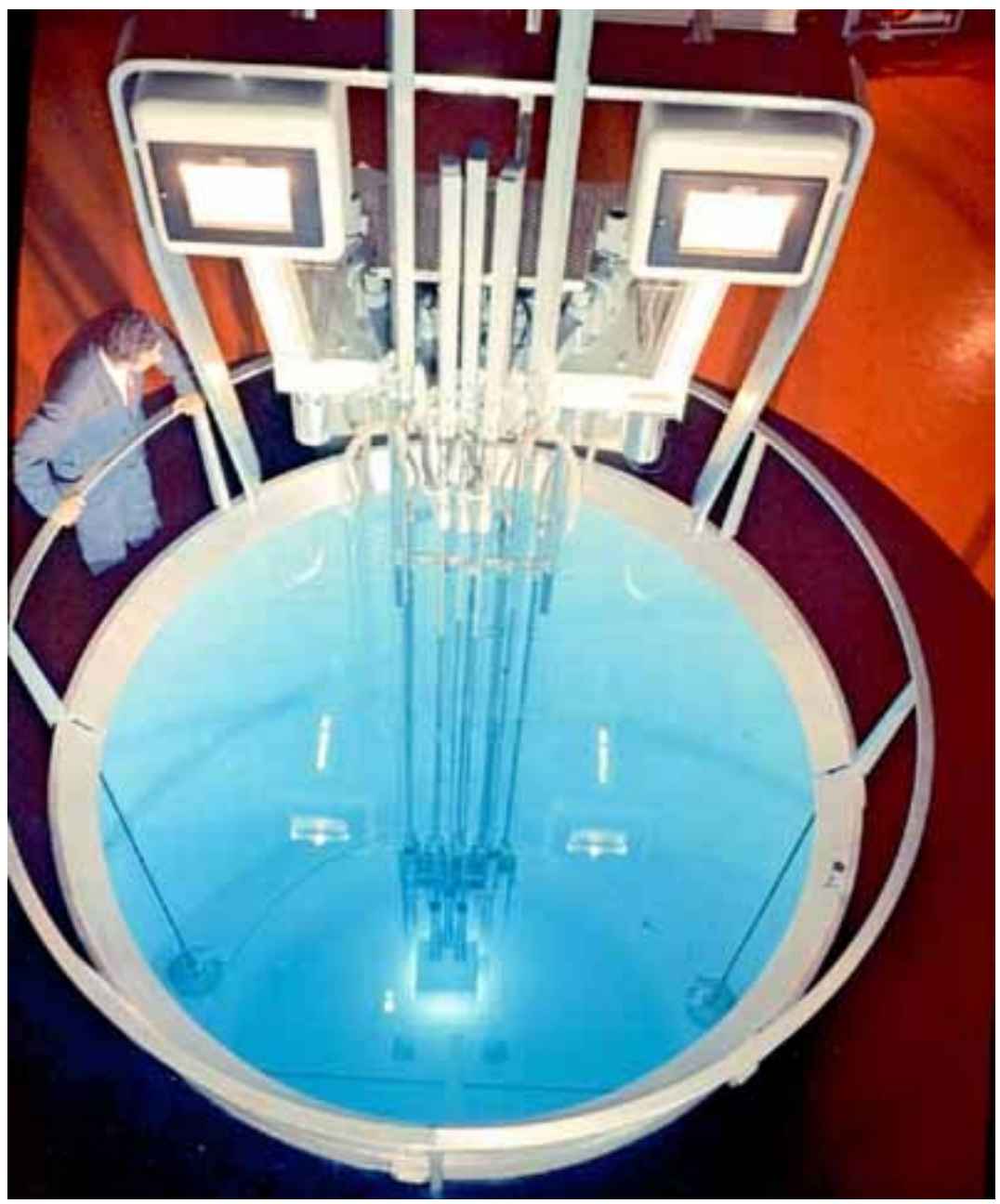

Fig. 39. The Geneva reactor. (ORNL Photo 17105)

including forced cooling, partial concrete shielding, and beam lines, converted it into a $10 \mathrm{MW}$ multipurpose facility that was used productively until 1994.

\section{The Pool Critical Assembly}

Duplicates of many parts remained after the Geneva reactor demonstration was completed. They were used to put together a new facility called the Pool Critical Assembly (PCA) in a corner of the pool containing the BSR. As shown in Fig. 40, the PCA, which was completed in 1958, was made versatile by using stacked grid plates that would accept either round BSR or square ORR end boxes. The PCA was useful for testing proposed modifications to BSR equipment and procedures. In addition, because it was operable up to $10 \mathrm{~kW}$, it could also handle some of the low-power experiments that would otherwise be performed in another reactor.

The PCA proved particularly valuable as a training facility for reactor operators, primarily for ORNL and TVA, and as a means of providing hands-on experience to nuclear engineering students from colleges and universities across the country until it was shut down in 1987. 


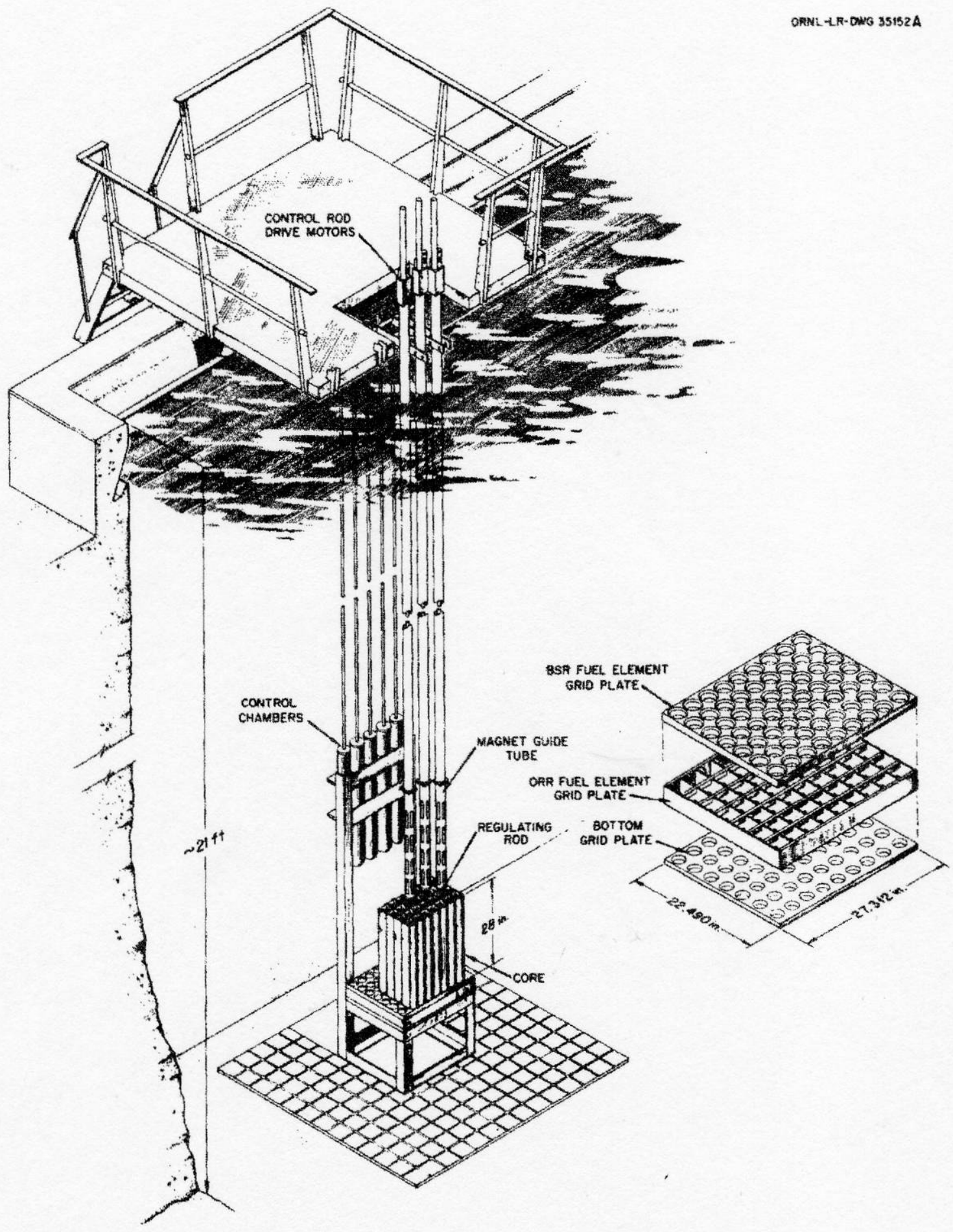

Fig. 40. Drawing of the PCA in the BSR pool.

(ORNL-LR-DWG 35152A) 


\section{TOWER SHIELDING FACILITY}

The Aircraft Nuclear Propulsion (ANP) Program begun in 1946 soon grew into a major national activity, and shield weight was a critical issue. The BSR was available for shielding studies, but an understanding of air scattering was important for aircraft, and the BSR could not help with that, nor could it test full-size models of shields. In addition, the analysis of shielding became more complex with the idea of dividing the shield between the reactor and the crew compartment.

In 1952, ORNL proposed to address ANP shielding problems by hanging full-scale reactor and shield models high in the air. Approval was received, and the Tower Shielding Facility (TSF) was built on Copper Ridge in a remote area south of the main Laboratory area. The TSF (Fig. 41) was formed from four $315 \mathrm{ft}$ towers, separated by $200 \mathrm{ft}$ in one dimension and $100 \mathrm{ft}$ in the other. Cables attached to the towers could hoist the reactors and shields to $200 \mathrm{ft}$ above the ground. The facility was operated from an underground building, and a fence kept people and animals away.

\section{TSR-I}

The first Tower Shielding Reactor (TSR-I) was essentially a BSR. It was tested in a $12 \mathrm{ft}$ diam water-filled tank and in specially designed shield assemblies into which the core was lowered. When the core was in the tank, the reactor support system could rotate or move it to any position within a horizontal plane for measurements. Cooling was by forced convection. When testing began in 1954, the initial power limit was $100 \mathrm{~kW}$, but permission was soon obtained for operation at up to $500 \mathrm{~kW}$. When not in use, the reactor was stored in a deep pool between the towers.

As the testing program proceeded, considerable difficulty was encountered in interpreting data from the BSR-type core and applying it to a spherical power reactor. A different core was seen to be

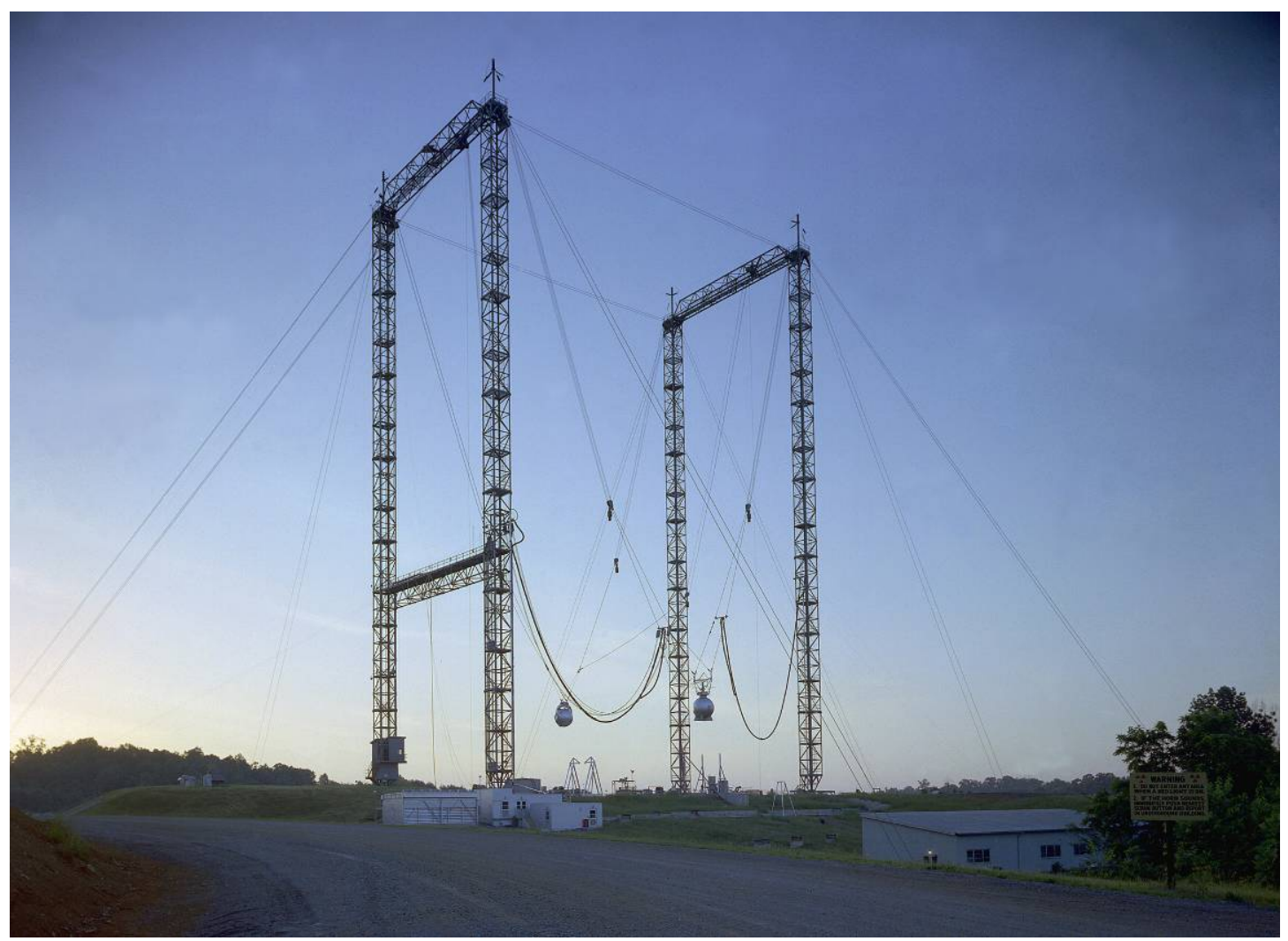

Fig. 41. A reactor and shield suspended at the TSF. (ORNL Photo 50397) 
needed, and design studies of it were soon begun. After four years of TSR-I use, it was replaced with a new reactor. To permit easier analysis of the results, the specifications called for it to be spherical, with the control elements placed in the center and specially shaped to cause minimum perturbation of the radiation.

\section{TSR-II}

The new reactor, TSR-II, was still water cooled, and MTR-type fuel plates were used again. But they were curved, as shown in Fig. 42, and 71 different sizes were needed. The reactor, seen in cross section in Fig. 43, was 29 in. in diameter and was enclosed in an aluminum pressure vessel with a hemispherical base. A 17 in. aluminum sphere in the center contained umbrella-shaped boron carbide control plates that were moved in and out by hydraulic cylinders.

Cooling water at 800 gpm was pumped through the reactor from the ground using the hoses visible in Fig. 44. Operation had advanced to $100 \mathrm{~kW}$ by early 1961, just a few months before the termination of the national ANP program. Approval was eventually secured for operation at $1 \mathrm{MW}$, but that was not until 1972.

Two other reactors in addition to the two built in Oak Ridge were operated at the TSF. One was the Aircraft Shield Test Reactor (ASTR), a portable water-cooled reactor built by Convair for ANP shielding studies. Convair had run it in ground tests at Fort Worth and then airborne aboard a B-36 bomber. In 1958 the company operated it at the TSF with the crew compartment of the B-36 for comparison with the airborne results.

The second reactor was a compact zirconium-hydride-moderated reactor similar to the SNAP-10A assembly flown on a satellite in 1965 in the Space Nuclear Auxiliary Power (SNAP) program. It was run at the TSF from 1967 to 1969 in studies related to SNAP reactor shielding.

While the ANP program was in progress and after its demise, shielding and other types of studies were performed for various government and private organizations. This work included a joint U.S.-Japan study of shielding for fast reactors, which probably contributed to the AEC's decision to
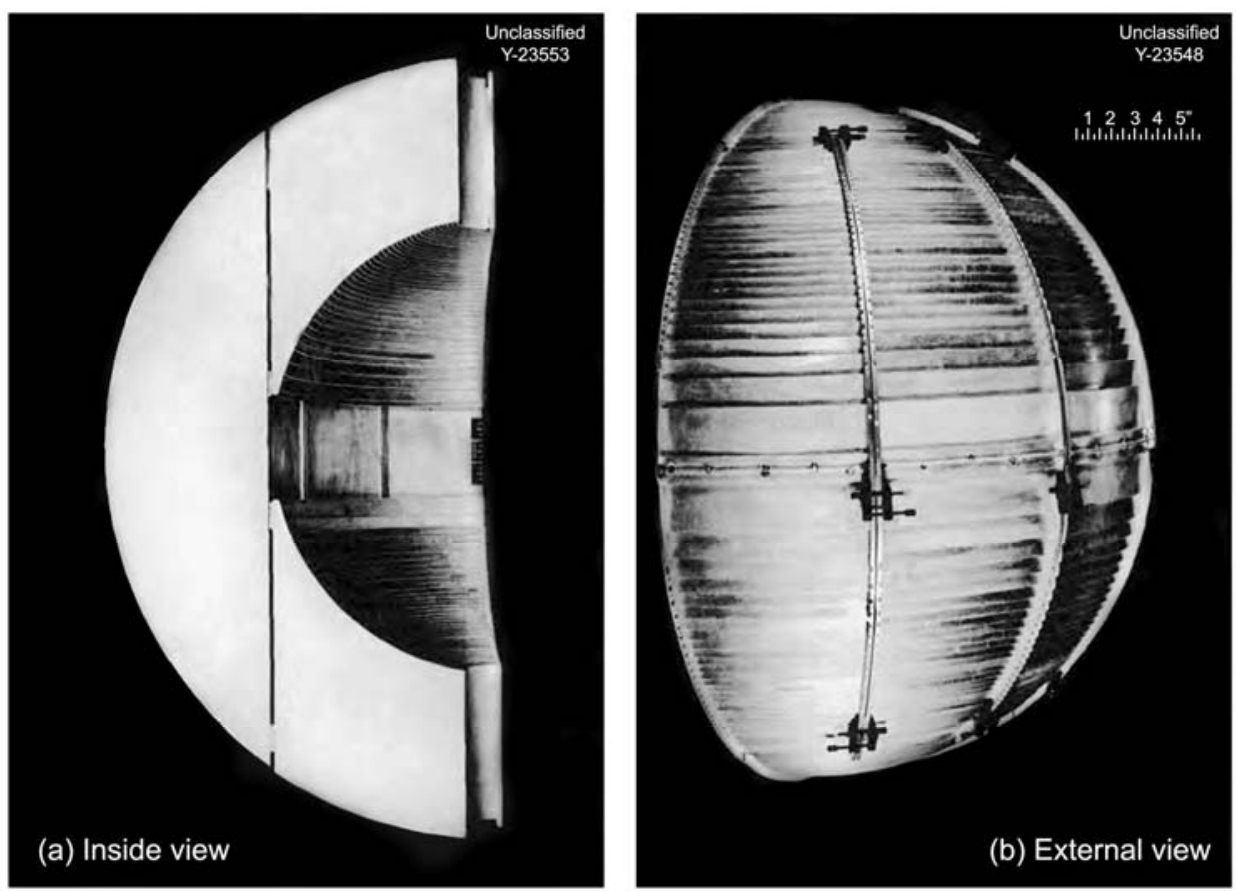

Fig. 42. TSR-II core. 


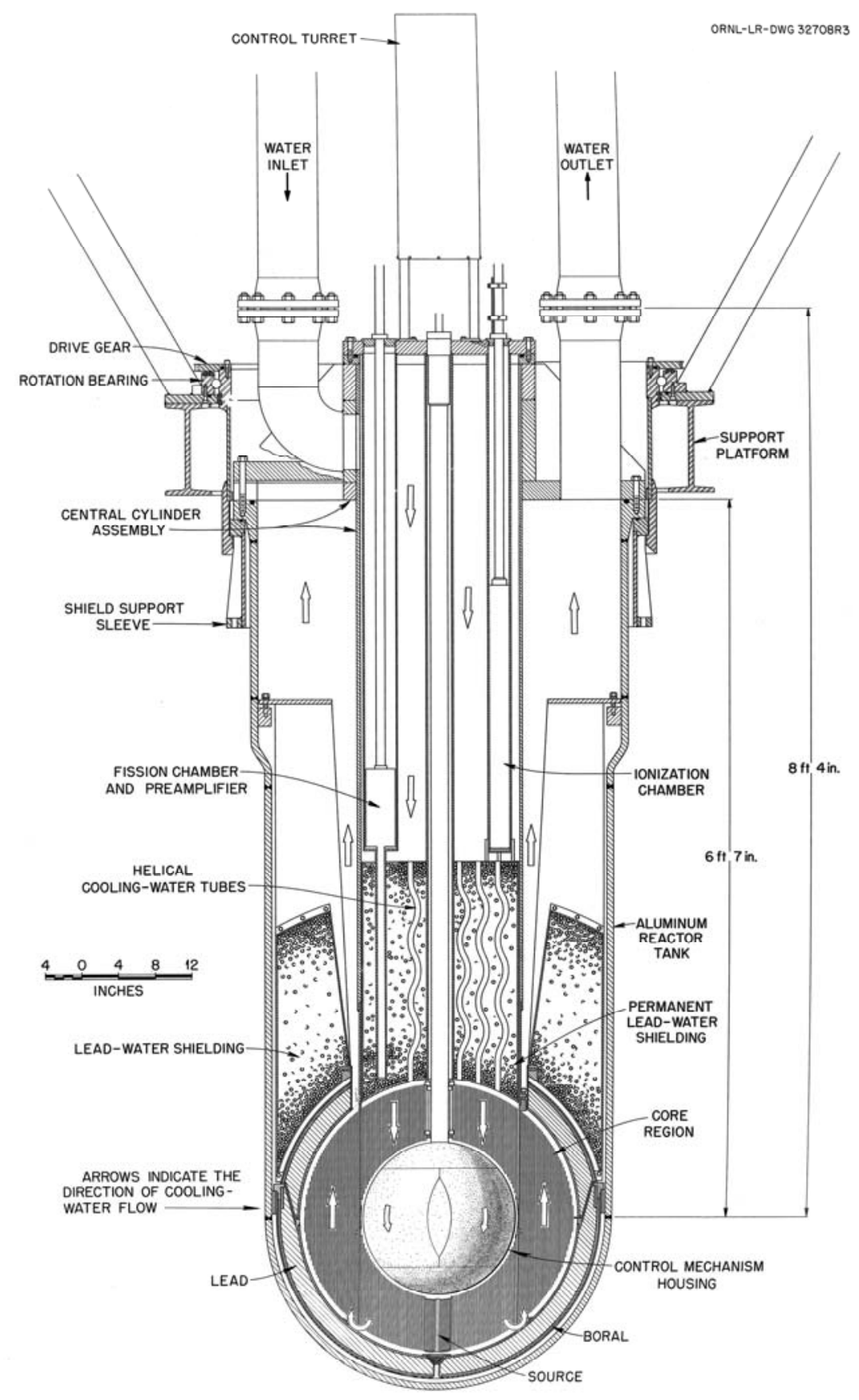

Fig. 43. TSR-II cross section. (ORNL-DWG 87-11650)

allow the TSF to return to operation when, as noted earlier, many other reactors were permanently shut down following the Chernobyl accident.

In 1957, Pratt and Whitney ran a roaring jet engine for 50 hours while it was exposed to strong radiation to learn what damage might be done to engine components. And in perhaps the most spectacular tests of all, the tower hoists were used to drop heavy casks for shipping radioactive fuel from different heights onto armor plate to determine their structural integrity in a highway accident. 


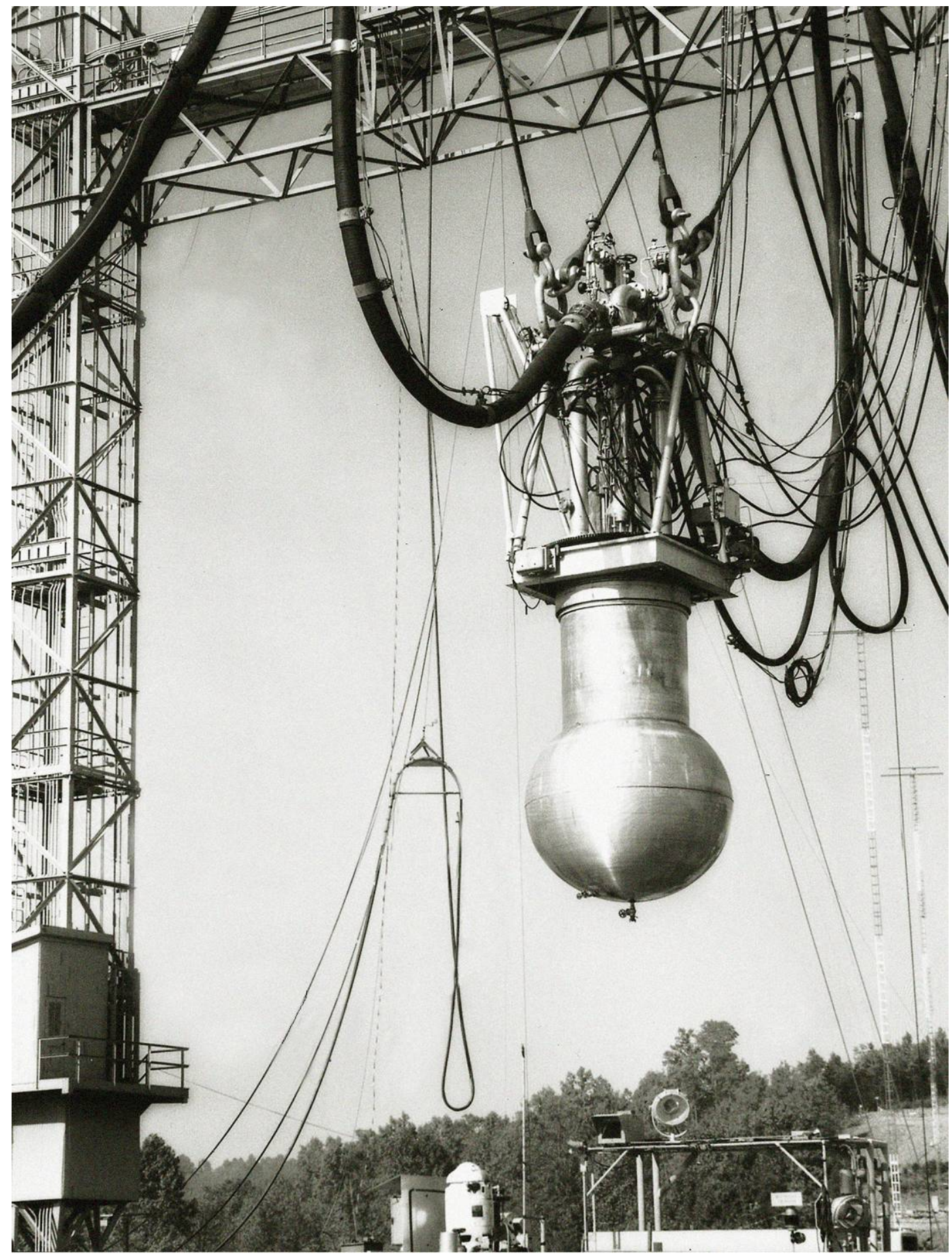

Fig. 44. The TSR-II suspended from the TSF towers. (ORNL Photo 4978-98)

Over the lifetime of the TSF, a variety of shields were tested; in addition, valuable basic data were obtained on shield materials and air scattering. However, during the years leading up to its final shutdown in 1992, the TSR-II was mainly used in a concrete shield on the ground as an easily accessible radiation source. 


\section{OAK RIDGE RESEARCH REACTOR}

With a substantial role in the ANP and with numerous basic research programs in progress, the Laboratory concluded in the 1950s that it needed a high-flux facility like the MTR in Oak Ridge. The AEC granted approval, and construction was completed in 1958. So the Oak Ridge Research Reactor (ORR) was built alongside the Graphite Reactor, the LITR, and the BSR, providing the Laboratory with an impressive array of research reactors. With four reactors in the same area, the control rooms were co-located to reduce the number of operators needed.

The ORR was similar to the MTR and used MTR-type fuel elements, but it had better access for research. As seen in Fig. 45, the core was contained in an $18 \mathrm{ft}$ high aluminum vessel that was irregular in shape but somewhat resembled a cylinder flattened on one side. On the flat side, as shown in Fig. 46, the concrete shield was replaced by a large pool, which made it easy to position experiments near the core. Materials irradiated in what was called the Pool Side Facility could be moved under water without packaging to the end of the pool and lifted into a hot cell for disassembly

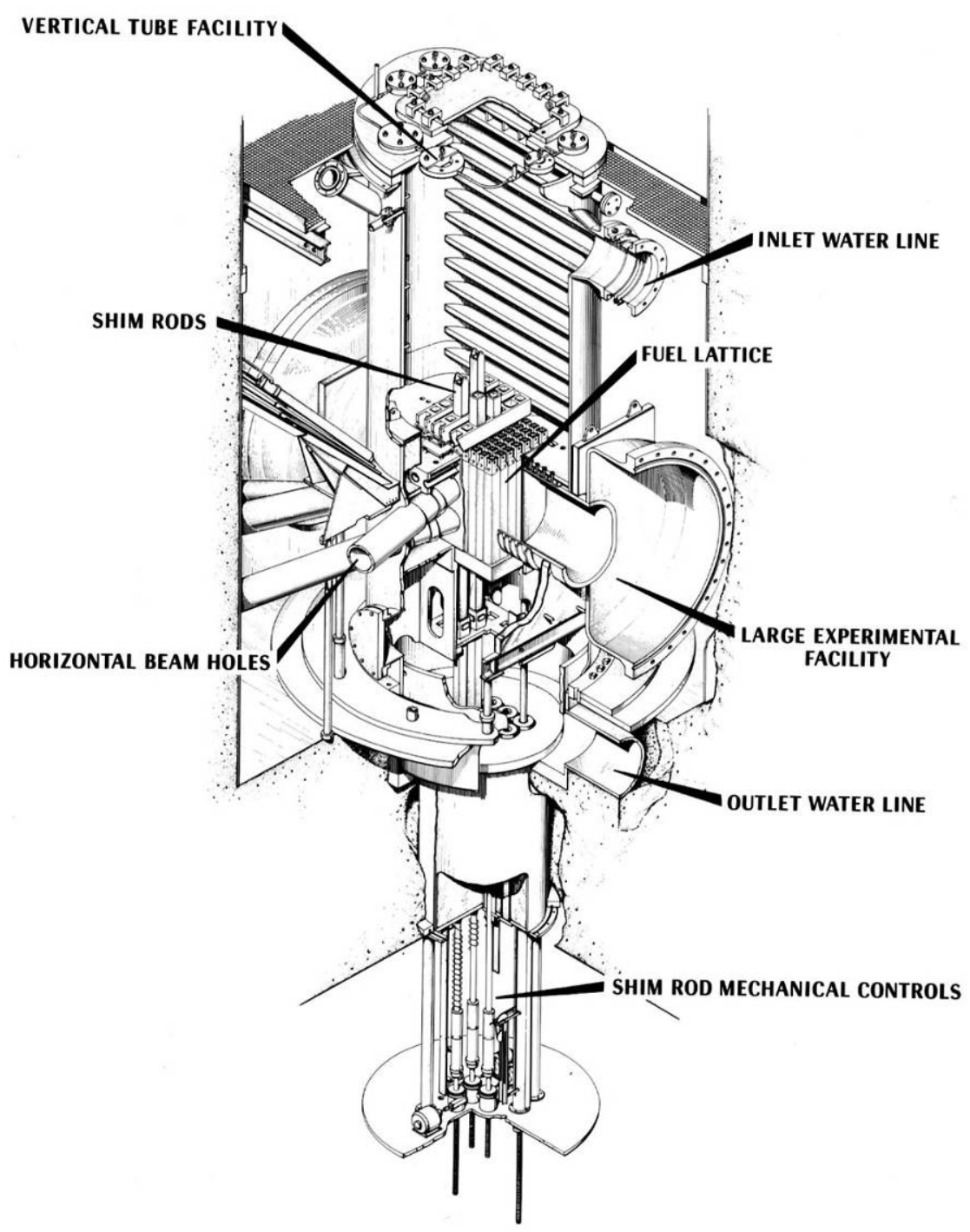

Fig. 45. Cutaway view of the ORR. 


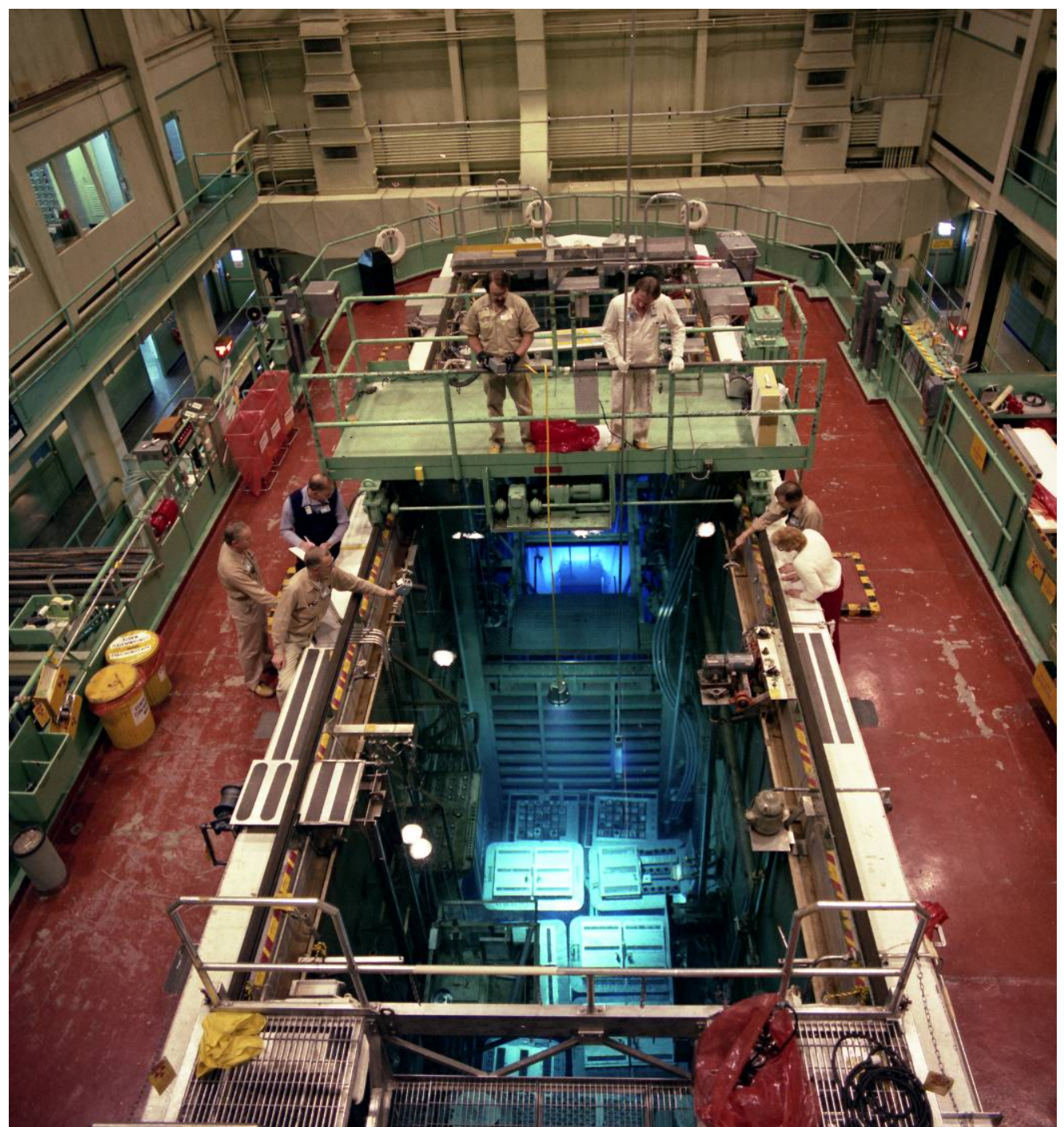

Fig. 46. Pool-side view of the ORR. (ORNL Photo 8104-83)

and examination. Large penetrations in the concrete-shielded sides of the reactor provided space for water- or gas-cooled "loops" in which sections of fuel elements could be tested. Numerous beam tubes provided access for research, and materials could also be lowered from above into test spaces in the core.

Beryllium reflector elements that fit into core grid positions could be positioned to control the flux distribution, and a number of them had openings in the center into which experiments or isotopeproduction stringers could be placed. Hydraulically operated "rabbits" permitted samples to be inserted and removed from two positions while the reactor was operating.

The control rods entered from below, making the fuel elements easily accessible from above, and the upper grid plate was split in an arrangement that permitted leaving experiments in place during refueling. Consequently, it was possible to refuel in a few hours, and when necessary, elements could be quickly replaced with spares to avoid long waits for the decay of xenon-135.

In spite of its high power and location in the center of the Laboratory, the ORR did not have a “containment” building. Instead, as can be seen in Fig. 47, it was "confined” in an airtight structure that was operated at a slight negative pressure and vented to a stack through scrubbers and filters that 


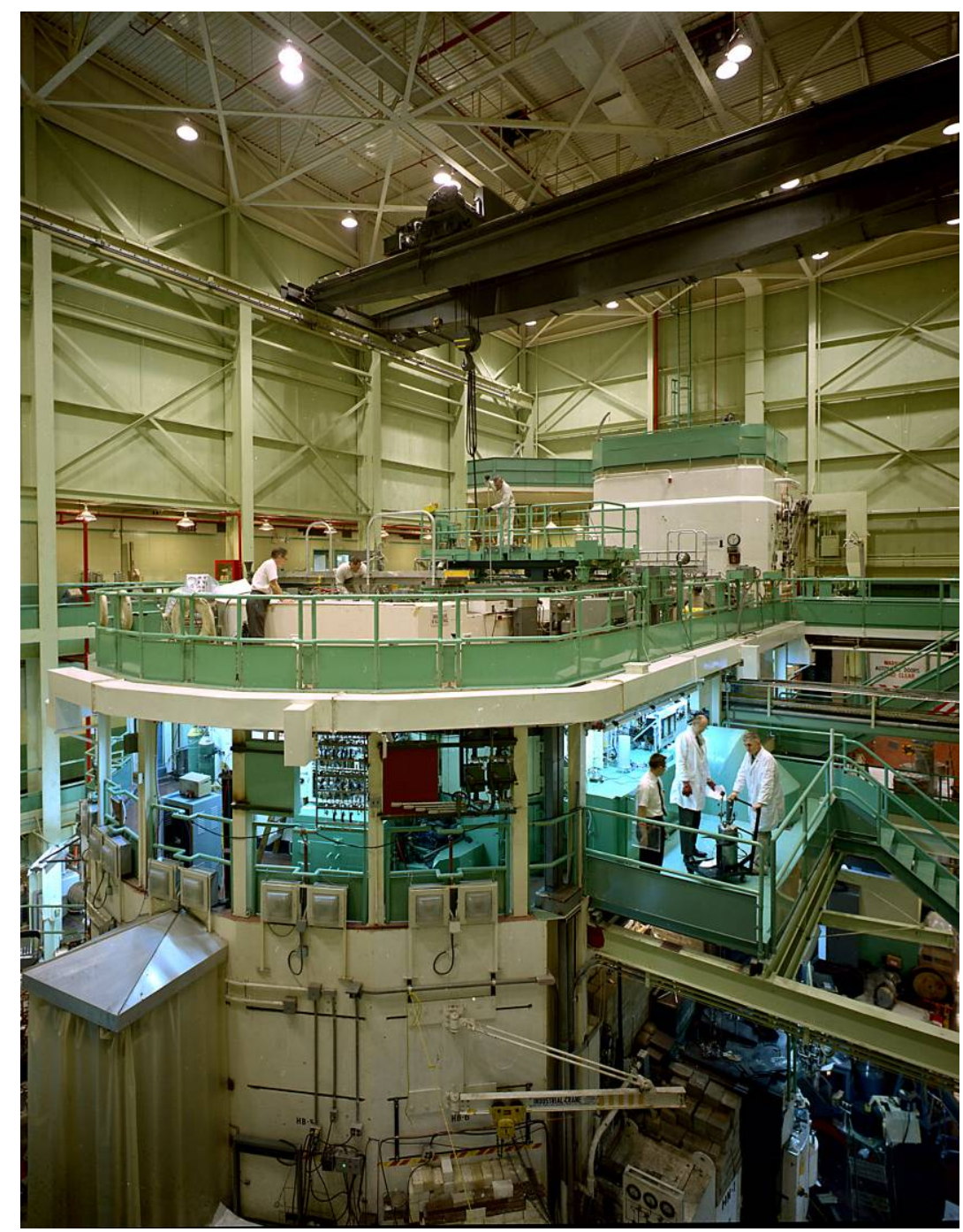

Fig. 47. The ORR inside its “confinement” building. (ORNL Photo 86784)

would trap any escaping radioactivity. Such an arrangement might not be permitted today, but it was approved at the time after extensive review.

Operation began in 1958 at a nominal $20 \mathrm{MW}$, but the air-cooled heat exchangers were found to remove only $15 \mathrm{MW}$ during the summer. They were replaced with evaporative coolers having higher capacity. Other changes were made as well, and regulatory approval was soon obtained to operate at 30 MW.

Among the many uses of the ORR were neutron scattering research, fundamental investigations of the behavior of metals and ceramics under radiation, and the testing of materials for reactor fuel elements and for fusion devices. It also became the major world supplier of radioisotopes.

The ORR worked well for 29 years with no serious difficulties or interruptions. Since it was flexible and easy to use, its features were copied in reactors at a number of laboratories around the world. 


\section{HIGH-FLUX ISOTOPE REACTOR}

Glenn Seaborg, the co-discoverer of plutonium, californium, and other heavy elements, was interested in the production of large quantities of californium-252, which can be irradiated in cyclotrons to generate even heavier elements referred to as superheavies.

Californium is element 98 and four steps above plutonium in the periodic table. Small amounts had been made with cyclotrons, but the route proposed for large quantities was to irradiate the intermediate elements americium and curium, which could be separated from the plutonium being produced by the reactors at the Savannah River Site.

ORNL proposed building a very high-flux reactor particularly suited to the production of californium and other superheavy elements, and with Seaborg's support, approval was secured. Construction began in 1961 in Melton Valley, south of the main Laboratory campus (Fig. 48), and criticality was achieved in August 1965.

To get the high flux needed, the flux trap principle that was used in the reflector of the MTR was exploited, but with the trap in the center of the core so that it is fed by fast neutrons from all sides. The fast neutrons are moderated in the trap to the thermal energies needed for transuranic isotope production. Aluminum-clad curved plates are used in the fuel elements; they are formed into two concentric rings, leaving an open region in the center where a cluster of target elements can be located. The outer diameter of the ring-shaped fuel elements is $17 \mathrm{in}$;; the inner diameter is $5 \mathrm{in}$.; and they are $2 \mathrm{ft}$ high. Involute fuel-plate geometry with exacting fabrication standards provides uniform thickness of the coolant channels.

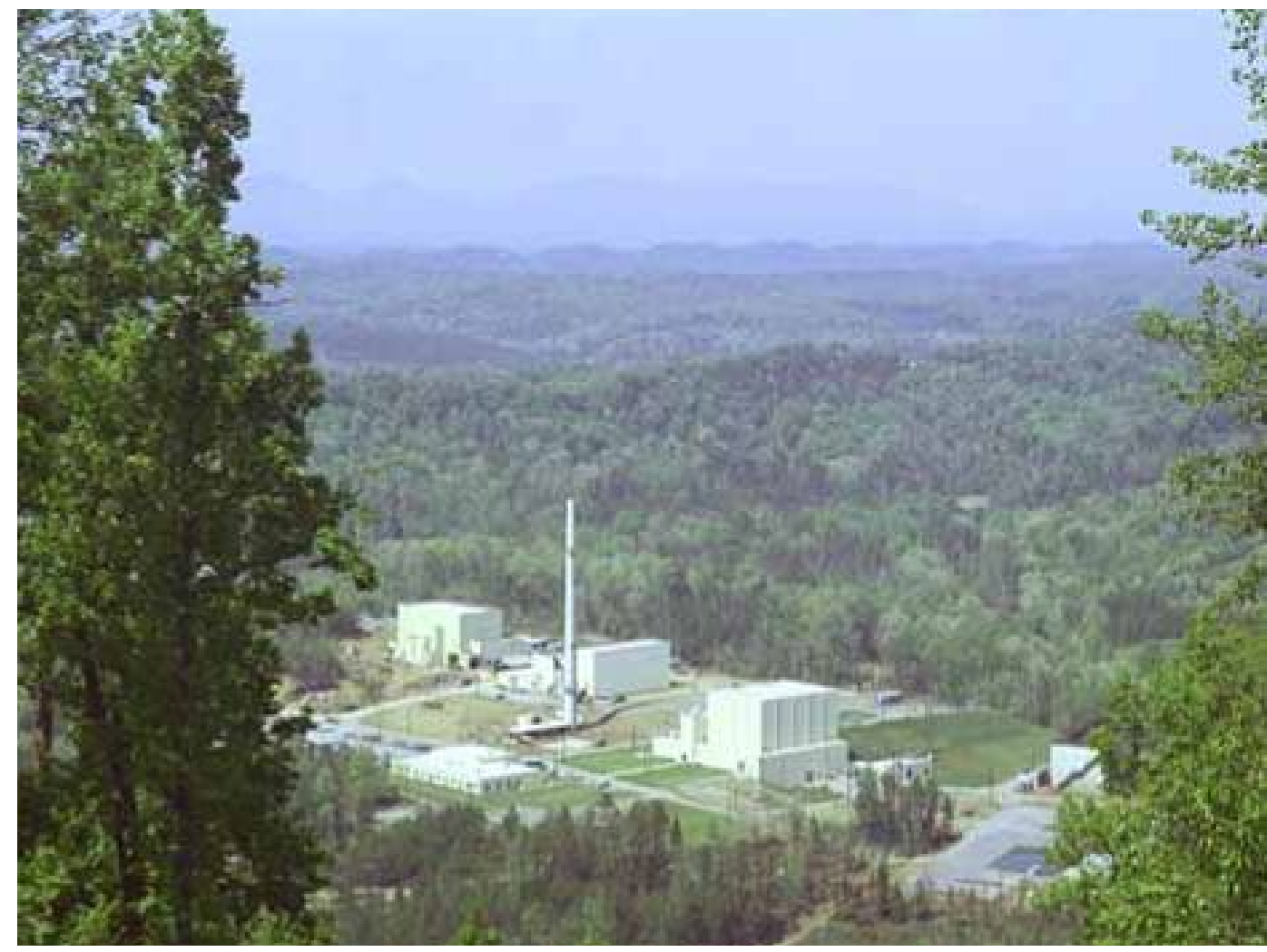

Fig. 48. The HFIR and other facilities in Melton Valley. In this 1966 photograph, the HFIR is just to the right of center, with its cooling tower at the far right and the HFIR office building in the left foreground. The Thorium-Uranium Fuel Cycle Development Center is on the left, and the Transuranium Processing Facility is behind the smokestack. (ORNL Photo 83715) 
In contrast to MTR-type elements, the "meat" of the fuel plates in HFIR, shown in Fig. 49, is a $\mathrm{U}_{3} \mathrm{O}_{8}$ - $\mathrm{Al}$ cermet, with the uranium concentration varied across the core inversely to the neutron flux to flatten the power distribution. In addition, boron is included in the fuel as a burnable poison to further flatten the flux and to extend the life of the core. These features permit an unusually high average power density. Successful development of the fuel elements was a major achievement.

As shown in Fig. 50, the core is surrounded by a beryllium reflector. Because beryllium swells when exposed to radiation, the reflector is made of three rings with the inner one designed to be replaceable. Poison-bearing curved control plates in an annular region between the core and the reflector provide shimming, regulation, and safety; their design is also very sophisticated. They have three regions of different poison content, and sections are moved vertically in opposite directions to minimize the axial flux peaking. High-velocity water cools the fuel and target elements, and special water chemistry control limits the buildup of aluminum oxide on the fuel plates. The neutron flux in the target region was and remains the highest in the world.

The AEC expected the HFIR to be used only for production of radioisotopes, but Weinberg saw its value as a source of high-flux neutrons for research and insisted on the inclusion of beam tubes penetrating close to the core, as shown in Fig. 50. In addition, 38 vertical positions of various sizes were provided in the reflector, and some space is available in the target region for other irradiations. A hydraulically operated "rabbit" provides access to the high flux for short-term irradiations, and two pneumatic rabbits shuttle samples into the reflector for neutron activation analysis.

The reactor is enclosed in a 3 in. thick, $8 \mathrm{ft}$ diam pressure vessel and was originally operated at 650-750 psig to suppress local boiling, which could occur although the coolant is heated only to about $160^{\circ} \mathrm{F}$. It is immersed in a pool of water, and to replace the fuel elements, a breech-lock type hatch on the pressure vessel is removed, the elements are lifted out, as seen in Fig. 51, and fresh elements are inserted using long-handled tools. The fuel elements must be replaced every 23 to 27 days and refueling takes about 6 days. Since the bulk temperature of the coolant is below the boiling point and thus has little stored energy, the HFIR was approved with ORR-type confinement in spite of its high power and high power density.

Fabrication of target rods and the recovery of californium and other heavy elements require a facility in which the highly radioactive rods can be dissolved and the valuable products recovered by

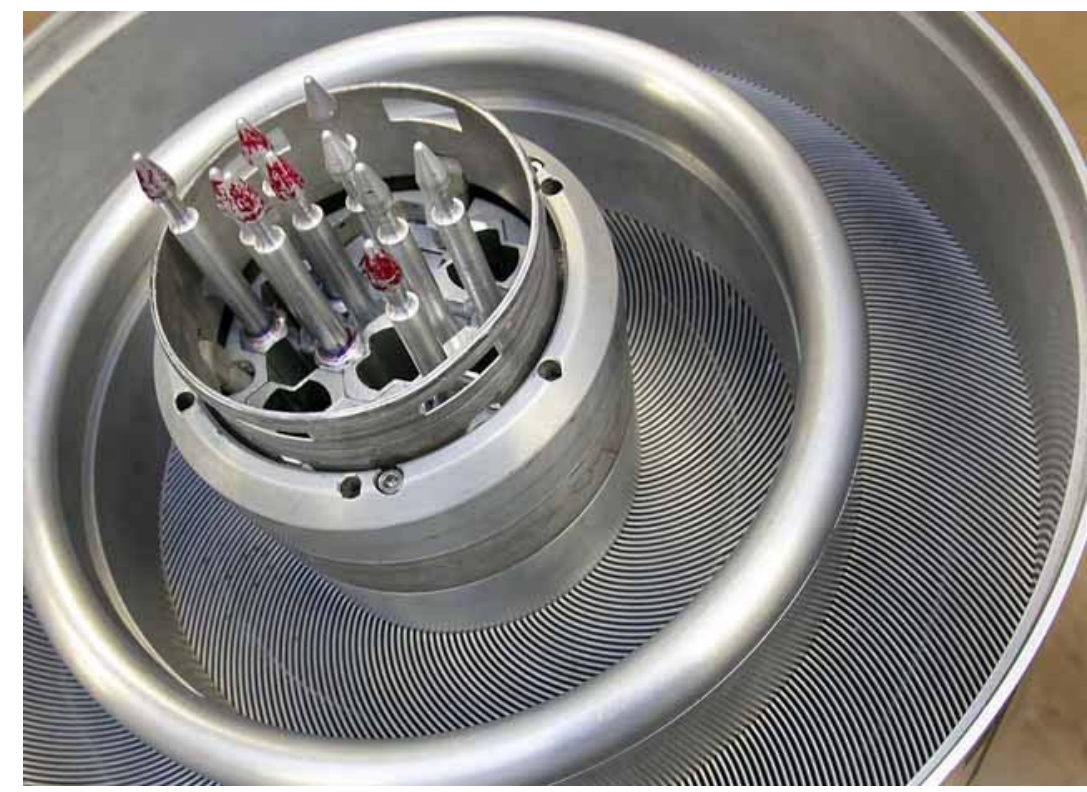

Fig. 49. HFIR fuel element with target rods in the flux trap. (ORNL Photo 2008-P01868) 


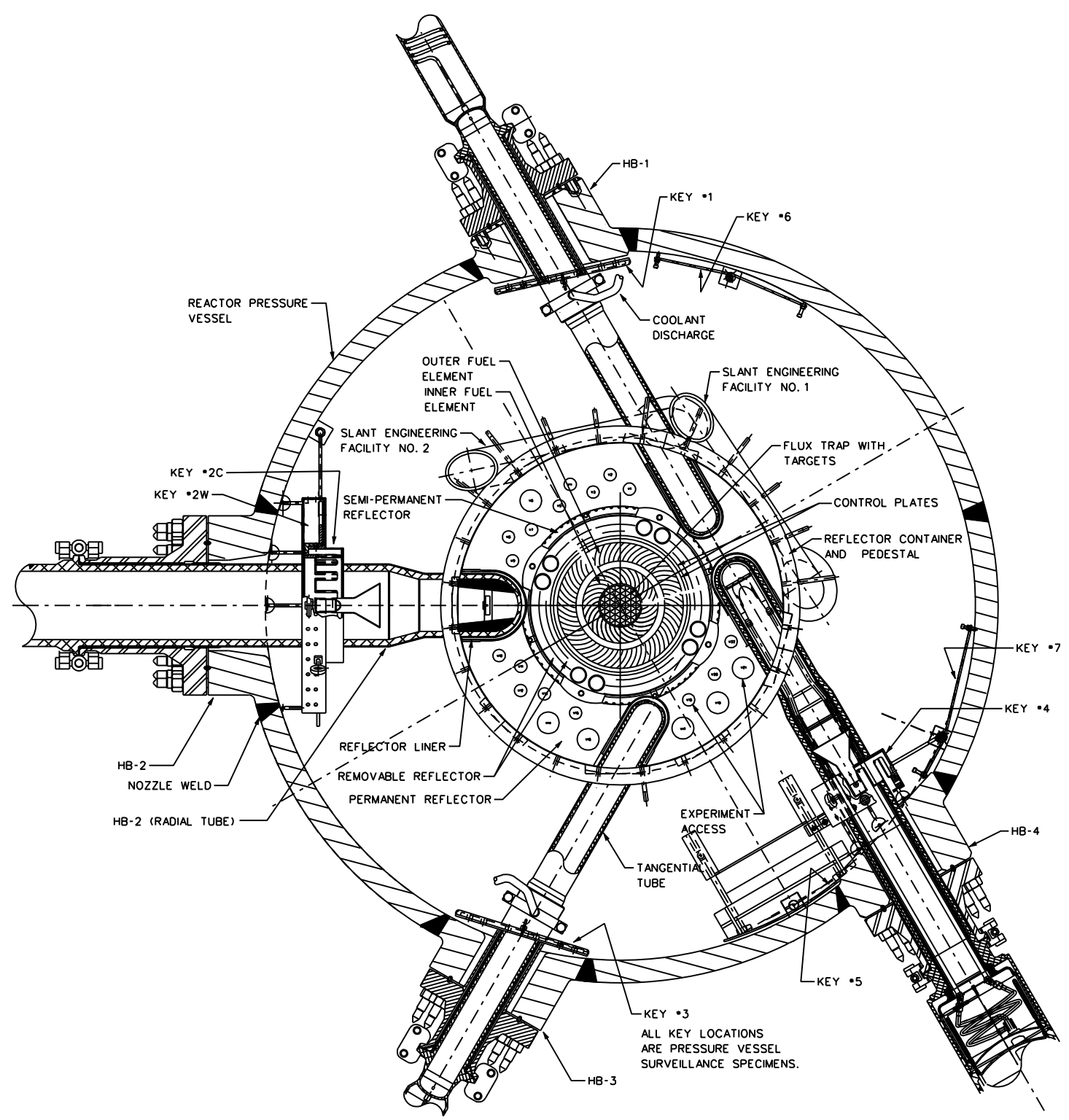

Fig. 50. Cross section of the HFIR at the horizontal midplane of the core.

(Fig. 5.3-2, ORNL/HFIR/SAR 2344, Rev. 9)

solvent extraction. Consequently, a specialized processing plant in a set of hot cells was built near the reactor. The operating gallery of the Transuranium Processing Plant, which today is part of the Radiochemical Engineering Development Center (REDC), is shown in Fig. 52.

The HFIR ran very well for 20 years. Then the testing of some surveillance specimens revealed that embrittlement of the pressure vessel by neutrons had occurred faster than predicted. As a result, in November 1986 the HFIR was shut down for extensive reviews. Fortunately, ORNL was the home of the Nuclear Regulatory Commission's program to evaluate the safety of heavy-wall pressure vessels. Application of the program's data showed that the technical specifications for the HFIR vessel were conservative, and evaluations and tests performed, including pressure testing, were reassuring.

Responding to the reviews, the surveillance program was updated, periodic pressure tests were specified, and the operating pressure was reduced to 468 psig, which required lowering the power to 


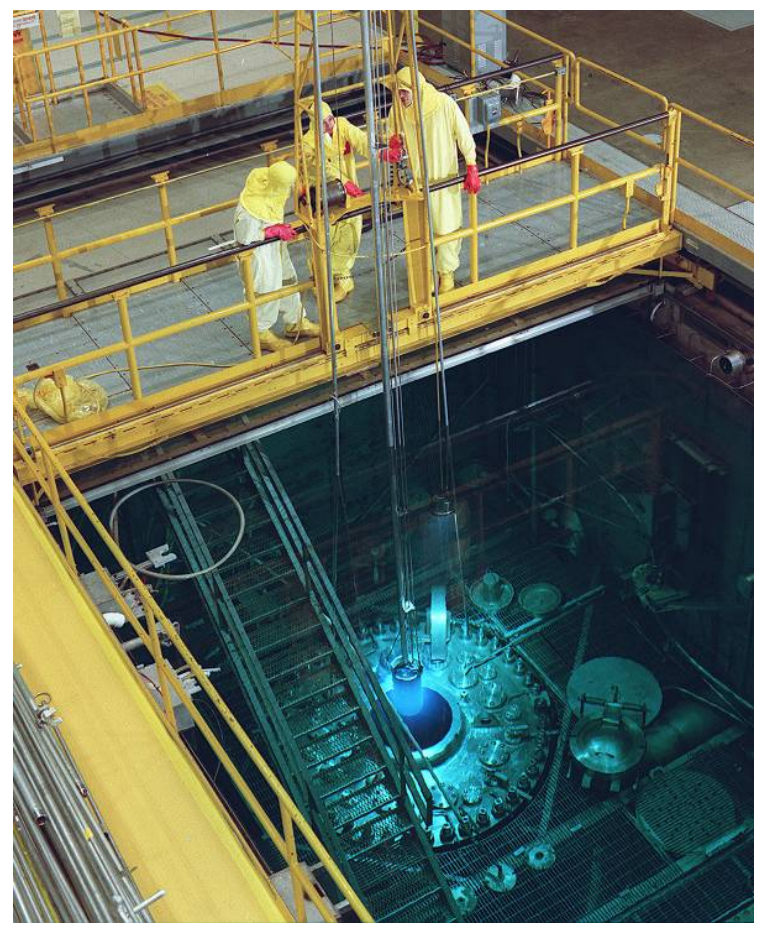

Fig. 51. Replacement of HFIR fuel element. (ORNL Photo 11299-92)

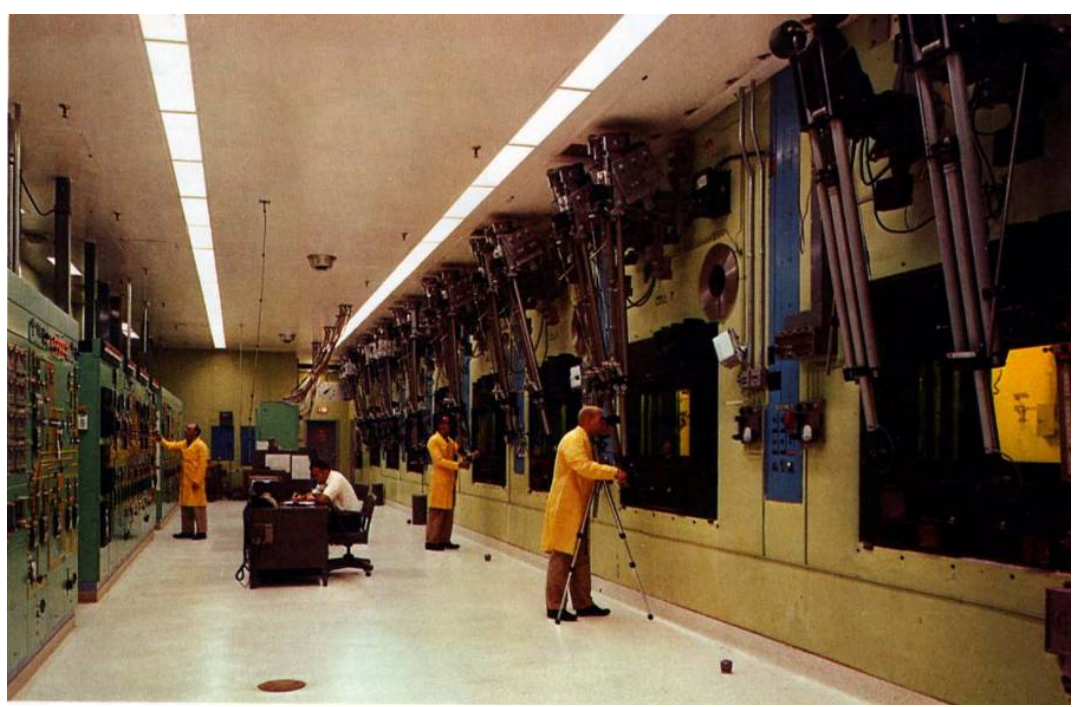

Fig. 52. The operating gallery of the Transuranium Processing Facility.

85 MW from the original level of $100 \mathrm{MW}$. After being down for two and a half years, the HFIR was restarted. Subsequent evaluations indicate that it can run safely for another three decades.

Over the years, the research and isotope production capabilities of the HFIR have been upgraded a number of times. Last year, a vessel slightly larger than a softball and filled with liquid hydrogen was inserted at the inner end of a beam tube. Neutrons that enter this region, called a "cold trap," are cooled to $22 \mathrm{~K}$. At this temperature, they have long wavelengths and an unusually low velocity and are useful for research that cannot be done with higher velocity neutrons. 
The HFIR is still used for the production of californium and other special radioisotopes. Its multiple test facilities are used to determine the effects of neutron irradiation on the properties and behavior of materials. And its beam lines, equipped with a collection of special instruments, provide thermal and cold neutrons for applied and fundamental research in a variety of fields.

Today the HFIR, shown in Fig. 53, is ORNL's only operating reactor, but it is among the world's most powerful and capable research reactors, and about 500 scientists from around the world visit Oak Ridge annually to use its facilities.

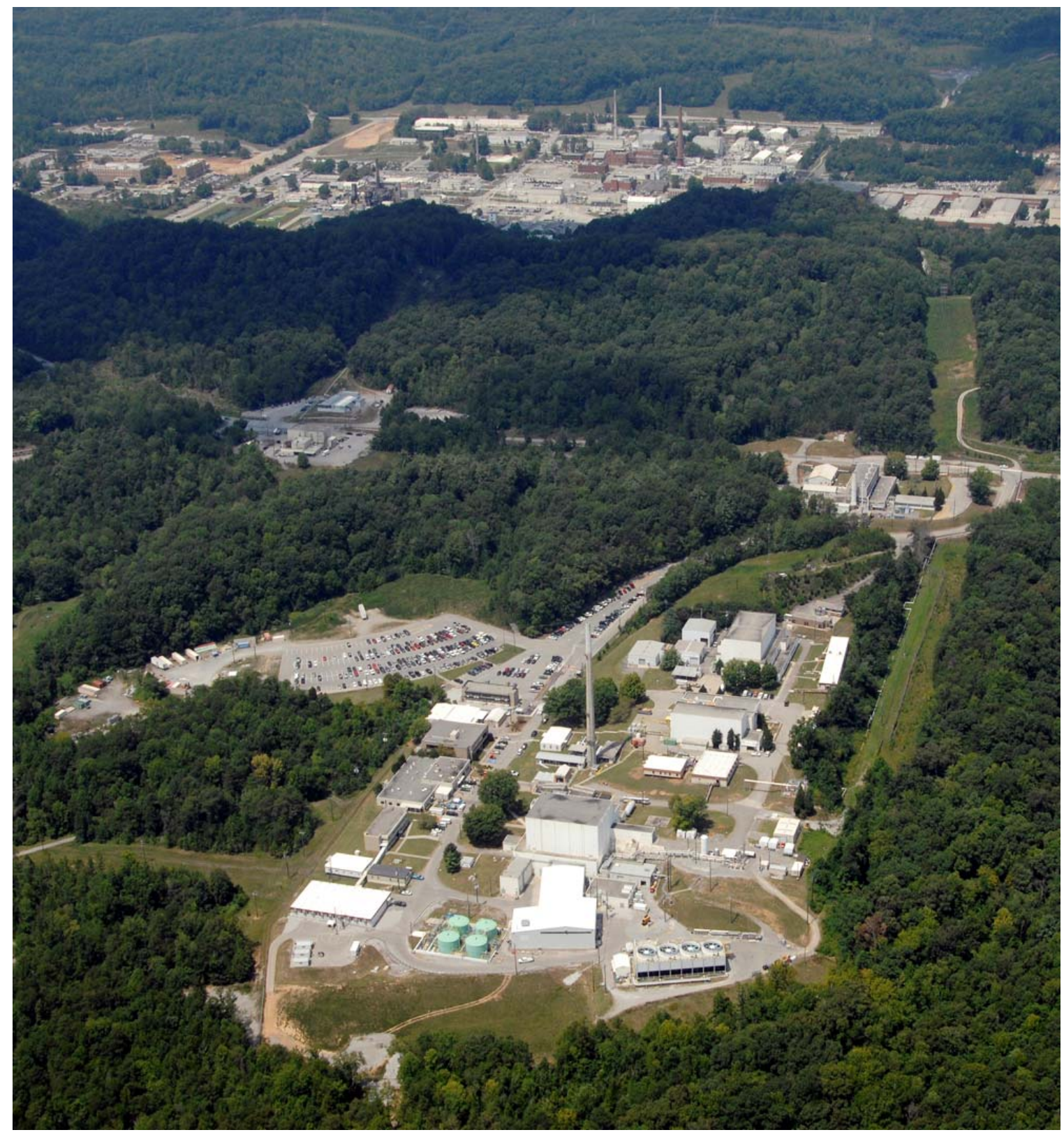

Fig. 53. ORNL's reactors today. The HFIR complex is in the foreground. The Graphite Reactor is visible in the background, slightly to the right of center. (ORNL Photo 2008-P02643) 


\section{EPILOGUE}

Sometimes the question is raised as to which of ORNL's reactors has been the most important. There is no single answer to that, of course. The Pile created the Laboratory, and the pioneering production of radioisotopes there has been of signal importance. The broad development programs that went with the homogeneous and molten-salt power reactors built the strong technology base that has allowed the Laboratory to become a leader in many fields. The MTR and LITR influenced

Rickover's choice of pressurized water for submarines when his group was here in training, and that decision set the direction for most of the world's power reactors. The BSR and ORR were the progenitors of large numbers of research reactors. And the HFIR has been the crown jewel of our research facilities for 46 years.

So all were important, and their effect has been lasting. 


\section{BIBLIOGRAPHY}

\section{General}

G. M. Adamson et al., Metals and Ceramics Division History 1946-1996, ORNL/M-6589, Oak Ridge National Laboratory, Oak Ridge, Tennessee, 1999.

Arthur Holly Compton, Atomic Quest, Oxford University Press, New York, 1956.

Richard K. Genung, Robert L. Jolley, and John E. Mrochek, comps., A Brief History of the Chemical Technology Division, ORNL/M-2733, Oak Ridge National Laboratory, Oak Ridge, Tennessee, 1993; see also Robert L. Jolley, Richard K. Genung, L. E. McNeese, and John E. Mrochek, comps., The ORNL Chemical Technology Division, 1950-1994, ORNL/M-2733/R1, Oak Ridge National Laboratory, Oak Ridge, Tennessee, October 1994.

W. L. Greenstreet, comp., History of the Engineering Technology Division of Oak Ridge National Laboratory, 1944-1992, ORNL/M-2318, Oak Ridge National Laboratory, Oak Ridge, Tennessee, 1992.

Leland Johnson and Daniel Schaffer, Oak Ridge National Laboratory: The First Fifty Years, The University of Tennessee Press, Knoxville, 1994 [also published as Oak Ridge National Laboratory Review 25, Nos. 3 and 4 (1992)].

Barbara K. Lyon, ed., Oak Ridge National Laboratory Review 9 (4), 1-124 (1976): Special bicentennial issue containing "a skeleton history of the Laboratory’s first 25 years.”

Richard Rhodes, The Making of the Atomic Bomb, Simon and Schuster, New York, 1986

Henry DeWolf Smyth, Atomic Energy for Military Purposes: The Official Report on the Development of the Atomic Bomb under the Auspices of the United States Government, 1940-1945, Princeton University Press, Princeton, New Jersey, 1945.

D. R. Stapleton, comp., A Brief History of the Research Reactors Division of the Oak Ridge National Laboratory, ORNL/M-2342, Oak Ridge National Laboratory, Oak Ridge, Tennessee, 1993.

W. E. Thompson, comp., History of the Oak Ridge National Laboratory, 1943-1963 ("First Rough Draft”), ORNL-CF/63-8-75, Oak Ridge National Laboratory, Oak Ridge, Tennessee, 1963.

Alvin M. Weinberg, The First Nuclear Era: The Life and Times of a Technological Fixer, American Institute of Physics, New York, 1994.

\section{Chicago Pile}

The First Reactor, DOE/NE-0046, U. S. Department of Energy, Washington, December 1982.

Oak Ridge Graphite Reactor

C. D. Cagle and L. B. Emlet, Slug Ruptures in the Oak Ridge National Laboratory Pile, ORNL-170, Oak Ridge National Laboratory, Oak Ridge, Tennessee, October 13, 1948.

“Oak Ridge Graphite Reactor” (pamphlet), Oak Ridge National Laboratory, Oak Ridge, Tennessee 1963.

Carolyn Krause, ed., “Wartime Laboratory,” Oak Ridge National Laboratory Review 25 (3-4), 1-28 (1992).

\section{Aqueous Homogeneous Reactors}

S. E. Beall and C. E. Winters, "The Homogeneous Reactor Experiment," Chemical Engineering Progress 50 (5), 256-262 (May 1954).

Paul N. Haubenreich, “Two Years of HRE-2 Operation,” Nuclear Science and Engineering 8, 467-479 (1960). 
Homogeneous Reactor Program Progress Report for Period from December 1, 1960 to May 31, 1961, ORNL-3167, Oak Ridge National Laboratory, Oak Ridge, Tennessee, Aug. 30, 1961 (last in a series of progress reports that began in 1949; usually issued quarterly, they cover the HRE and HRT and all aspects of the related R\&D program).

James A. Lane, ed., "Part I: Aqueous Homogeneous Reactors,” pp. 1-561 in Fluid Fuel Reactors, Addison-Wesley, Reading, Massachusetts, 1958.

M. W. Rosenthal, S. Jaye, and M. Tobias, Power Excursions in the HRT, ORNL-2798, Oak Ridge National Laboratory, Oak Ridge, Tennessee, 1960.

\section{Molten-Salt Reactors}

E. S. Bettis et al., "The Aircraft Reactor Experiment—Design and Construction,” Nuclear Science and Engineering 2, 804-825 (1957).

E. S. Bettis et al., "The Aircraft Reactor Experiment-Operation,” Nuclear Science and Engineering 2, 841-843 (1957).

D. W. Cardwell and P. N. Haubenreich, Indexed Abstracts of Selected References on Molten-Salt Reactor Technology, ORNL-TM-3595, Oak Ridge National Laboratory, Oak Ridge, Tennessee, December 1971.

W. K. Ergen, A. D. Callihan, C. B. Mills, and Dunlap Scott, "The Aircraft Reactor ExperimentPhysics,” Nuclear Science and Engineering 2, 826-840 (1957).

H. G. MacPherson, ed., "Part II: Molten-Salt Reactors,” pp. 565-697 in Fluid Fuel Reactors, Addison-Wesley, Reading, Massachusetts, 1958.

H. G. MacPherson, “The Molten Salt Reactor Adventure,” Nuclear Science and Engineering 90, 374-380 (1985).

“Molten-Salt Reactor Experiment” (pamphlet), Oak Ridge National Laboratory, Oak Ridge, Tennessee, 1966.

“A Review of Molten Salt Reactor Technology,” Nuclear Applications and Technology 8 (2), 102219 (February 1970): Special issue comprising a set of ten papers including M. W. Rosenthal, P. R. Kasten, and R. B. Briggs, "Molten-Salt Reactors: History, Status, and Potential”; Paul N. Haubenreich and J. R. Engel, "Experience with the Molten-Salt Reactor Experiment”; and W. R. Grimes, "Molten-Salt Reactor Chemistry."

M. W. Rosenthal, P. N. Haubenreich, and R. B. Briggs, The Development Status of Molten-Salt Breeder Reactors, ORNL-4812, Oak Ridge National Laboratory, August 1972.

Molten-Salt Reactor Program Semiannual Progress Report for Period Ending August 31, 1975, ORNL-5078, Oak Ridge National Laboratory, Oak Ridge, Tennessee, 1976 (last in a series of semiannual progress reports that began in 1957; they cover the MSRE and all aspects of the related $\mathrm{R} \& \mathrm{D}$ program).

\section{Package Power Reactors}

“Appendix D. Military Reactors: Army Nuclear Power Program,” pp. 145-148 in Highly Enriched Uranium: Striking a Balance, Rev. 1, U.S. Department of Energy National Nuclear Security Administration, January 2001.

A. L. Boch, Project Coordinator, Army Power Package Reactor Project: Progress Report, ORNL-2703, Oak Ridge National Laboratory, Oak Ridge, Tennessee, 1959 (describes ORNL's participation in the Army nuclear power program; information is presented in two parts that address two reactor types studied by the Army Reactors Branch: the APPR-l pressurized-water reactor program and the gas-cooled reactor experiment).

Lawrence H. Suid, The Army's Nuclear Power Program: The Evolution of a Support Agency, Greenwood Press, New York, 1990. 


\section{Gas-Cooled Reactor Program}

Conceptual Design of the Pebble Bed Reactor Experiment, ORNL-TM-201, Oak Ridge National Laboratory, Oak Ridge, Tennessee, May 17, 1962.

C. Rogers McCullough, Summary Report on Design and Development of High Temperature GasCooled Power Pile, MonN-383, Clinton Laboratories, Oak Ridge, Tennessee, September 15, 1947.

Donald B. Trauger, Horse Power to Nuclear Power, Hillsboro Press, Franklin, Tennessee, 2002.

\section{Health Physics Research Reactor}

J. A. Auxier, “The Health Physics Research Reactor,” Health Physics 11, 89-93 (1965).

"Health Physics Research Reactor” (pamphlet), Oak Ridge National Laboratory, Oak Ridge, Tennessee, n.d.

C. S. Sims and L. W. Gilley, "Twenty Years of Health Physics Research Reactor Operation,” Nuclear Safety 24 (5), 678-687 (September-October 1983).

\section{Tower Shielding Reactor}

F. J. Muckenthaler, The Tower Shielding Facility: Its Glorious Past, ORNL/TM-12339, Oak Ridge National Laboratory, Oak Ridge, Tennessee, May 7, 1997.

\section{Water-Cooled Research Reactors}

R. Chawla et al., "Irradiation Techniques Employed at the 10 MWth SAPHIR Reactor,” PSI-Bericht Nr. 123, Paul Scherrer Institut, Villigen, Switzerland (paper presented at the International Conference on Irradiation Technology, Saclay, France, May 20-22, 1992).

J. H. Erwin, R. C. Waugh, and J. H. Coobs, "Fabrication of Geneva Conference Fuel Elements," pp. 113116 in ORNL Metallurgy Division Semiannual Progress Report for Period Ending October 10, 1955, ORNL-1988, Oak Ridge National Laboratory, Oak Ridge, Tennessee, May 1956.

Kenneth D. George, The Oak Ridge Research Reactor (ORR), The Low-Intensity Testing Reactor (LITR), and the Oak Ridge Graphite Reactor (OGR) as Experiment Facilities, ORNL-TM-279, Oak Ridge National Laboratory, Oak Ridge, Tennessee, August 28, 1962.

T. P. Hamrick and J. H. Swanks, The Oak Ridge Reactor: A Functional Description, ORNL-4169, Vol. I, Oak Ridge National Laboratory, Oak Ridge, Tennessee, September 1968.

The High Flux Isotope Reactor: A Functional Description, ORNL-3572 (Rev. 2), Vol. IA, Oak Ridge National Laboratory, Oak Ridge, Tennessee, May 1, 1964.

J. R. Huffman, The Materials Testing Reactor Design, IDO-16121-PPCo, Phillips Petroleum Co./Idaho Operations Office, U.S. Atomic Energy Commission, October 1, 1953.

Susan M. Stacy, Proving the Principle: A History of the Idaho National Laboratory, DOE/ID-10799, Idaho Operations Office, U.S. Department of Energy, 2000, pp. 49-50.

L. E. Stanford, Description and Safety Analysis of the Pool Critical Assembly, ORNL-TM-3035, Oak Ridge National Laboratory, Oak Ridge, Tennessee, May 4, 1970.

“Transuranium Elements and the High Flux Isotope Reactor” (pamphlet), Oak Ridge National Laboratory, Oak Ridge, Tennessee, n.d. 



\section{APPENDIX A. EVOLUTION OF NUCLEAR REACTORS}

1932: James Chadwick at Cambridge bombards beryllium with alpha particles from polonium and unambiguously produces and identifies neutral particles that he names "neutrons."

1933: Irène and Frédéric Joliot-Curie, working in her mother's laboratory in Paris, bombard aluminum and other light elements with alpha particles from polonium and create and identify the first artificial radioactive elements.

1934: Enrico Fermi and associates at the University of Rome radiate most of the elements in the atomic table with neutrons from a radon/beryllium source, producing artificial radioactive elements. He discovers that slowing down the neutrons by collisions with hydrogen greatly increases the reaction rate. (Uranium was among the elements studied, but he misinterprets the results from it and misses the discovery of fission.)

1938: Chemists Otto Hahn and Fritz Strassman bombard uranium with slow neutrons and identify barium in the products. Hahn cannot understand how that could be and writes about it to physicist Lise Meitner, who had worked with him for years but had recently fled Germany to Sweden.

1938-1939: Meitner and her nephew Otto Robert Frisch, on vacation in Sweden, conclude that what Hahn was observing was fission, and if so, according to Einstein's relationship, about $200 \mathrm{MeV}$ of energy must be released per fission. Frisch returns to Bohr's institute in Copenhagen and assembles an ion chamber with which he confirms that the energy release was indeed $200 \mathrm{MeV}$. Frisch calls the process "fission."

1938: Fermi goes to Stockholm in December 1938 to accept the Nobel prize. Using the money he receives, continues on to the United States with his family to accept a position at Columbia University. (Eugene Wigner had come to the United States in 1930; Leo Szilard, in 1938.)

1939: Frisch tells Niels Bohr, who is just leaving for Princeton, about the discovery of fission, and Wigner, Szilard, Fermi, and others learn of it through him.

1939: Szilard, Fermi, and others at Columbia and F. Joliot-Curie in Paris determine that 2.5 to 3 neutrons are emitted in fission, showing that a chain reaction is possible.

1939: Fermi and Szilard propose a reactor formed of uranium in a graphite matrix. They apply for a patent but do not receive it until security is lifted in 1955.

1940: President Franklin Roosevelt creates the National Defense Research Committee to centralize scientific research with military applications, including fission research.

1940-1941: Using a cyclotron at Berkeley, a group led by Glenn Seaborg produces element 94, which they isolate and identify and name plutonium. They show that it can be fissioned by thermal neutrons.

1940-1941: Wigner and others develop the theory needed for designing reactors.

1941: The National Defense Research Committee is superseded by the Office of Scientific Research and Development. 
1941: Fermi, Szilard, et al. assemble a large graphite pile at Columbia University using lumps of uranium oxide in a graphite matrix and determine the multiplication factor. A series of piles follows in which purer uranium oxide and graphite are used as they became available, and the effects of lattice pitch, uranium/graphite ratio, etc. are studied.

1941: Arthur Holly Compton is put in charge of developing a plutonium bomb. He creates the Metallurgical Laboratory at the University of Chicago to which he moves the key participants in reactor development.

August 1942: The Army Corps of Engineers forms the Manhattan Engineer District (also known as the Manhattan Project) to manage the construction of plants for producing fissionable materials.

September 1942: General Leslie Groves takes charge of the Manhattan Project and immediately makes the decision to buy 59,000 acres of land in East Tennessee, which will come to be known as Oak Ridge. This area is initially proposed to include the plutonium production reactors, but DuPont recommends that they be located at a more remote site with more cooling water, and Hanford, Washington, is selected.

1942: Fermi continues building exponential piles of larger and larger size with purer and purer materials. After about 30 have been built, he has enough information to build the world's first nuclear reactor in a squash court at Stagg Field.

December 2, 1942: The Chicago Pile achieves criticality.

January 1943: Groves directs the Metallurgical Laboratory to build an air-cooled graphite reactor and a plutonium-separation pilot plant in Oak Ridge and expands DuPont's contract to include their construction.

November 3, 1943: The X-10 pile at Oak Ridge achieves criticality, becoming the world's first operational nuclear reactor. 